\title{
A Systematic Review of Non-Invasive Pharmacologic Neuroprotective Treatments for Acute Spinal Cord Injury
}

\author{
Brian K. Kwon,,2 Elena Okon, ${ }^{2}$ Jessica Hillyer, ${ }^{2}$ Cody Mann, ${ }^{2}$ Darryl Baptiste, ${ }^{3}$ \\ Lynne C. Weaver, ${ }^{4}$ Michael G. Fehlings, ${ }^{5}$ and Wolfram Tetzlaff ${ }^{2}$
}

\begin{abstract}
An increasing number of therapies for spinal cord injury (SCI) are emerging from the laboratory and seeking translation into human clinical trials. Many of these are administered as soon as possible after injury with the hope of attenuating secondary damage and maximizing the extent of spared neurologic tissue. In this article, we systematically review the available pre-clinical research on such neuroprotective therapies that are administered in a non-invasive manner for acute SCI. Specifically, we review treatments that have a relatively high potential for translation due to the fact that they are already used in human clinical applications, or are available in a form that could be administered to humans. These include: erythropoietin, NSAIDs, anti-CD11d antibodies, minocycline, progesterone, estrogen, magnesium, riluzole, polyethylene glycol, atorvastatin, inosine, and pioglitazone. The literature was systematically reviewed to examine studies in which an in-vivo animal model was utilized to assess the efficacy of the therapy in a traumatic SCI paradigm. Using these criteria, 122 studies were identified and reviewed in detail. Wide variations exist in the animal species, injury models, and experimental designs reported in the pre-clinical literature on the therapies reviewed. The review highlights the extent of investigation that has occurred in these specific therapies, and points out gaps in our knowledge that would be potentially valuable prior to human translation.
\end{abstract}

Key words: animal model; neuroprotection; spinal cord injury; systematic review; translational research

\section{Introduction}

$\mathbf{T}_{\mathrm{p} \text { tav }}$ HE SPINAL CORD INJURY (SCI) field is replete with therapeutic candidates that potentially enhance neurologic recovery by attenuating the pathophysiological processes triggered after acute injury, thereby minimizing secondary damage. In the pre-clinical testing of such therapies, the treatment is typically administered immediately or very soon after the injury is induced in an animal model (mainly rat or mouse). Neurologic efficacy in such models suggests that the therapy in question may have a "neuroprotective" role in acute human SCI. While many treatments are administered in this fashion, those that can be delivered systemically via intravenous infusion or even orally have the potential to reach the cord injury site most rapidly (as compared to a surgically delivered treatment). Since the methylprednisolone clinical trials, the SCI community has sought additional interventions that would follow the similar strategy of administration as early as possible after injury to minimize secondary damage. Such "non-invasive" therapies are the focus of this review.

Given the explosion of interest in acute SCI and the seemingly endless number of therapies that are reportedly found to be beneficial in animal models of SCI, the purpose of this initiative was to review specific non-invasive treatments in a systematic fashion so as to depict the current body of preclinical literature that might support the translation of such treatments into clinical trials. The field is large, and in this regard, it is difficult - if not impossible - to cover it comprehensively. Our strategy, therefore, was to select therapies that have reasonable "translational potential" by virtue of the fact that they are already in human clinical use for other indications, or because of the extent and depth of their pre-clinical investigation (or both). While it was not the intention to attempt to cover the entire SCI field, our goal was to apply the tenets of systematic review to the specific therapies that met

\footnotetext{
${ }^{1}$ University of British Columbia, Combined Neurosurgical and Orthopaedic Spine Program (CNOSP), Department of Orthopaedics, Vancouver, British Columbia, Canada.

${ }^{2}$ University of British Columbia, International Collaboration Repair Discoveries (ICORD), Vancouver, British Columbia, Canada.

${ }^{3}$ Toronto Western Hospital, Spinal Program, Krembil Neuroscience Centre, Toronto, Ontario, Canada.

${ }^{4}$ Robarts Research Institute at the University of Western Ontario, Bio Therapeutics Research Group, London, Ontario, Canada.

${ }^{5}$ University of Toronto, Department of Surgery, Toronto, Ontario, Canada.
} 
these conditions. By performing a systematic review of each of these therapies, we hoped to provide the field with an overview of the body of pre-clinical evidence that supports (or fails to support) the translation of the therapy into human trials.

\section{Methodology}

First, we selected acute SCI treatments that fit the following criteria: (a) a treatment that is already in human clinical use for some other related or unrelated condition, or if not currently in human use, is currently available in a form that could be given to humans; (b) a treatment that could be administered systemically (i.e., non-invasively) to an SCI patient (either orally or intravenously). A PubMed search was then conducted on "the therapy" and "spinal cord injury" (e.g., "minocycline and spinal cord injury"). From the list of studies generated through this fairly indiscriminant search, we applied the following criteria to review systematically the preclinical literature on these therapies:

- Studies in which the testing of the therapy was performed in an in-vivo animal model of SCI. Studies that were exclusively in-vitro experiments were excluded.

- Studies in which the spinal cord is traumatically injured. Non-traumatic local or global ischemia models and photochemical reaction models were excluded, as were traumatic root avulsion or dorsal root entry zone models.

- Studies in which the application of the therapy was via the systemic circulation. This included agents administered orally, or via subcutaneous, intraperitoneal, or intravenous injection. Studies in which the therapy was applied directly to the cord or via intrathecal injection/infusion were excluded.

- At least two peer-reviewed publications available on the therapy.

The data from those studies that fitted the criteria were then extracted into a table format to depict the animal model, injury model, the treatment's dose and timing, the experimental groups tested in the study and the " $n$ per group," and the reported behavioral and non-behavioral outcomes (e.g., histological, biochemical, or physiological outcomes). A summary statement about the body of literature was then generated.

\section{Results}

Using this selection process, we identified the following therapies: erythropoietin, systemic hypothermia, nonsteroidal anti-inflammatory agents (NSAIDs), anti-CD11 antibodies, minocycline, progesterone, estrogen, magnesium sulfate, riluzole, polyethylene glycol, atorvastatin, inosine, and piaglitazone (Table 1).

The PubMed searches on these therapies were conducted in the spring/summer of 2008 by SCI researchers across Canada and updated in June 2009. By applying the previously described criteria (essentially, in-vivo animal studies utilizing a traumatic model of SCI to test a pharmacologic or noninvasive therapy), the following studies were generated, and the tables for each of these respective therapies are listed below.

\section{Erythropoietin (Table 2)}

Erythropoietin (EPO) has been studied quite extensively in acute SCI. The systematic review produced 19 studies, all of which utilized Sprague Dawley (10), Wistar (eight), or Long Evans (one) rats, with one study utilizing a knockout mouse (Brines et al., 2004). Some form of contusion SCI was employed in 12 studies, aneurysmal clip or rod compression was employed in six studies, and one study utilized a unilateral hemisection (King et al., 2007). All injuries occurred in the thoracic spine; to date there is no evaluation of EPO in a cervical SCI model. EPO was administered at a variety of doses but most commonly at $1000 \mathrm{IU} / \mathrm{kg}$ or $5000 \mathrm{IU} / \mathrm{kg}$, either intraperitoneally, or intravenously. A dose effect was demonstrated in experiments by Gorio and colleagues (2005), Kaptanoglu and colleagues (2004), and Kontogeorgakos and colleagues (2009). Interestingly, in the studies by both Gorio and colleagues (2005) and Kontogeorgakos and colleagues (2009) in which different doses of EPO were tested intravenously or subcutaneously respectively, the optimal results were observed with the lower doses. With respect to time window of effective intervention, EPO was administered at the time of injury in half of the studies and within 30-60 min in the remainder. Improvements in behavioral outcomes were reported by Boran and colleagues (2005) and Gorio and colleagues (2002) with a 60 -min delay in intervention, although this was not found by others (Mann et al., 2008; Pinzon et al., 2008).

Non-behavioral outcomes included improved white and grey matter sparing, reduced apoptosis and lipid peroxidation, reduced ERK phosphorylation, and decreased inflammatory cytokine release and neutrophil invasion. Many authors reported improved locomotion with Basso, Beattie, and Breshnan (BBB) scores, or improved function on the swimming test. Of note, the recent reports of Guìzar-Sahagún and colleagues (2009), Mann and colleagues (2008), and Pinzon and colleagues (2008) revealed no histological or behavioral improvements with EPO administered either $12 \mathrm{~h}$ pre-injury, immediately at the time of injury, or $1 \mathrm{~h}$ post injury respectively. The study by Pinzon and colleagues (2008) is notable as an NIH-sponsored attempt to reproduce the positive effects of EPO described previously, particularly in the studies by Gorio and colleagues. The study by Mann and colleagues (2008) examined both erythropoietin and darbepoetin, a more bioavailable version of EPO, but found neither to have any neuroprotective efficacy. Like minocycline, it is unclear how to interpret these contradictory reports on the efficacy of EPO in acute SCI.

\section{Systemic hypothermia (Table 3)}

While technically not a "drug," systemic hypothermia was included in this review as it is a relatively "non-invasive" treatment that is applied to the cord in a systemic, nonoperative manner (as compared to local hypothermia, which requires intrathecal cooling devices or open surgery). Systemic hypothermia has had a long history of study, stemming from the early 1990s. A recent resurgence in the interest in systemic hypothermia has arisen due to its well-publicized application in Kevin Everett, an NFL football player who suffered a cervical SCI in the fall of 2007.

We identified 17 papers that fulfilled the criteria of studying systemic hypothermia after traumatic SCI (although some describe the same set of experimental animals but report different outcomes in different papers). These mostly utilized Sprague Dawley rats, although the injury models were quite variable, and included one generic weight-drop device, two 
Table 1. Non-Invasive Therapies Systematically Reviewed

\begin{tabular}{|c|c|c|c|}
\hline Therapy & Current human use & Mode of human administration & $\begin{array}{l}\text { Published studies } \\
\text { meeting criteria }\end{array}$ \\
\hline Erythropoietin & For increasing red blood cell production & Subcutaneous & 19 \\
\hline $\begin{array}{l}\text { Systemic } \\
\text { Hypothermia }\end{array}$ & $\begin{array}{l}\text { Neuroprotection in cardiac arrest, neonatal } \\
\text { hypoxic encephalophathy }\end{array}$ & $\begin{array}{l}\text { Endovascular or body surface } \\
\text { cooling }\end{array}$ & 17 \\
\hline NSAIDs & Anti-inflammatory/analgesic agent & Oral & 17 \\
\hline Anti-CD11d mAB & $\begin{array}{l}\text { Humanized antibody in development } \\
\text { (currently not used clinically) }\end{array}$ & IV & 11 \\
\hline Minocycline & Antibiotic and treatment of acne & Oral (but IV formulation exists) & 10 \\
\hline Progesterone & Hormone replacement & Oral & 10 \\
\hline Estrogen & Hormone replacement & Oral & 8 \\
\hline Magnesium & Pre-eclampsia, cardiac arrest & IV & 9 \\
\hline Riluzole & Amyotrophic lateral sclerosis & Oral administration & 8 \\
\hline Polyethylene Glycol & $\begin{array}{l}\text { Excipient in many drugs, also used in many } \\
\text { laxatives, toothpaste, skin creams }\end{array}$ & Oral or IV & 5 \\
\hline Atorvastatin & Cholesterol lowering agent & Oral & 3 \\
\hline Inosine & Dietary supplement & Oral & 3 \\
\hline Pioglitazone & Type II diabetes & Oral & 2 \\
\hline
\end{tabular}

with the NYU weight-drop impactor, one with the OSU impactor, 10 with cord compression induced by a balloon or clip, and one cord transection. Three studies (Jou et al., 2000; Lo et al., 2009; Strain and Waldrop, 2005) utilized a cervical injury model, while the remainder studied midthoracic to upper lumbar injuries. Systemic hypothermia was typically induced to a level of $30-34^{\circ} \mathrm{C}$, which was maintained for as little as $20 \mathrm{~min}$ to as long as $4 \mathrm{~h}$, or, in some cases, until the experiment was completed. In four studies, hypothermia was induced prior to the injury; in an additional 11 studies, hypothermia was induced at the time of injury or just after injury without any significant delay in intervention; in the remaining two studies, hypothermia was started at $15 \mathrm{~min}$ (Westergren et al., 2001) or $30 \mathrm{~min}$ (C.G. Yu et al., 2000) post injury. The study by $\mathrm{Yu}$ and colleagues (2000) in which hypothermia was begun 30 min post injury described improved behavioral recovery in the hypothermia-treated animals.

With respect to outcomes, 11 out of 17 studies only reported on histological/biochemical/physiological outcomes and did not report any behavioral outcomes. In general, these studies reported reduced apoptosis, myeloperoxidase activity, vasogenic edema, and tissue damage. For the six papers that assessed behavioral recovery, four reported on improvements in hindlimb function (Jou et al., 2000; Lo et al., 2009; Morino et al., 2008; C.G. Yu et al., 2000), while two reported no improvements (Martinez-Arizala and Green, 1992; Westergren et al., 1999).

\section{NSAIDs (Table 4)}

NSAIDs have had a long history of investigation stemming back to the 1980s, indicative of the long-standing appreciation for the role of inflammation in the secondary injury cascade post SCI. The most extensively studied NSAID is indomethacin. The systematic review revealed 10 papers published from 1991 to 2006 that reported on the effects of indomethacin in rat models (Wistar, Lewis, SD) and also a rabbit model. Standard contusion injury devices were not available at the time that many of these studies were performed, and hence, a wide range of injury models were described (weight drop, clip or forcep compression, longitudinal incision). A very wide range of intraperitoneal or intravenous indomethacin doses have been tested, from $0.1 \mathrm{mg} / \mathrm{kg}$ to $20 \mathrm{mg} / \mathrm{kg}$, with most in the $2-10 \mathrm{mg} / \mathrm{kg}$ range. Strangely, in many cases, indomethacin treatment was started 30-60 min prior to injury. In the remaining studies, the drug was given at the time of injury, and hence, no time window of efficacy has been established. Many of the indomethacin studies examined non-behavioral outcomes only, and showed decreased edema, BBB permeability, and less overall tissue damage. Simpson and colleagues in 1991 reported improved performance on an inclined plane test with indomethacin, but more recently, Harada and colleagues (2006) reported decreased performance on the inclined plane test with 5,10 , and $20 \mathrm{mg} / \mathrm{kg}$ doses given $1 \mathrm{~h}$ prior to injury.

Other NSAIDs that have been reported in either one or two studies include BW755C, celebocid, SC58125, NS-398, naproxen, aspirin, and ibuprofen. Again, in many of these studies, the drug was given either prior to or within minutes of injury. Ibuprofen, however, has more recently been found to promote both histologic and behavioral improvements in thoracic contusion SCI models when administered 3 days post injury (Wang et al., 2009) or even 7 days post injury (Fu et al., 2007). These two studies also revealed that ibuprofen was superior to naproxen in both behavioral and non-behavioral outcomes. Interestingly, the role of ibuprofen in reducing RhoA activation raises the potential that this drug may have therapeutic benefit through the promotion of axonal sprouting (i.e., not exclusively attenuation of inflammation). The doses utilized in the preclinical studies $(60-70 \mathrm{mg} / \mathrm{kg} /$ day) merit discussion. At these doses, a $70 \mathrm{~kg}$ individual would receive 4,200 to $4,900 \mathrm{mg}$ of ibuprofen per day, which does slightly exceed the $3,200 \mathrm{mg} /$ day maximum does recommendation for rheumatologic and arthritic conditions. However, FDA guidelines for the conversion of a therapeutic dose in rats to a "human equivalent dose" suggest a human equivalent dose of closer to the $700-800 \mathrm{mg} /$ day range (FDA, 2005). Hence the therapeutic dose in human SCI patients may be well within a range known to be clinically safe.

\section{Anti-CD11d antibodies (Table 5)}

The anti-CD11d antibody approach has been pioneered by Dr. Lynne Weaver and colleagues, and all 11 papers found 


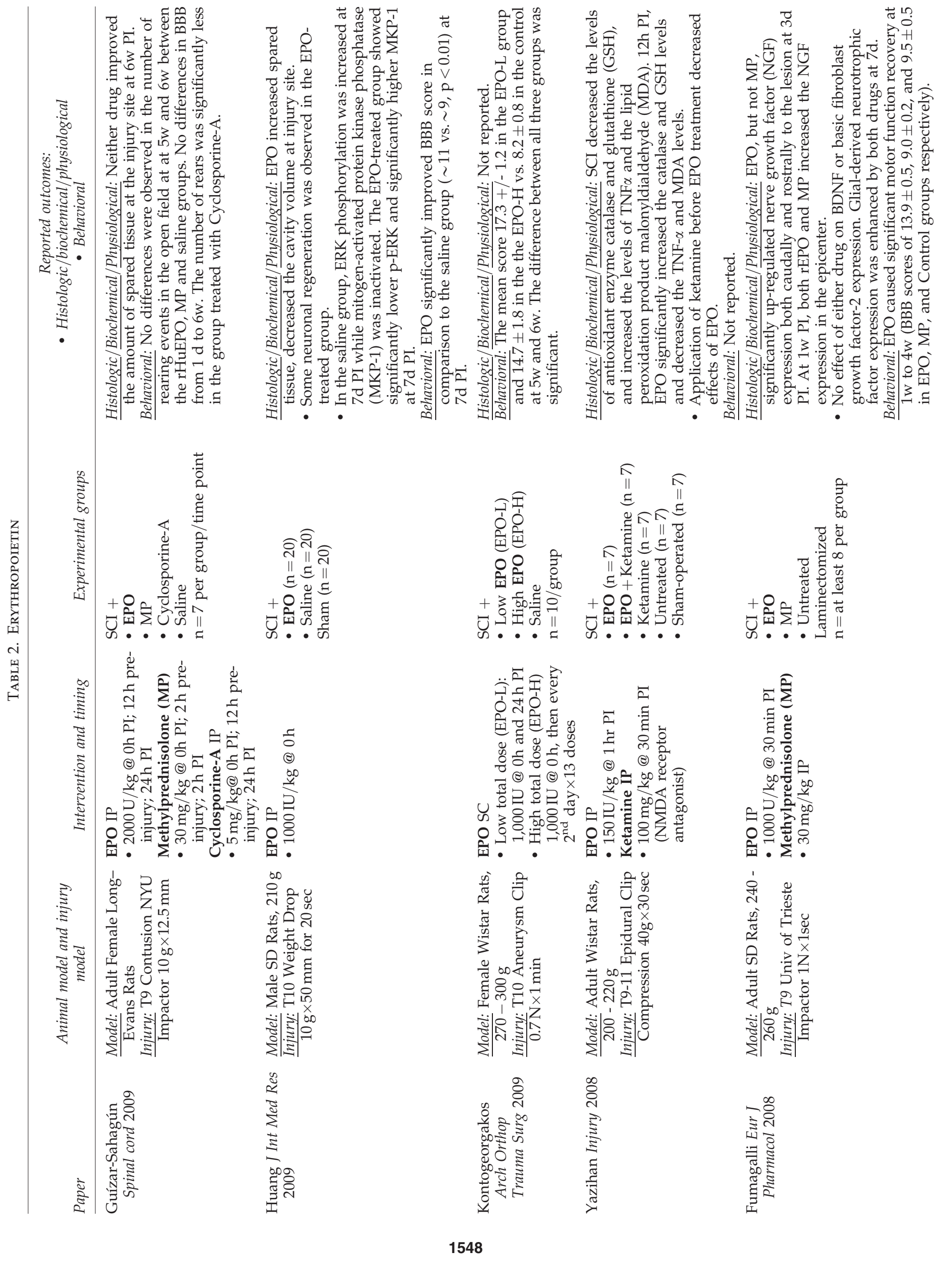



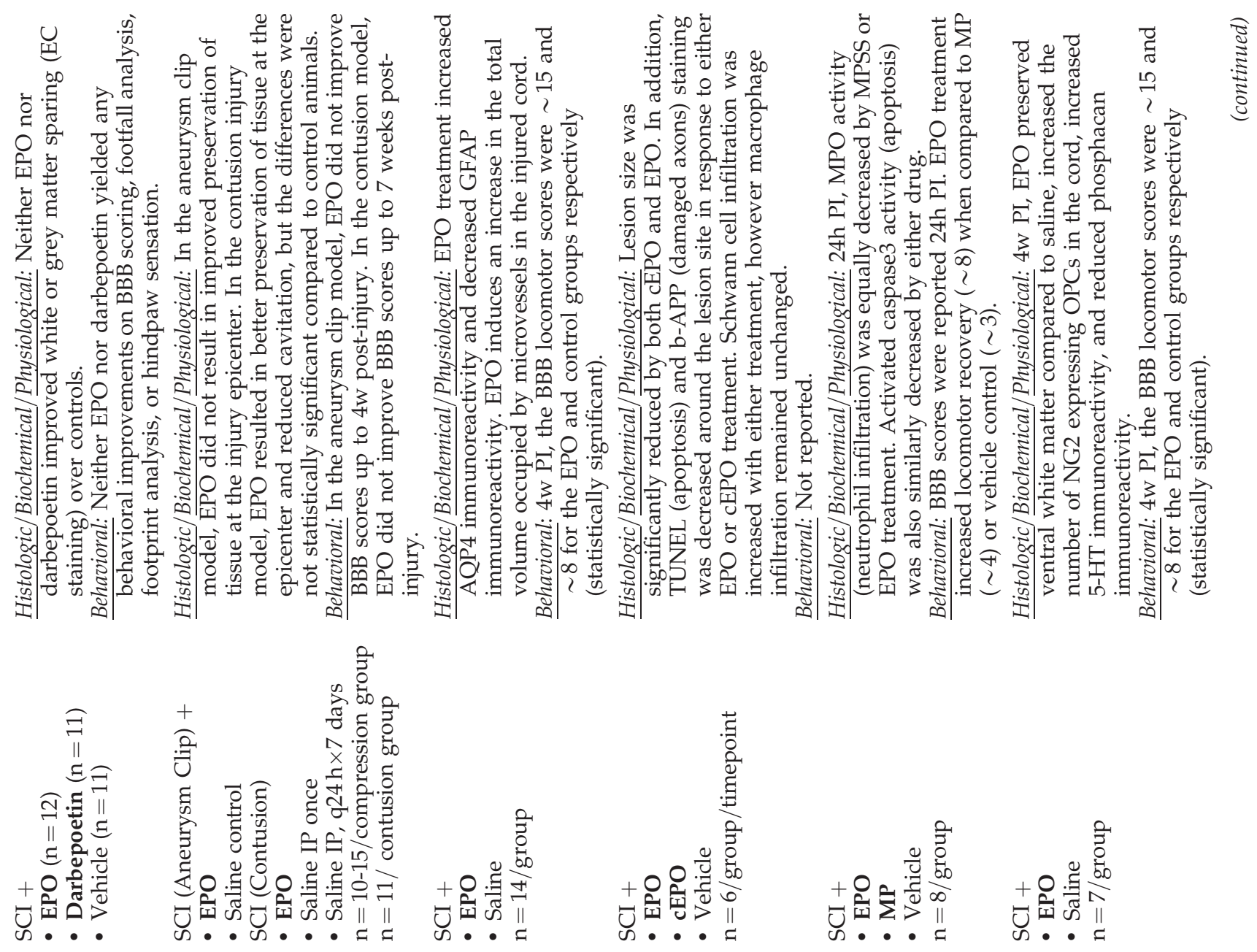

夏
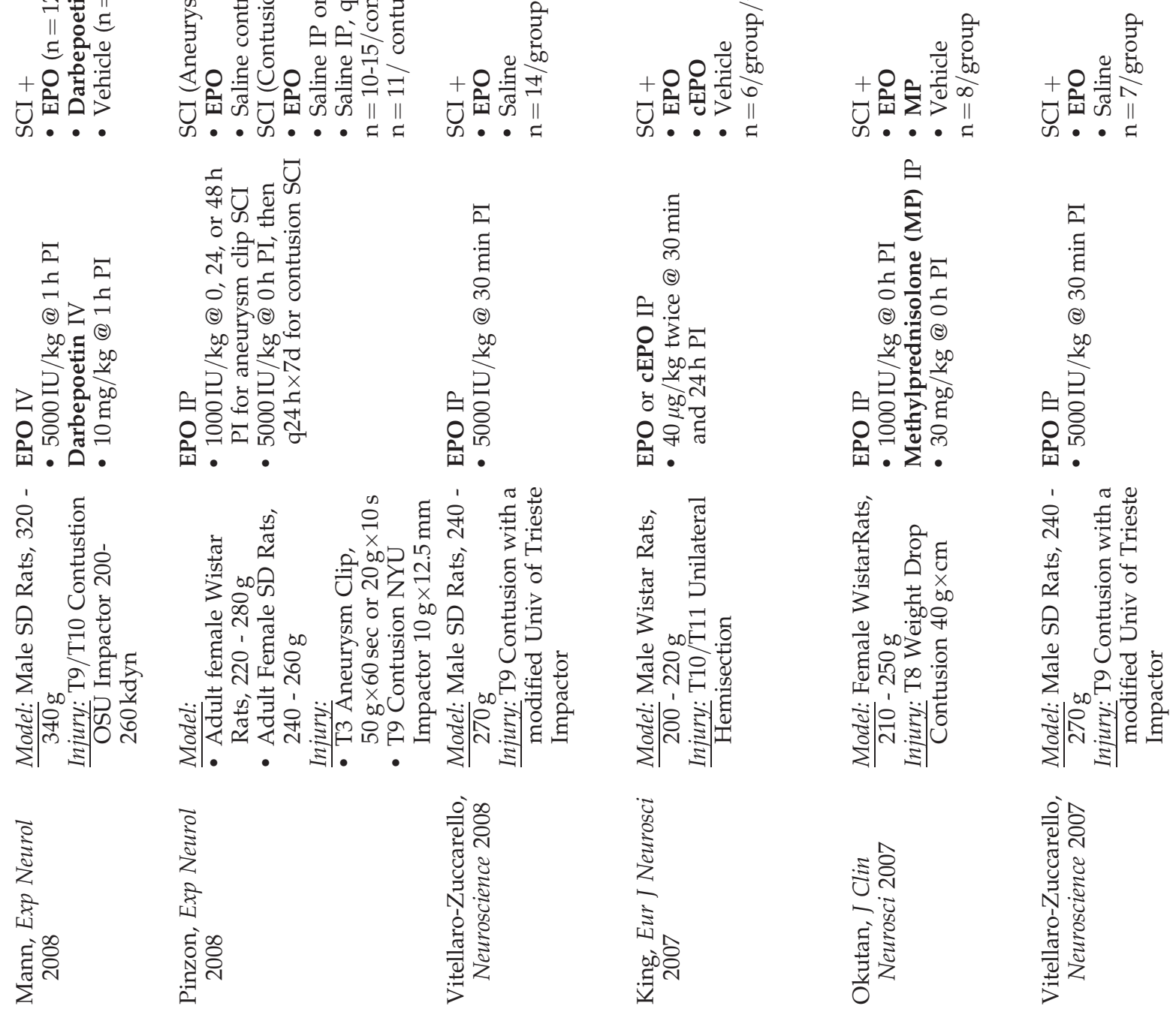


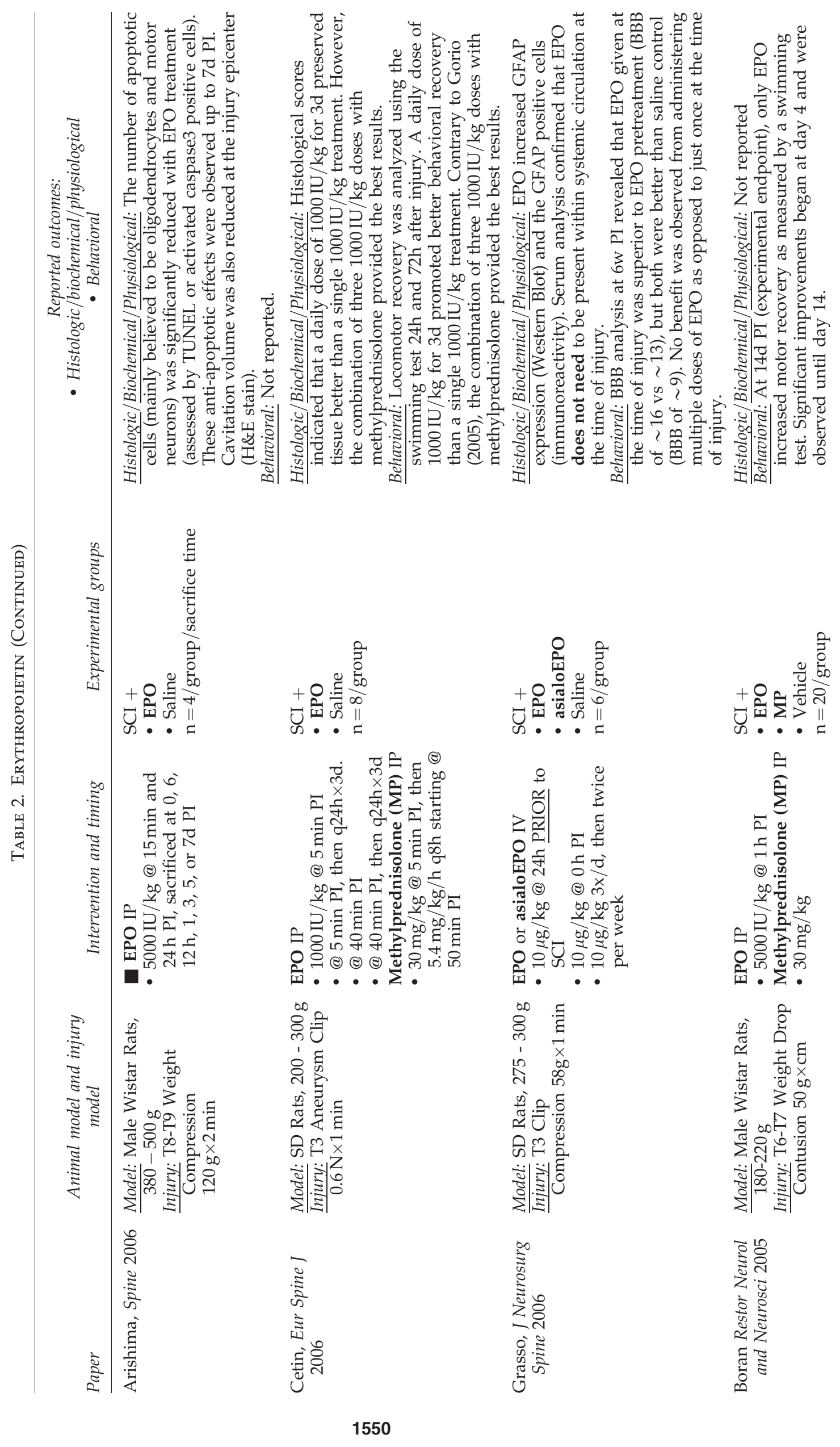




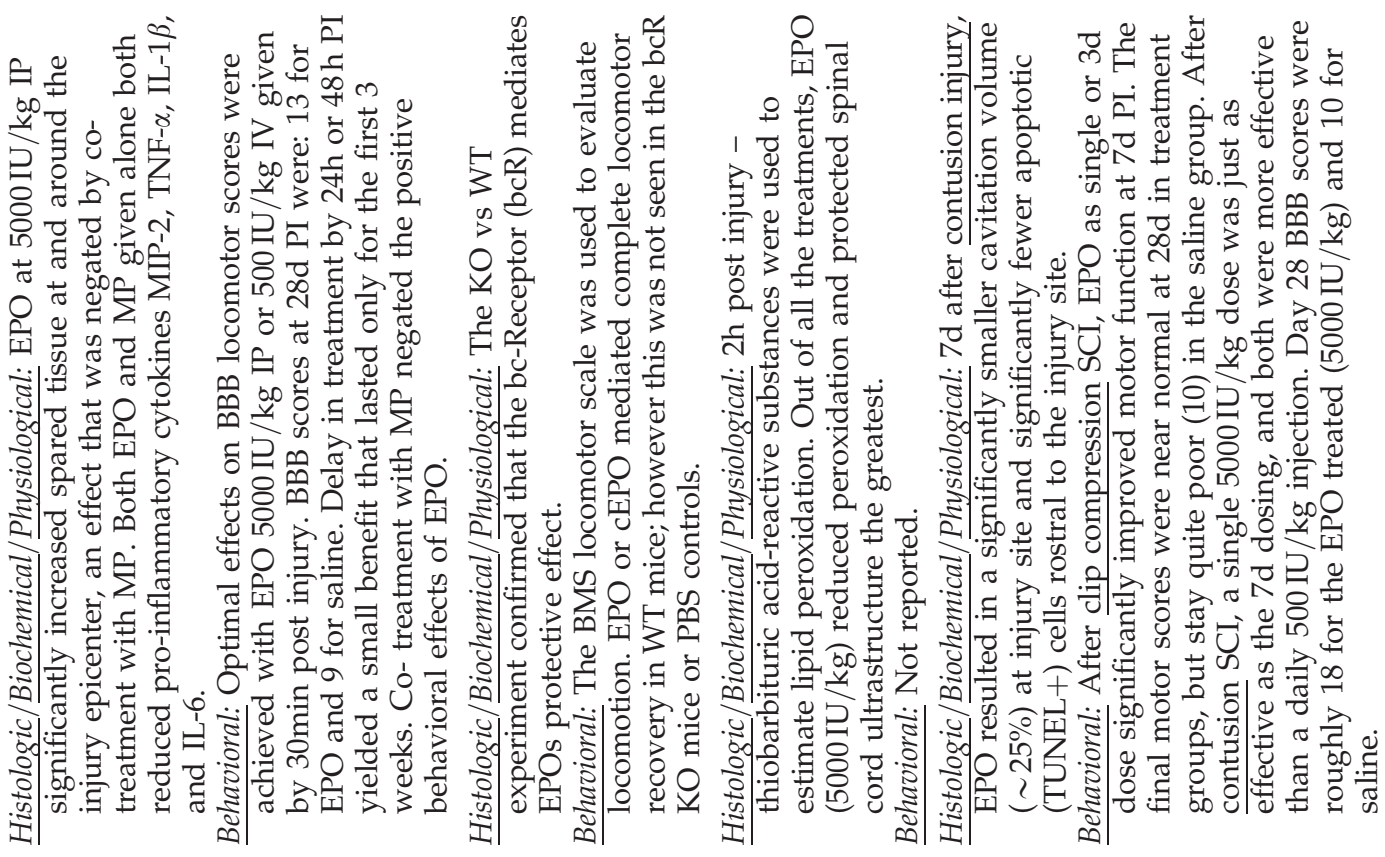

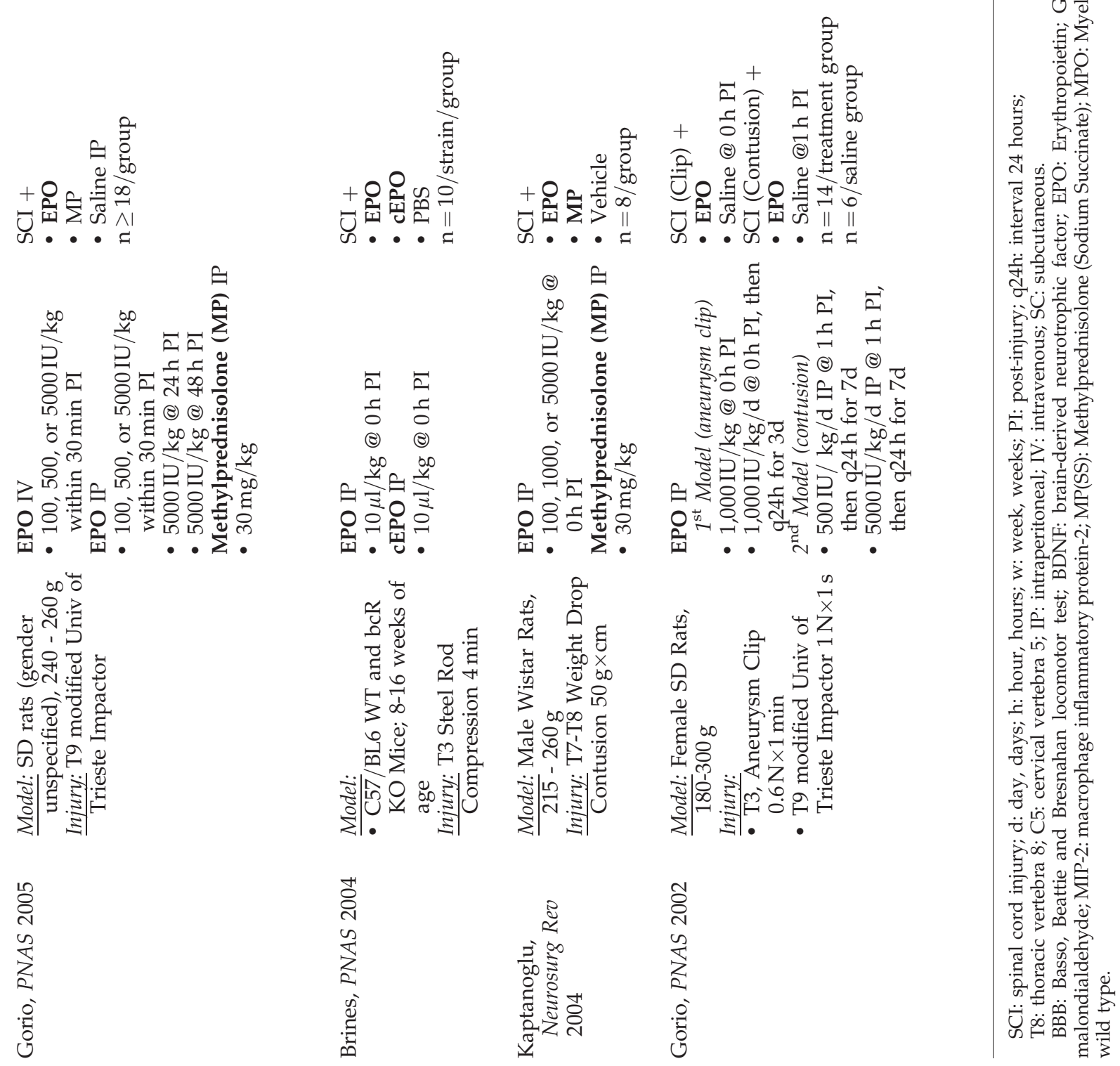




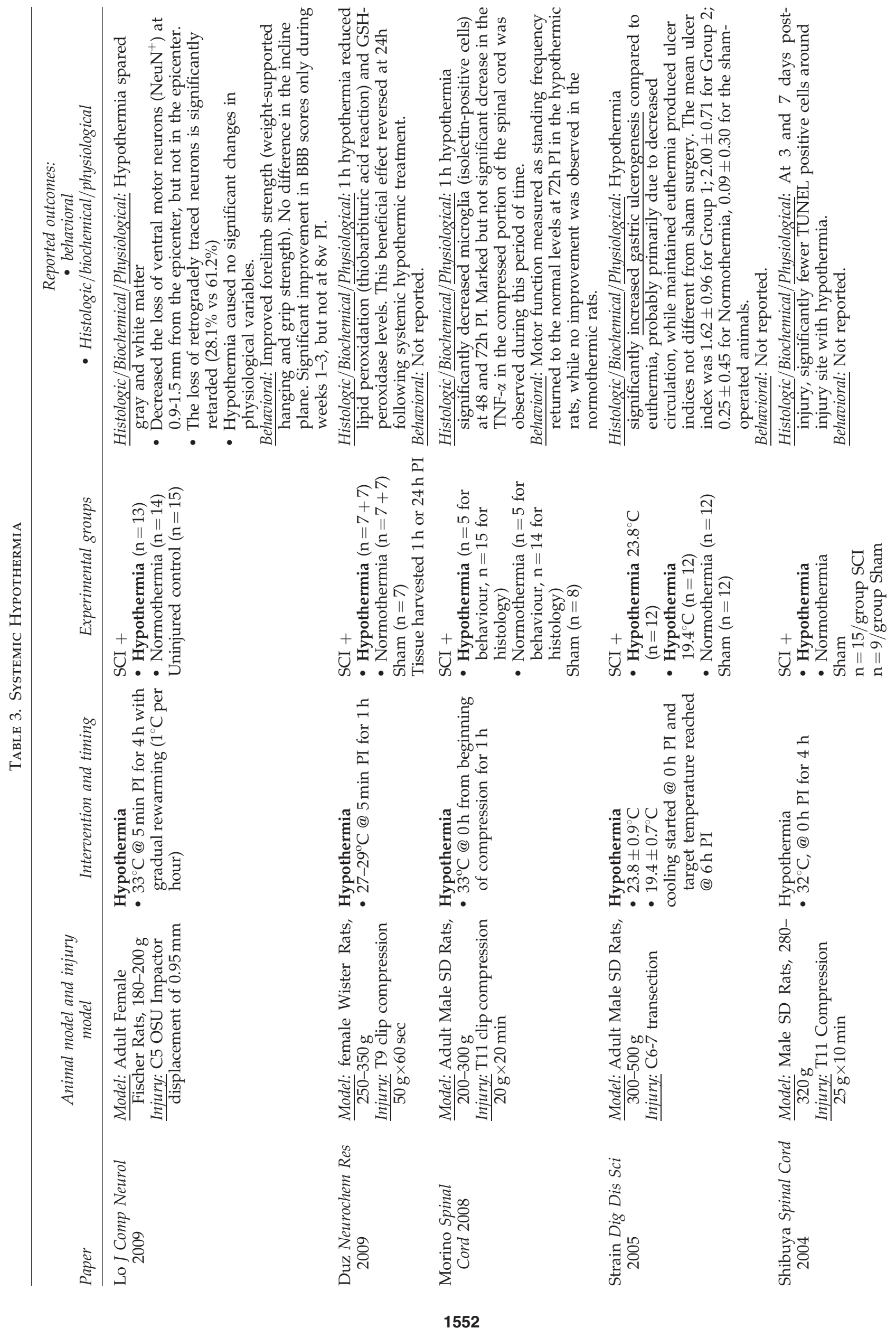



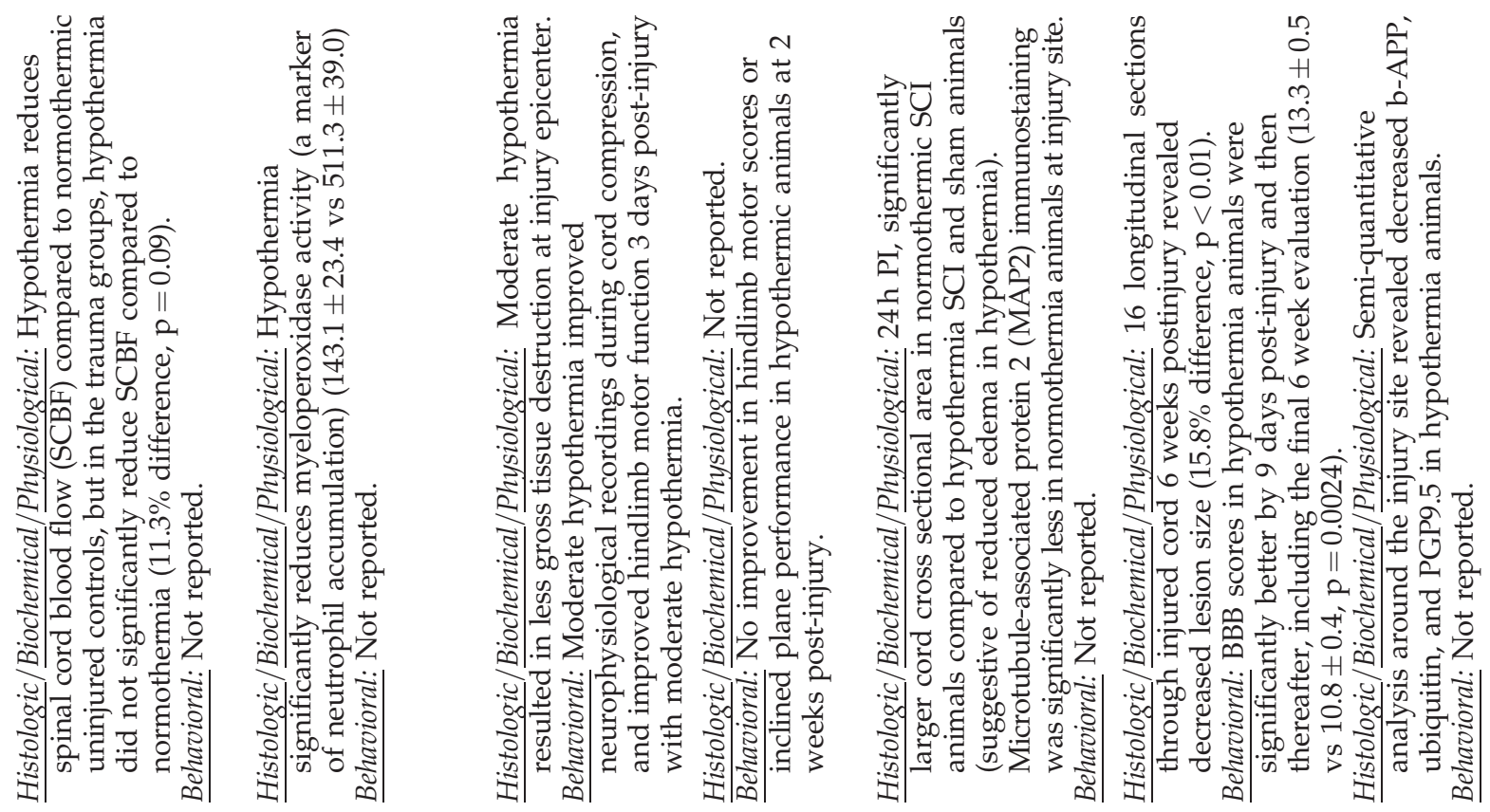

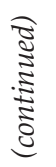

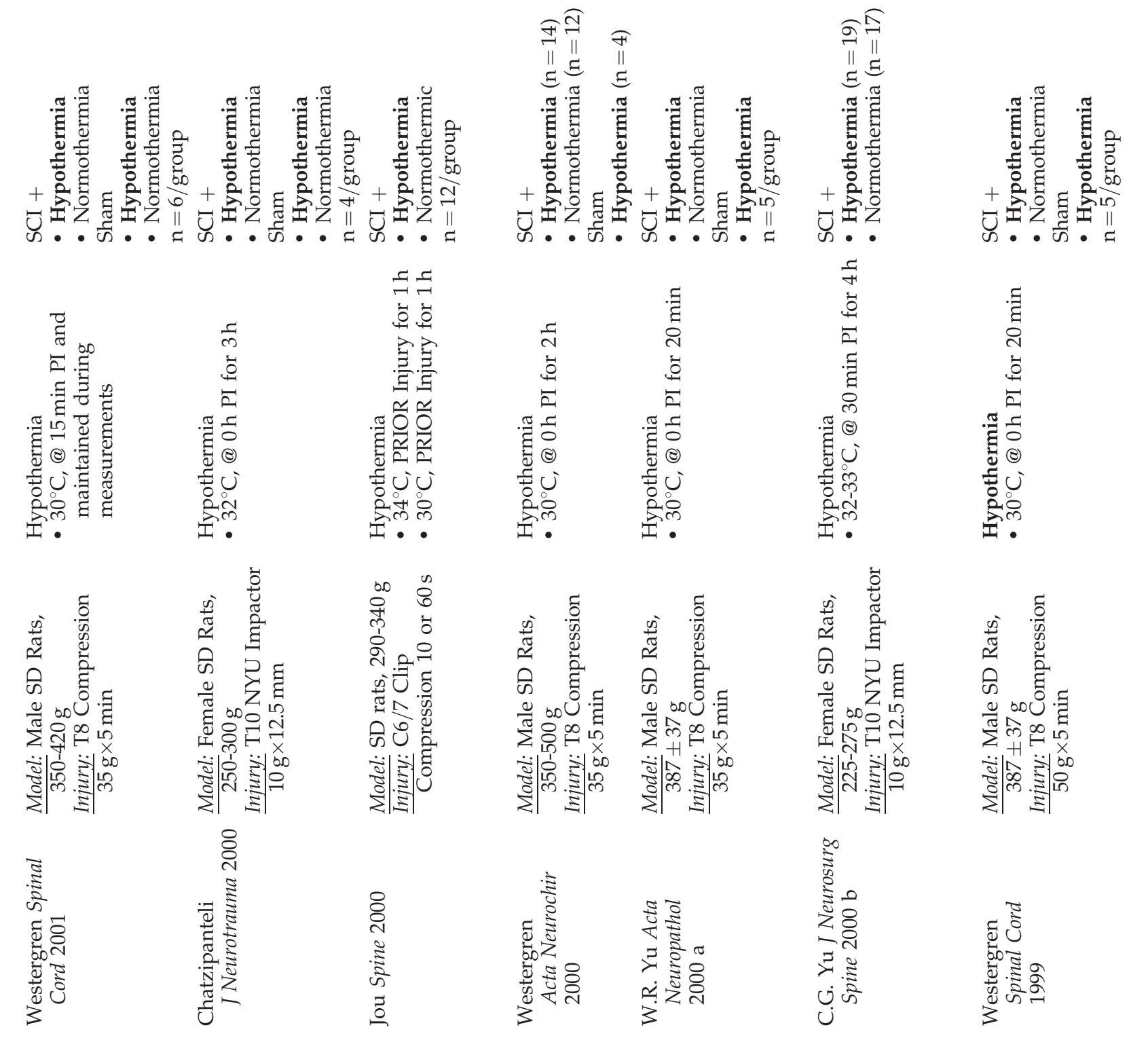




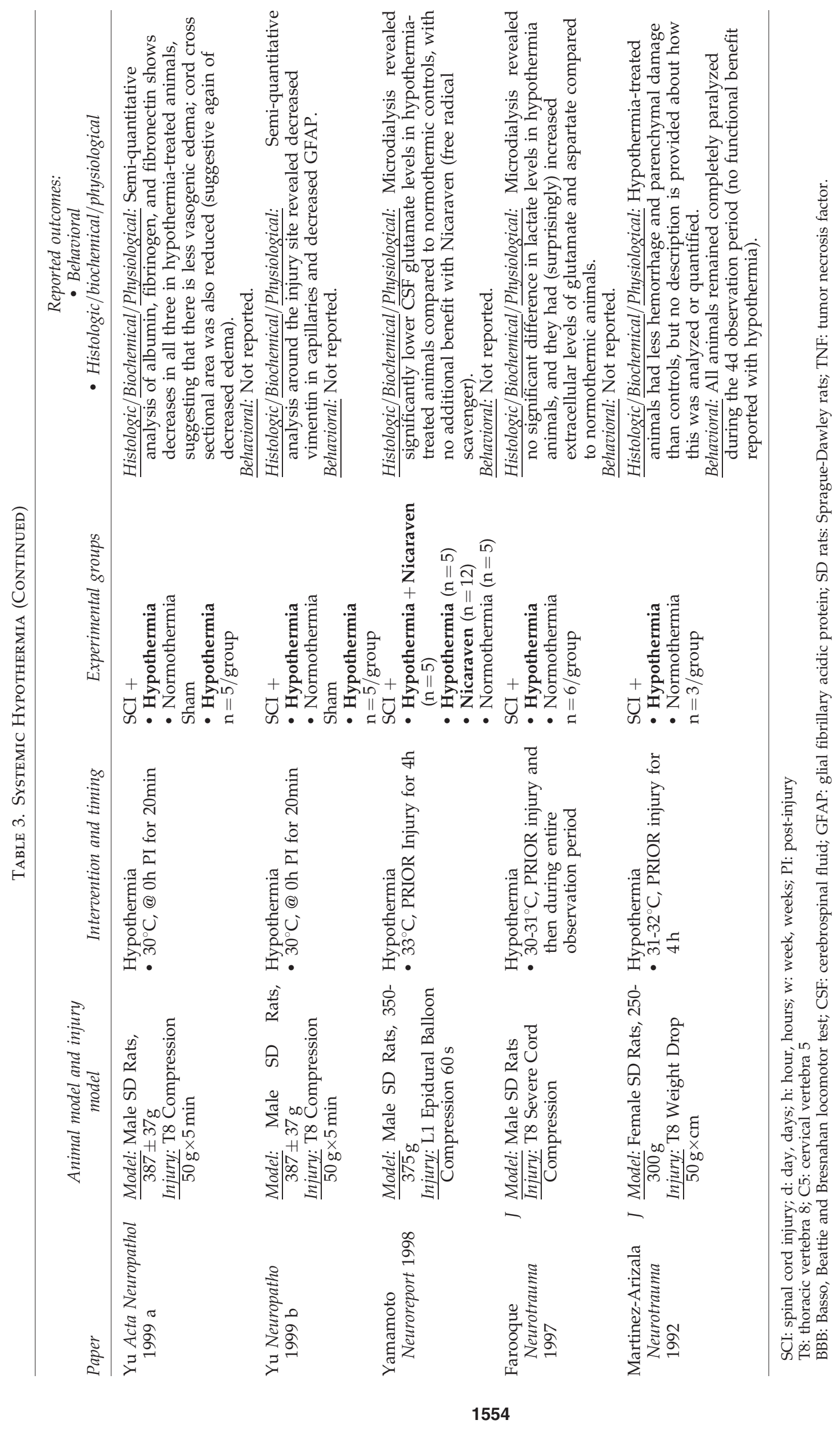




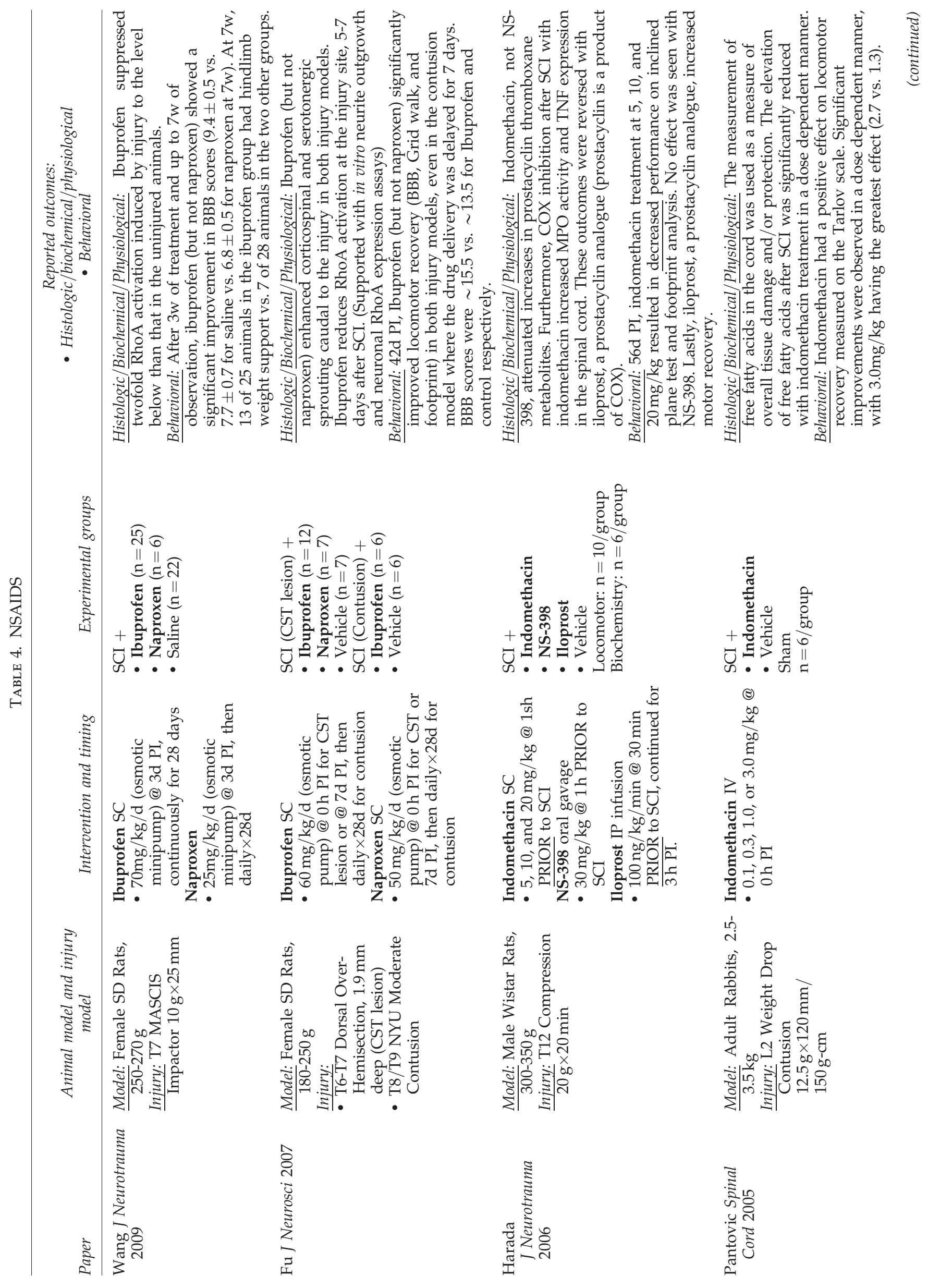




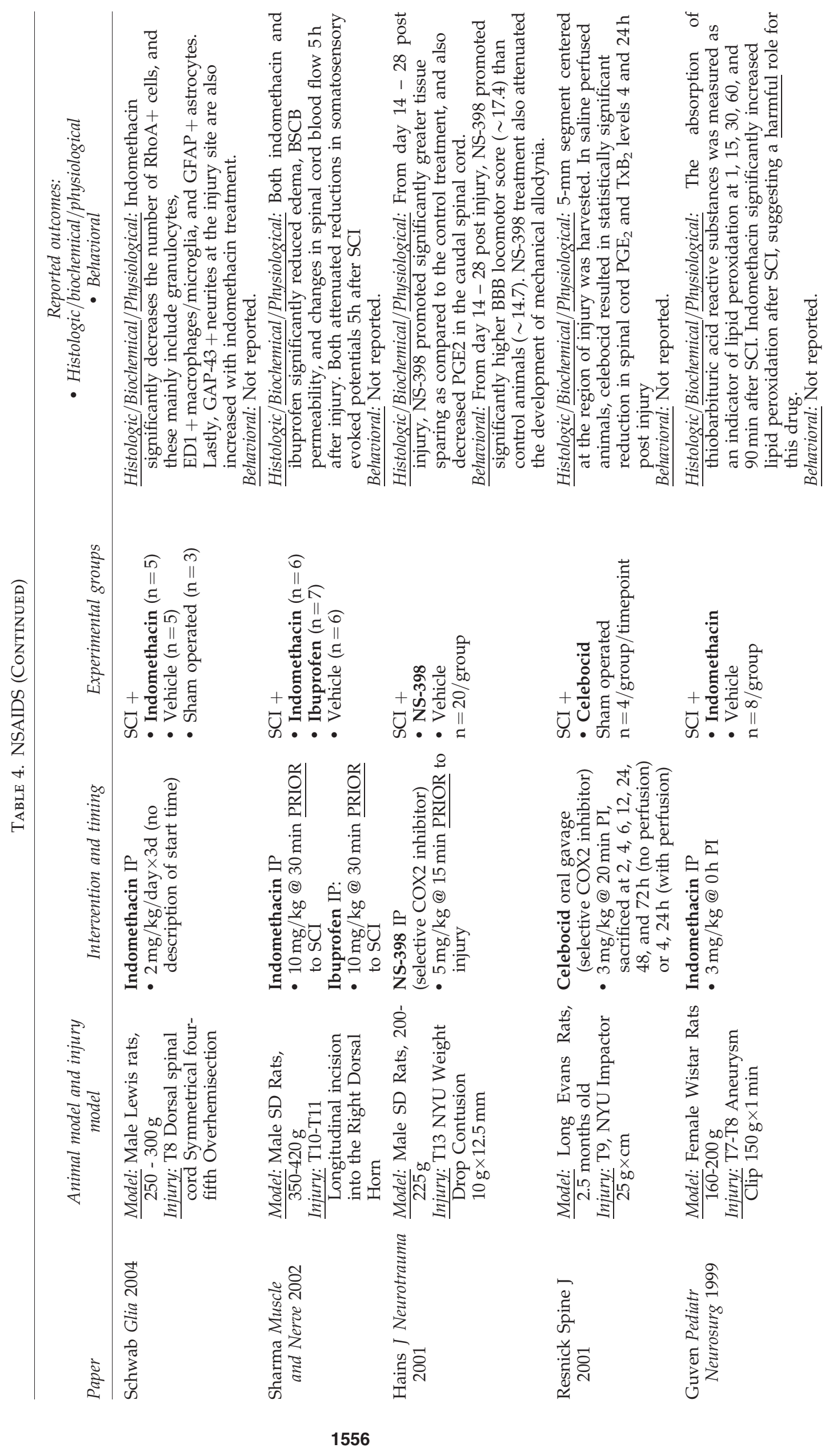



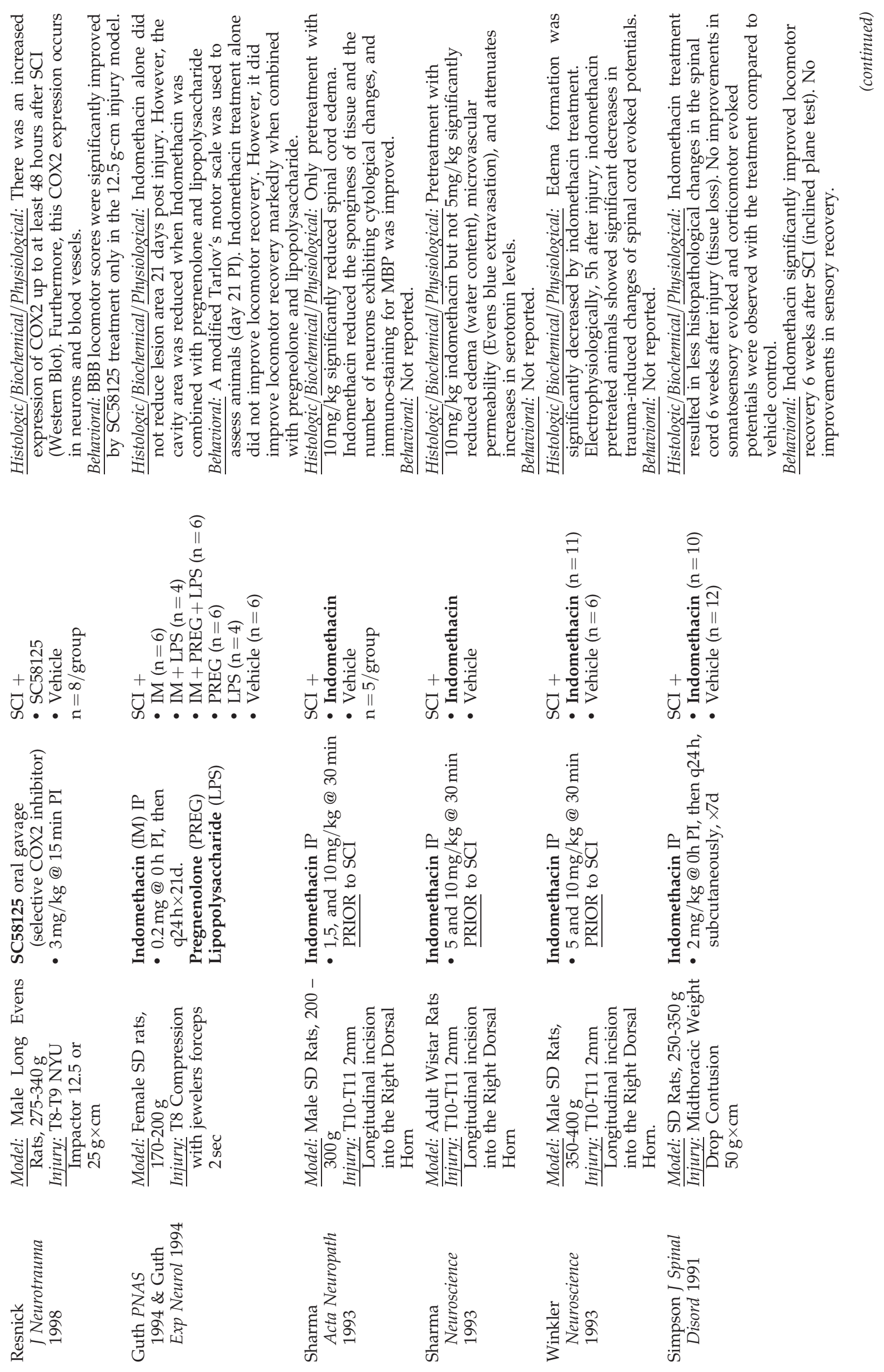


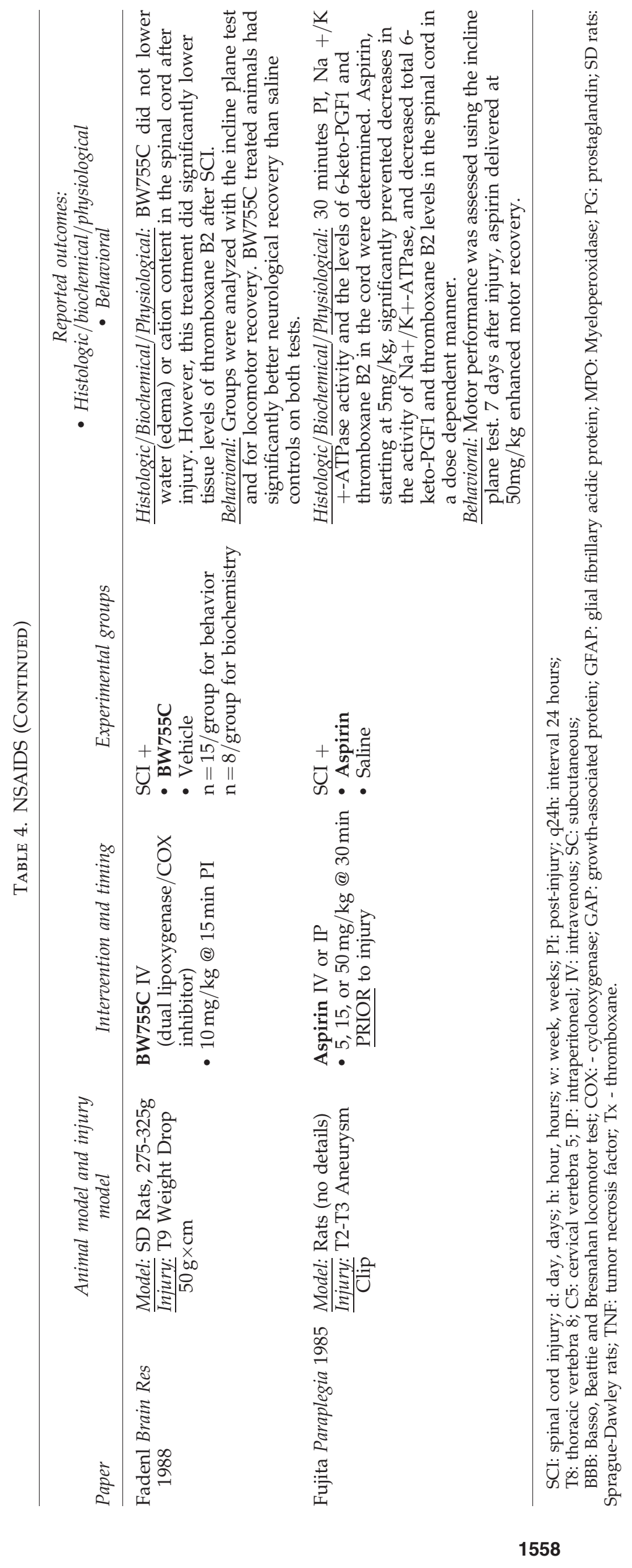


in this systematic review were published from this single laboratory. The CD11/CD18 integrin family has several members, and this antibody is directed against the CD11d subunit of the CD11d/CD18 integrin that is expressed only by certain leukocytes such as neutrophils and monocytes. The selectivity and specificity of targeting this subunit with this antibody is key to its effectiveness. Other CD11 integrins containing the subunits $\mathrm{a}-\mathrm{c}$ have more widespread cellular distributions and antibodies directed against them have not been particularly useful as neuroprotective treatments. Relative homogeneity in animal species (Wistar) and injury model (T4 clip compression) exists amongst these studies. The antibody treatment is administered intravenously in all cases. A dose response has been demonstrated insofar as $1 \mathrm{mg} / \mathrm{kg}$ appeared to be better than $5 \mathrm{mg} / \mathrm{kg}$ in an early study, and has been the dose used in all subsequent studies. The dosing regimen most extensively studied is $1 \mathrm{mg} / \mathrm{kg}$ started $2 \mathrm{~h}$ post injury and repeated at 24 and $48 \mathrm{~h}$ post injury. Given that multiple studies report a beneficial effect with this approach started $2 \mathrm{~h}$ post injury, a 2 -h time window of intervention has been established. Recently, however, therapeutic efficacy has been shown when starting the treatment at 6 or $12 \mathrm{~h}$ post injury, which are important findings with respect to clinical applicability. Early studies focused on non-behavioral outcomes (and did not report behavioral outcomes at all). These largely confirmed the mechanism of action in terms of reducing neutrophil and macrophage invasion, decreasing inflammation and lipid peroxidation, and improving tissue sparing. Behavioral outcomes revealed increased BBB locomotor scores, decreased autonomic dysreflexia, and reduced mechanical allodynia.

\section{Minocycline (Table 6)}

Minocycline has been evaluated in a relatively extensive manner in acute SCI models. The systematic review resulted in 10 papers that met the inclusion criteria. Most of these (6 of 10) utilized Sprague Dawley rats, although three used adult Wistar rats, and one mouse SCI model was described. Most of the injury models employed a thoracic contusion at T9 with the NYU impactor, although balloon compression, clip compression, and partial transection models were also utilized by individual investigators. Minocycline was administered in a range of doses, and the effect of different doses was demonstrated by some authors (Festoff et al., 2006; Teng et al., 2004). The most common dose utilized was $90 \mathrm{mg} / \mathrm{kg}$ given intraperitoneally, although doses of $50 \mathrm{mg} / \mathrm{kg}$ were also utilized by Stirling and colleagues (2004) and Wells and colleagues (2003) in their studies. Most of the studies administered minocycline immediately after injury, but a window of efficacy was observed at $1 \mathrm{~h}$ post injury (Teng et al., 2004; Wells et al., 2003) and at $2 \mathrm{~h}$ post injury (Yune et al., 2007).

Non-behavioral outcome measures revealed tissue sparing, decreased cytochrome $\mathrm{c}$ release, decreased caspase 3 positive oligodendrocytes, and macrophages/microglia. Behavioral outcome measures revealed improved BBB, inclined plane, hindlimb coordination. The recent study by Marchand and colleagues (2008) reported an attenuation of neuropathic pain with intraperitoneally administered minocycline, which is an extension of important work by Hains and colleagues who previously demonstrated that intrathecally delivered minocycline inhibited the activation of microglia reduced pain behavior on mechanical and thermal stimulation of the paw (Hains and Waxman, 2006; Zhao et al., 2007a, 2007b). These papers were not included in the table because of the intrathecal (and chronic) mode of minocycline administration, but are noted here for their important insights on the role of inflammatory mediators in the generation of pain behavior.

Of note, two recent papers (Pinzon et al., 2008; Saganová et al., 2008) revealed limited neuroprotection and no significant functional benefit to minocycline. The study by Pinzon and colleagues was an NIH-sponsored attempt to reproduce the positive effects of minocycline that had been demonstrated by others; it failed to reveal any benefit to either intraperitoneally or intravenously administered minocycline at the $90 \mathrm{mg} / \mathrm{kg}$ dose. Reconciling the contradictory results from this attempted reproduction is difficult. Presently, intravenously administered minocycline is under evaluation as a neuroprotective compound for the management of SCI in a phase I/II pilot study in Calgary, Alberta.

\section{Progesterone (Table 7)}

The systematic review identified 10 studies that evaluated progesterone in traumatic SCI models. All of these studies utilized Sprague Dawley rats. Eight of 10 studies utilized a complete thoracic transection SCI model, and were from the same laboratory. One utilized the Infinite Horizon impactor (Fee et al., 2007) and one utilized the NYU impactor (Thomas et al., 1999) to induce clinically relevant thoracic contusion injuries. Progesterone was administered at $4 \mathrm{mg} / \mathrm{kg}$ in almost all studies, but also at $8 \mathrm{mg} / \mathrm{kg}$ by Fee and colleagues (2007) and $16 \mathrm{mg} / \mathrm{kg} /$ day by Labombarda and colleagues (2009). In all cases, the progesterone was started either 30 to $60 \mathrm{~min}$ post injury and was typically repeated daily two, three, or more times. The " $n$ per group" ranged from 4 to 19 , but was most often approximately five. All eight studies that utilized a transection injury reported only on non-behavioral outcomes, and typically within a few days post injury. These reported that progesterone treatment can alter gene and protein expression, cell morphology, and receptor and neurotransmitter expression in the injured spinal cord. Of the two studies that utilized contusion injuries, one reported no histologic improvement in progesterone-treated animals (Fee et al., 2007), while the other reported more white matter sparing (Thomas et al., 1999). The former reported no behavioral improvement on BBB testing, while the latter reported significant improvement.

\section{Estrogen (Table 8)}

The systematic review of estrogen turned up eight papers, all published within the last 5 years. Sprague Dawley rats were utilized in five studies, Wistars in one, and mice in two studies. Injury models were quite variable, and included midthoracic contusion with the NYU weight drop (three) or Infinite Horizon impactor (one), or a clip compression injury (two), forceps crush injury (one), and a thoracic transection injury (one). Estrogen was administered in an extremely wide range of doses, from $0.1 \mathrm{mg} / \mathrm{kg}$ to $600 \mathrm{mg} / \mathrm{kg}$, and in some cases subsequent dosing was also done. A dose effect was demonstrated in some studies (Cuzzocrea et al., 2008; Ritz and Hausmann, 2008; Yune et al., 2004). In seven of eight studies, the estrogen was started prior to, at the time of, or within $15 \mathrm{~min}$ of the injury. The most recent study by 


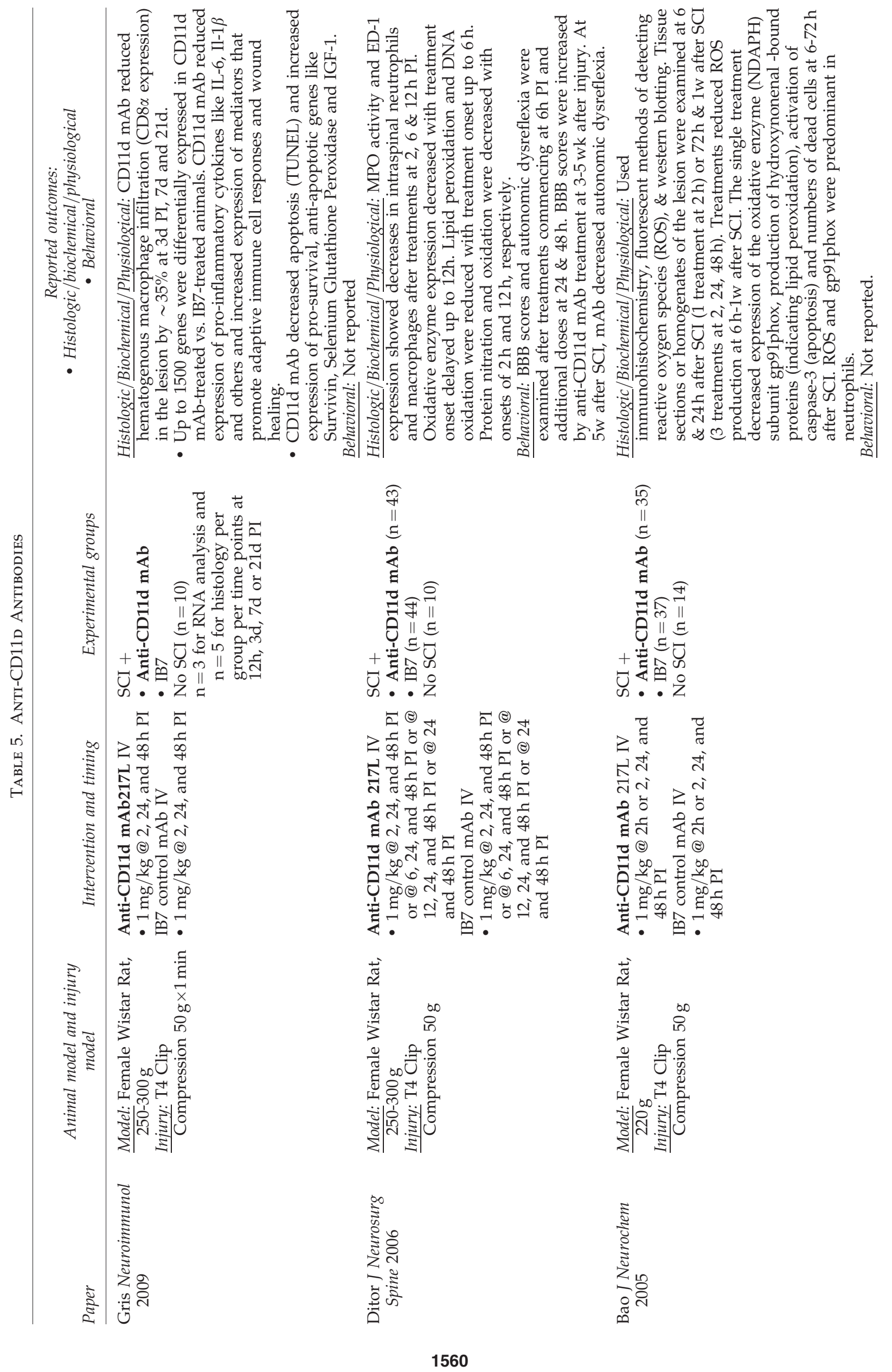




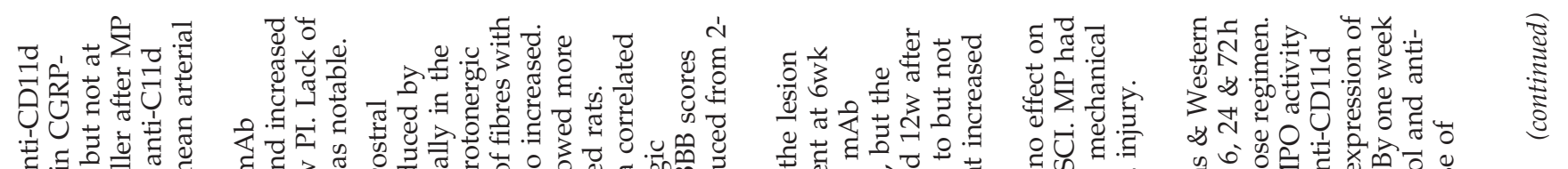

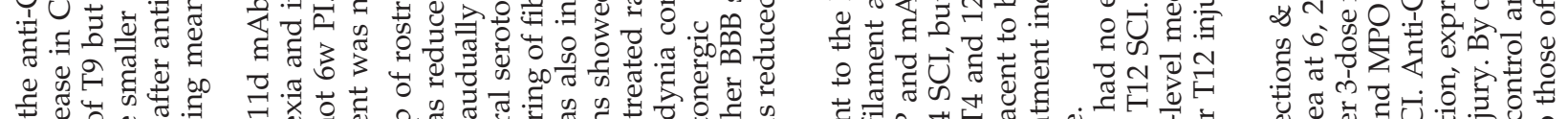

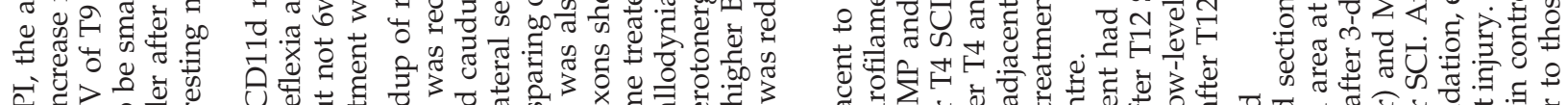

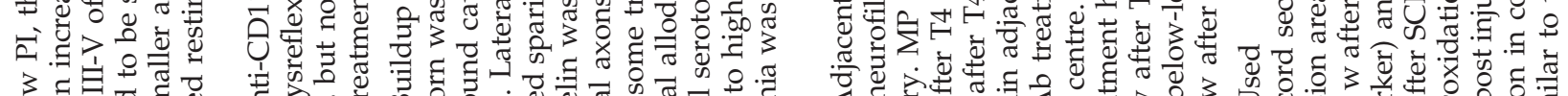

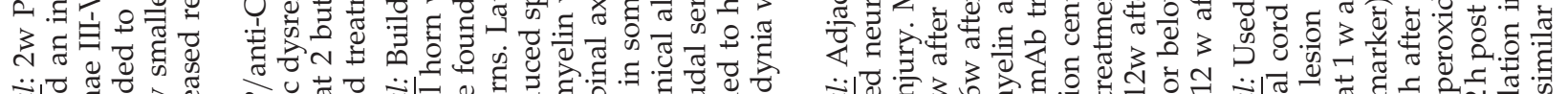

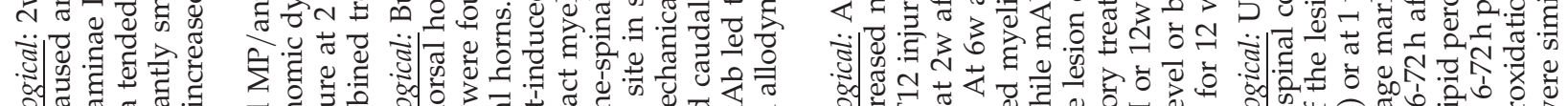

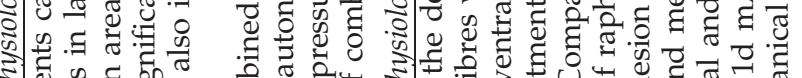

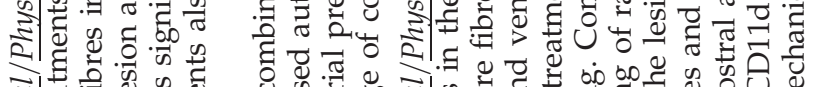

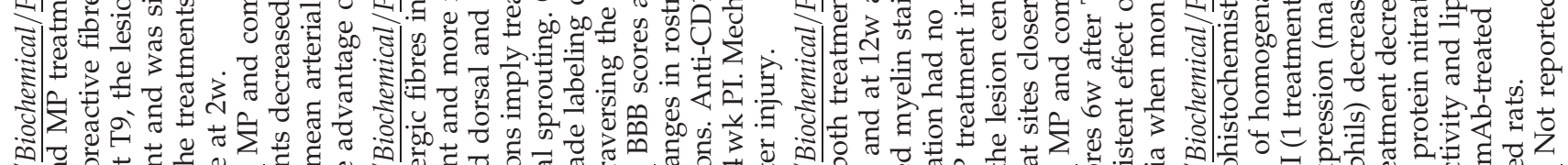

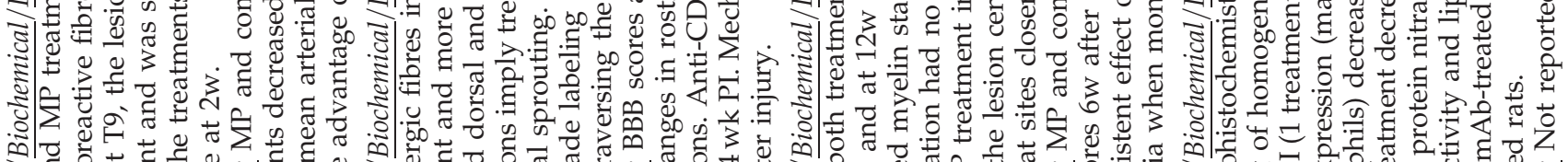

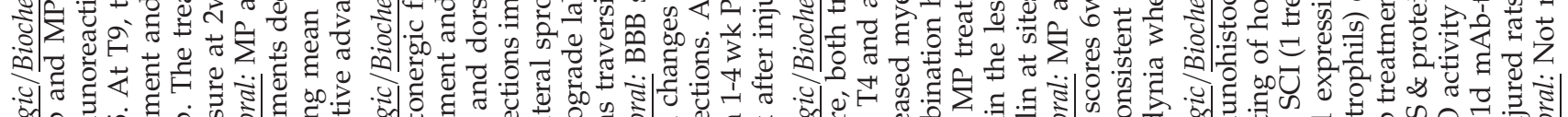

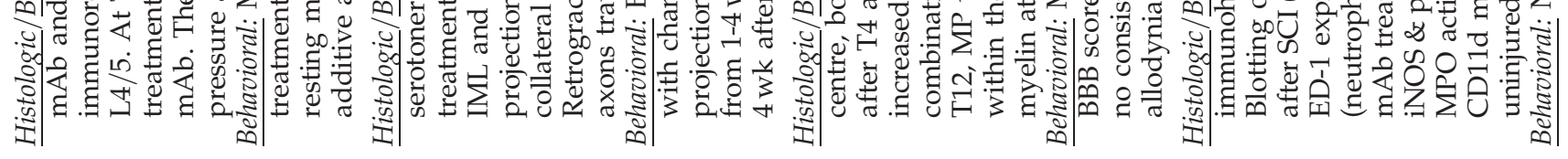

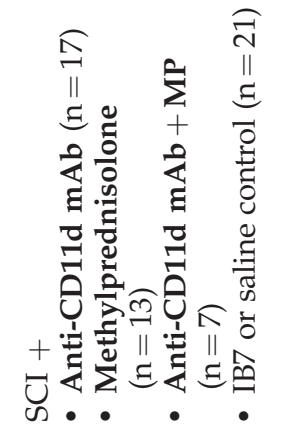

$z=\bar{x}$

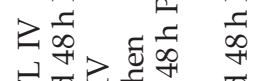

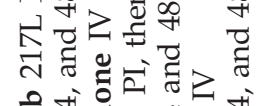

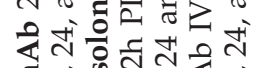

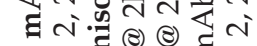

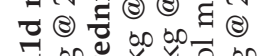

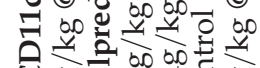

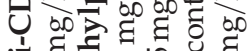

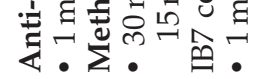

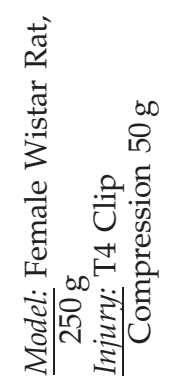

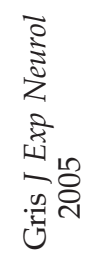
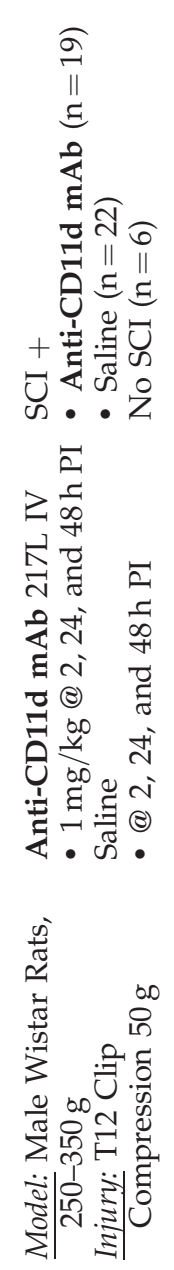

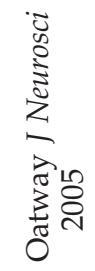
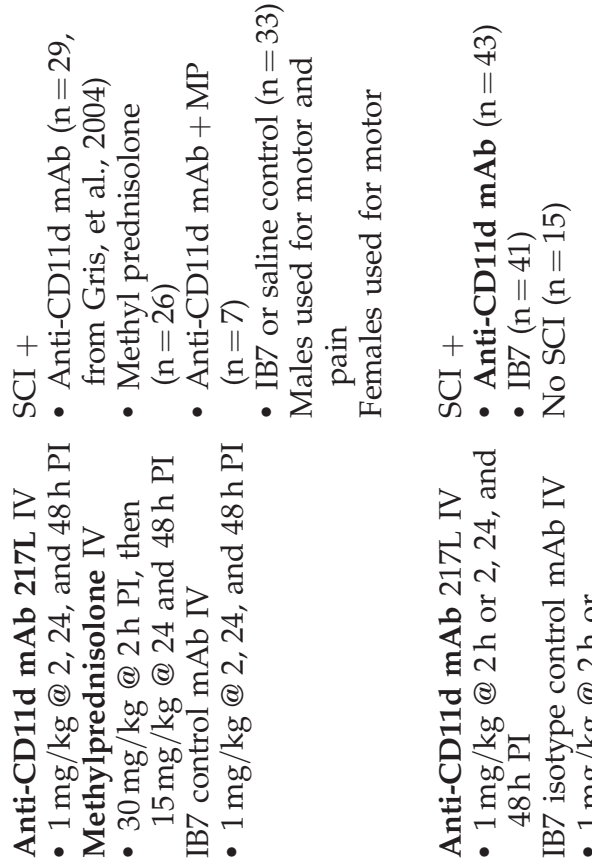

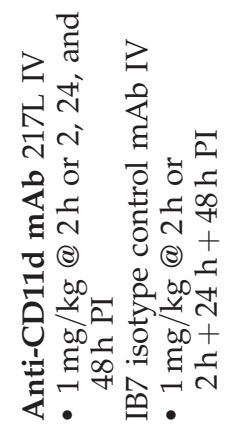
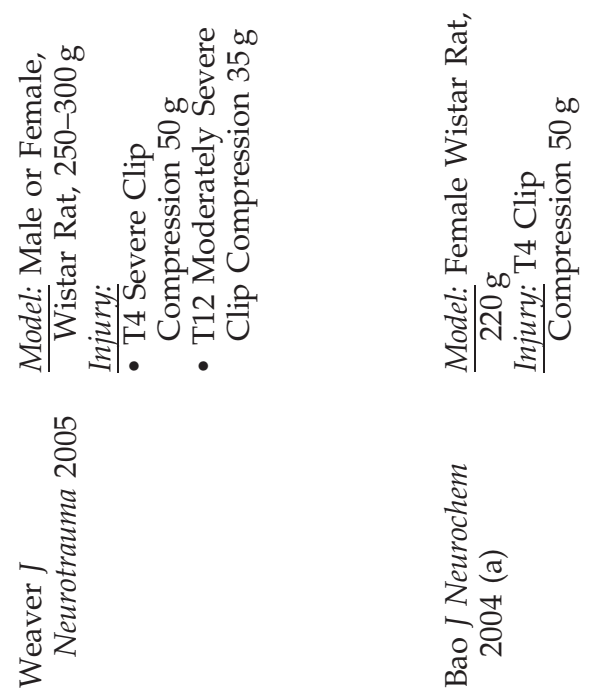


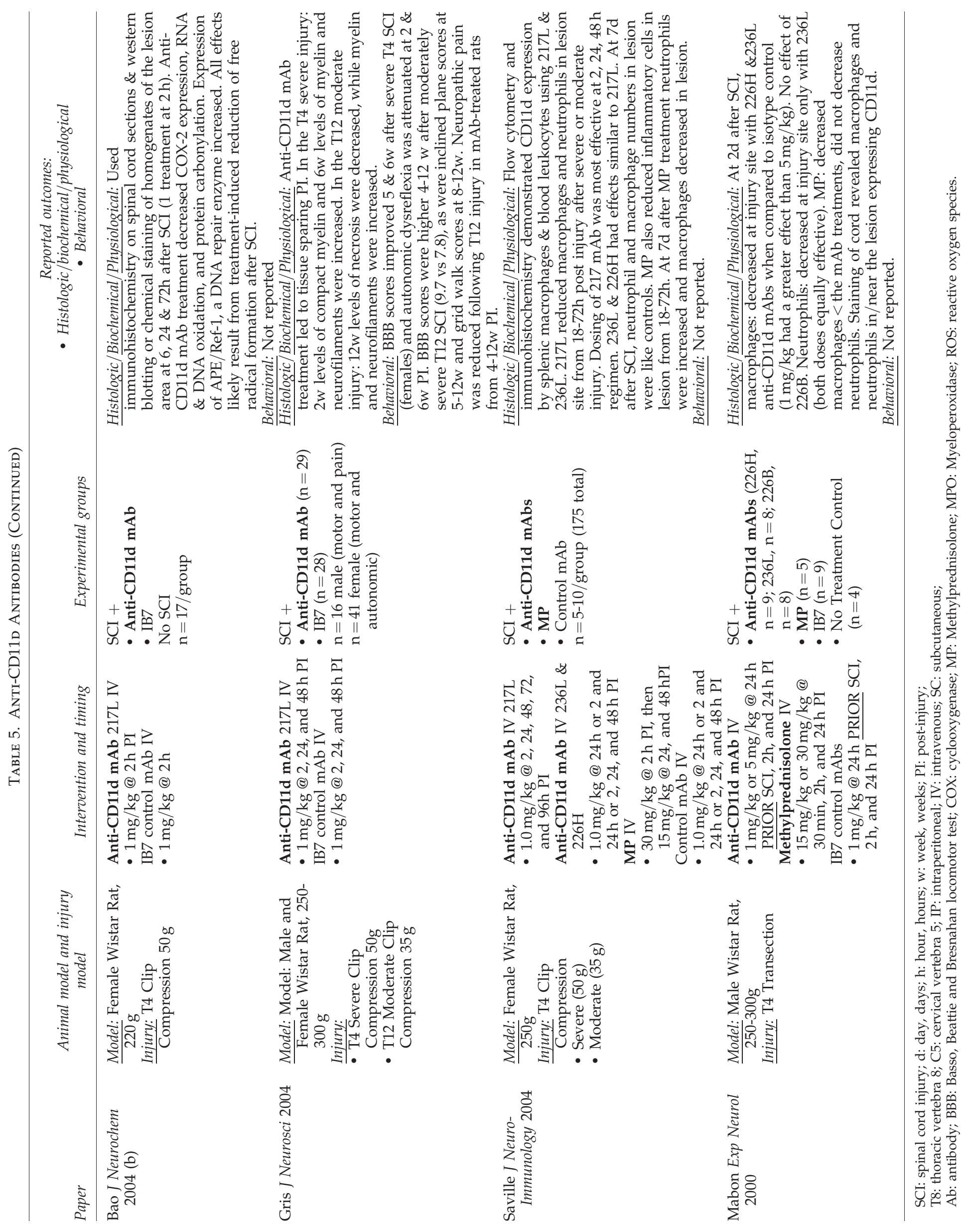




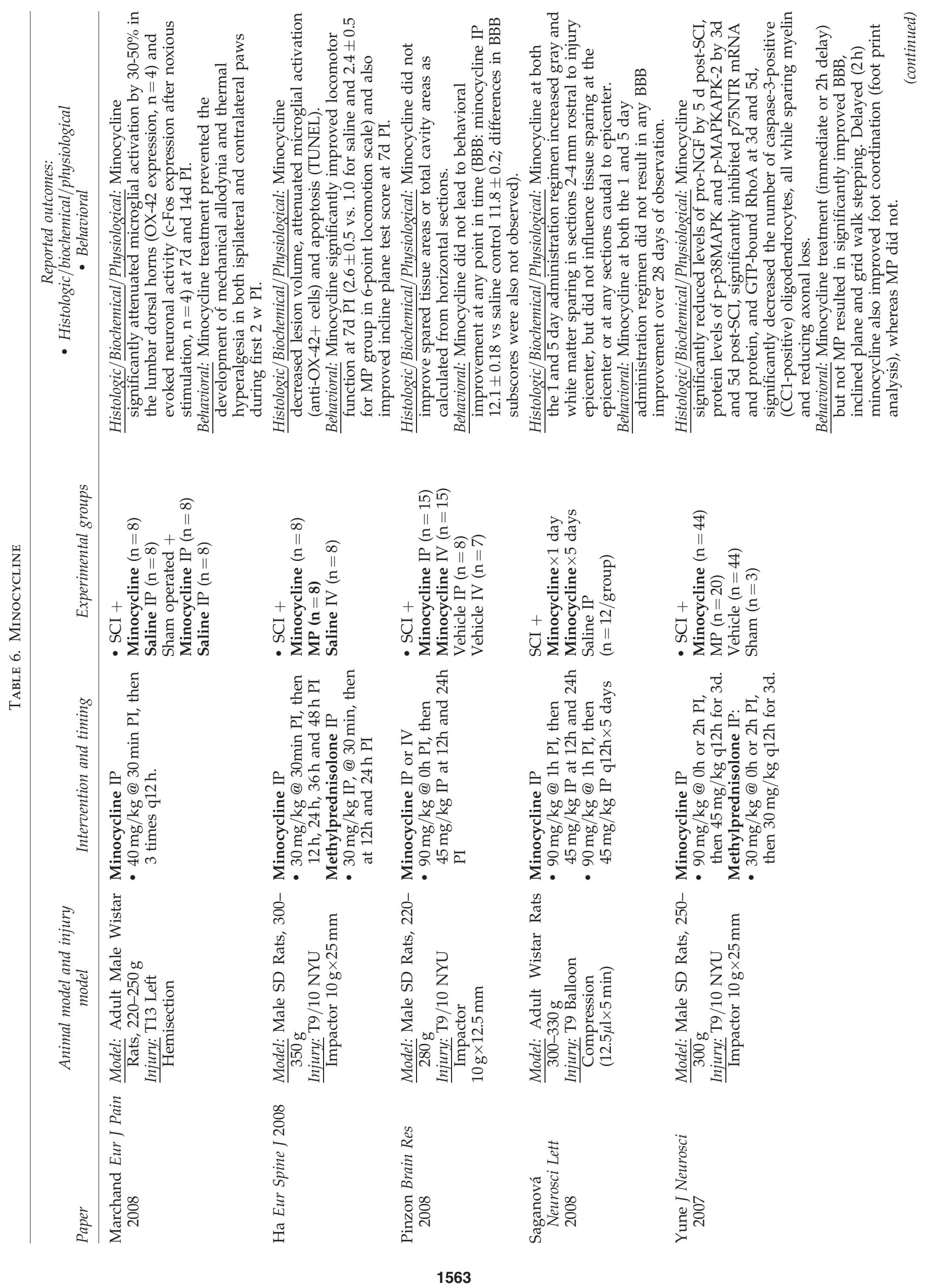




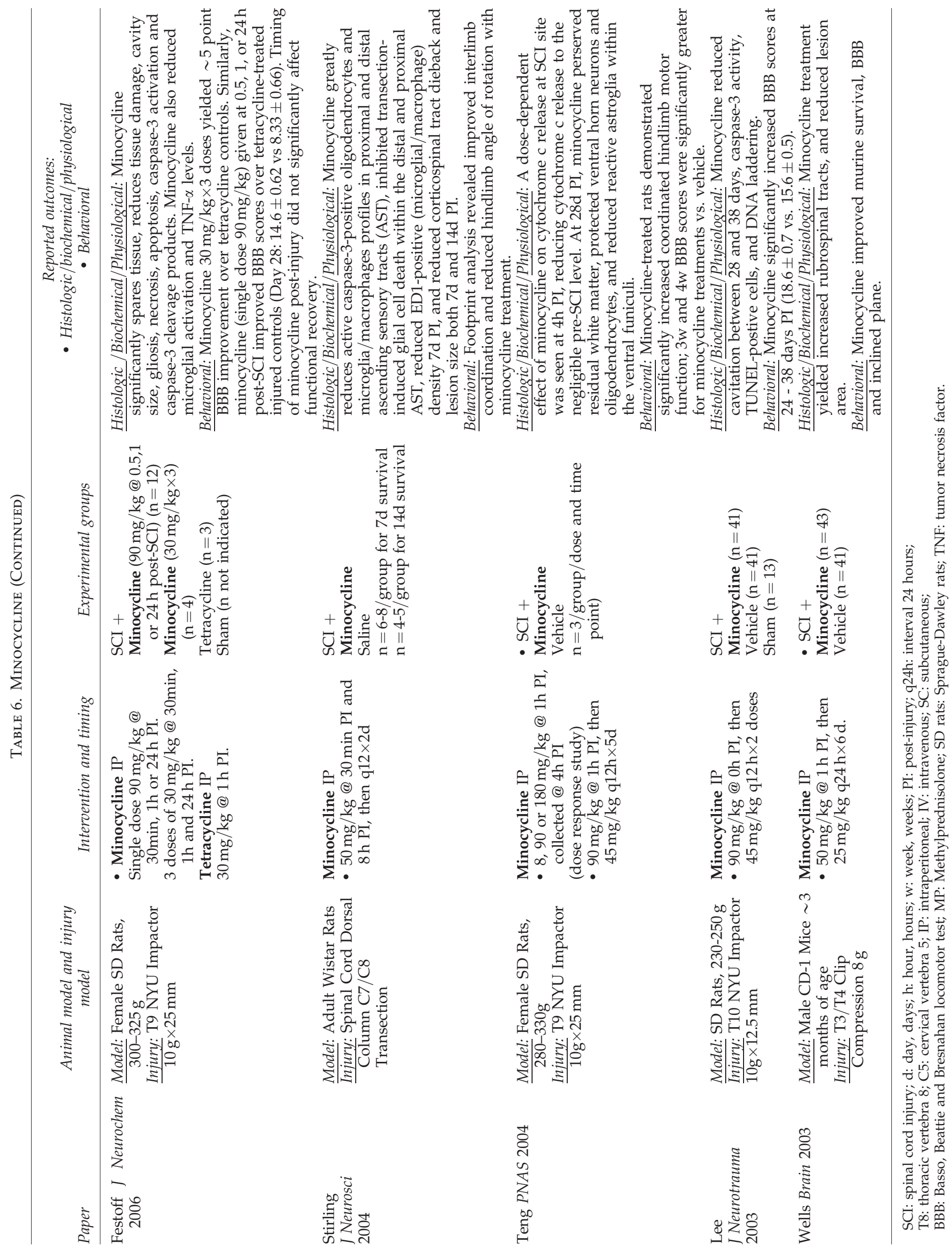




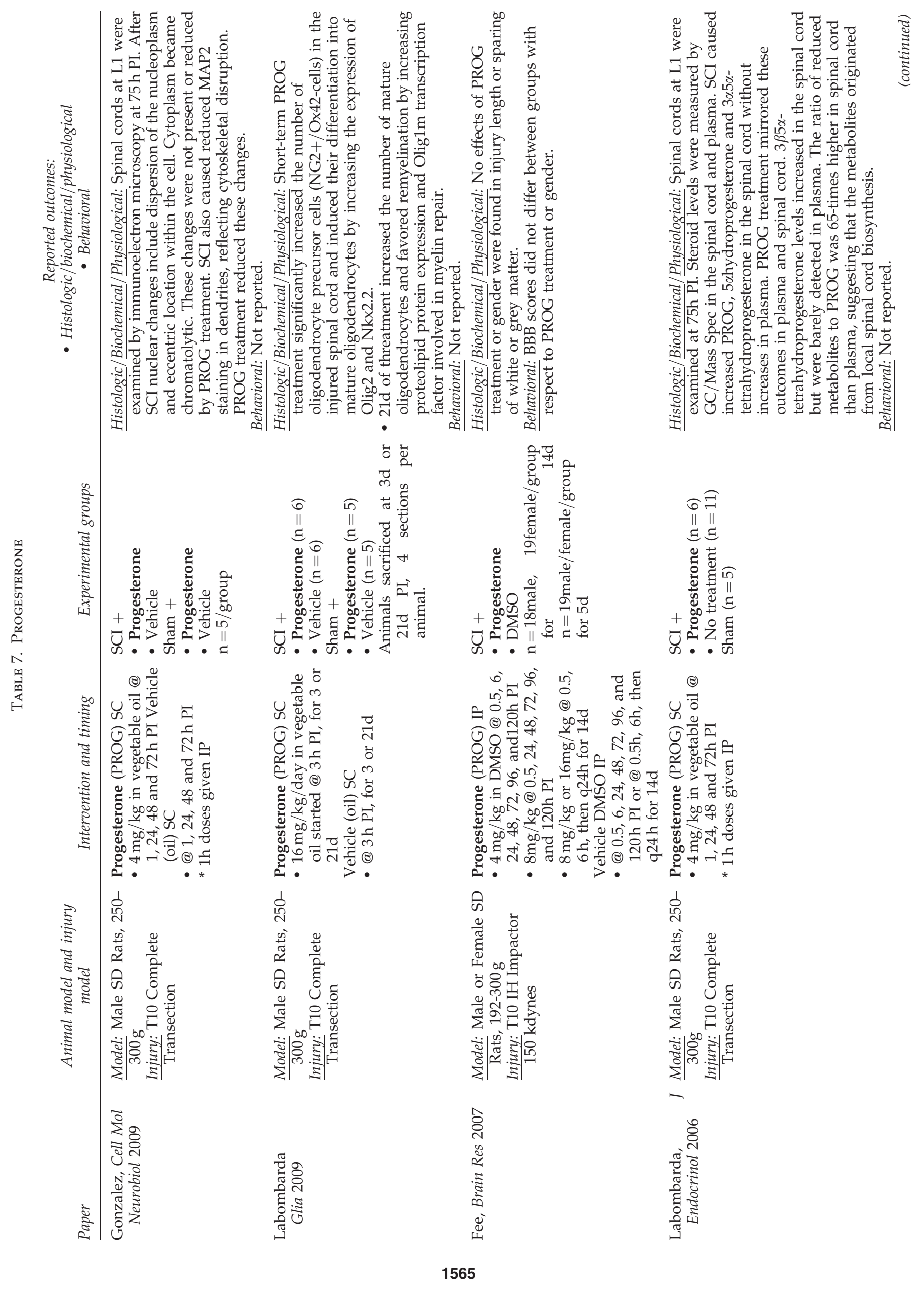




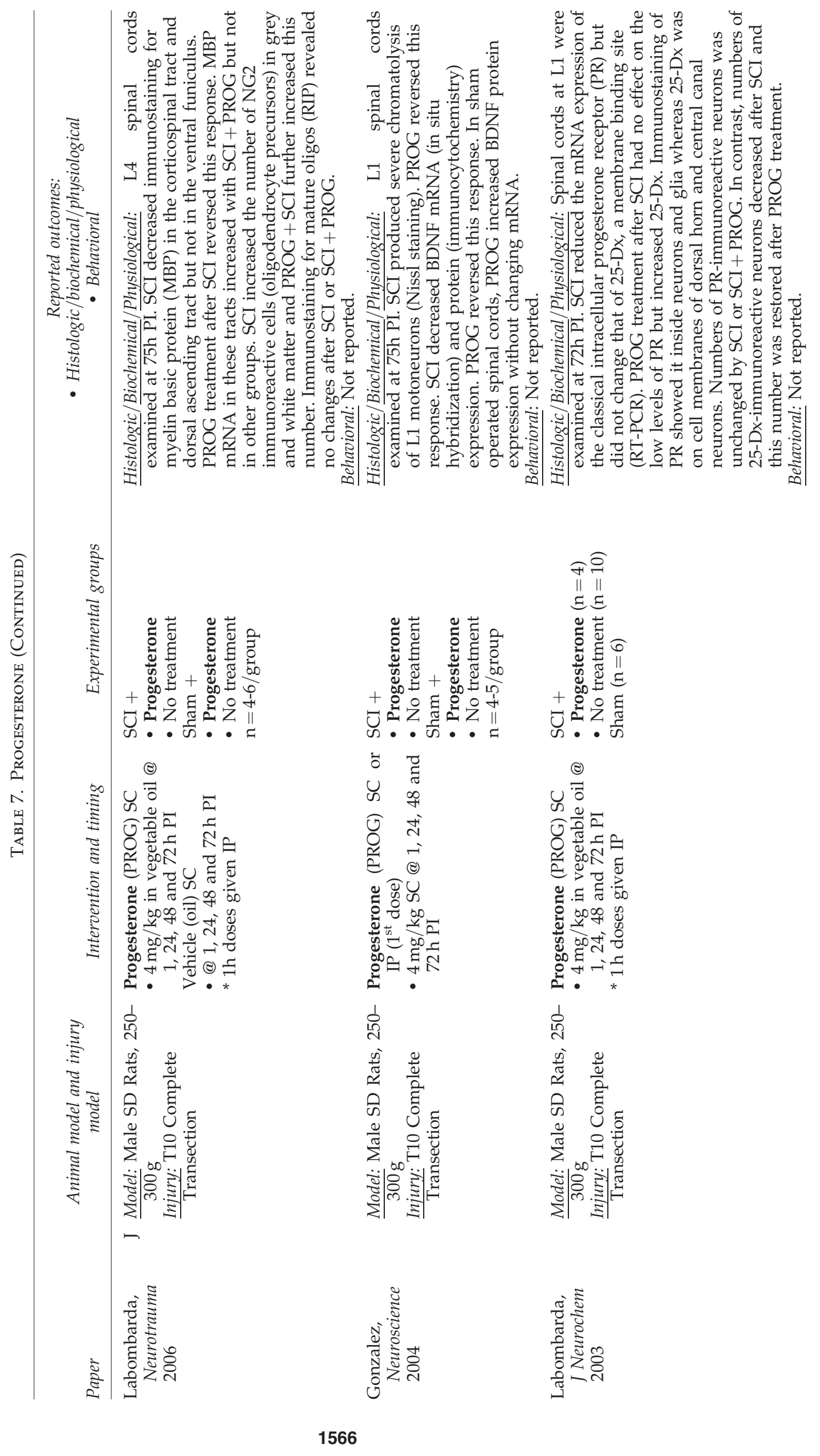




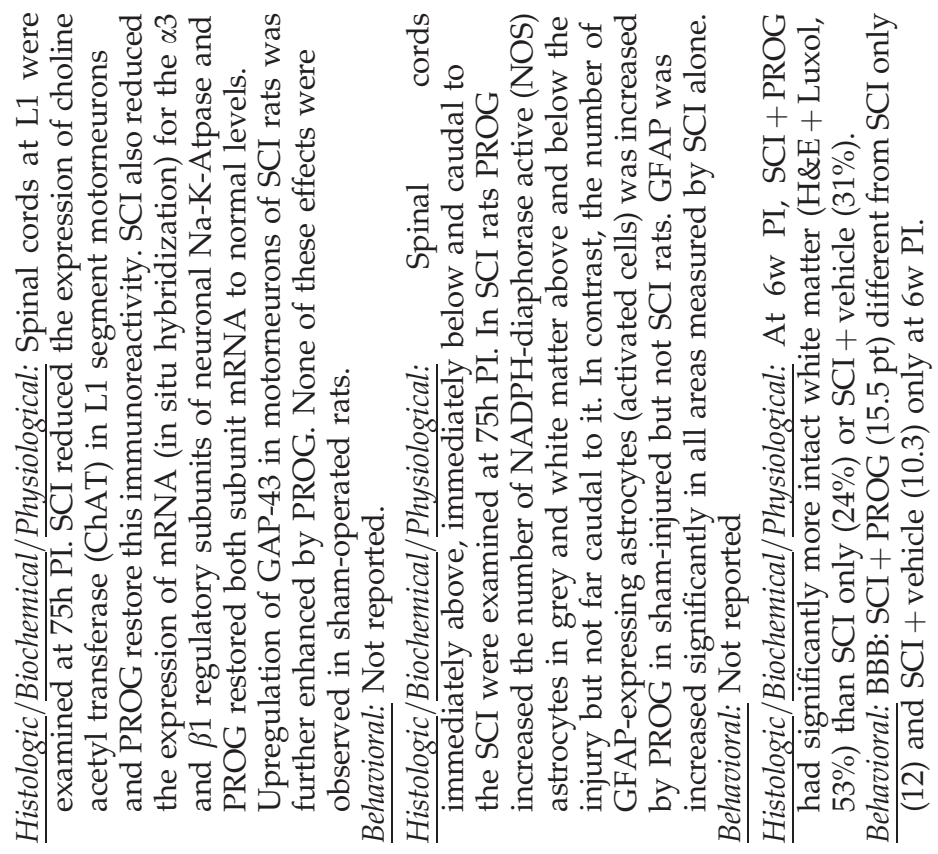
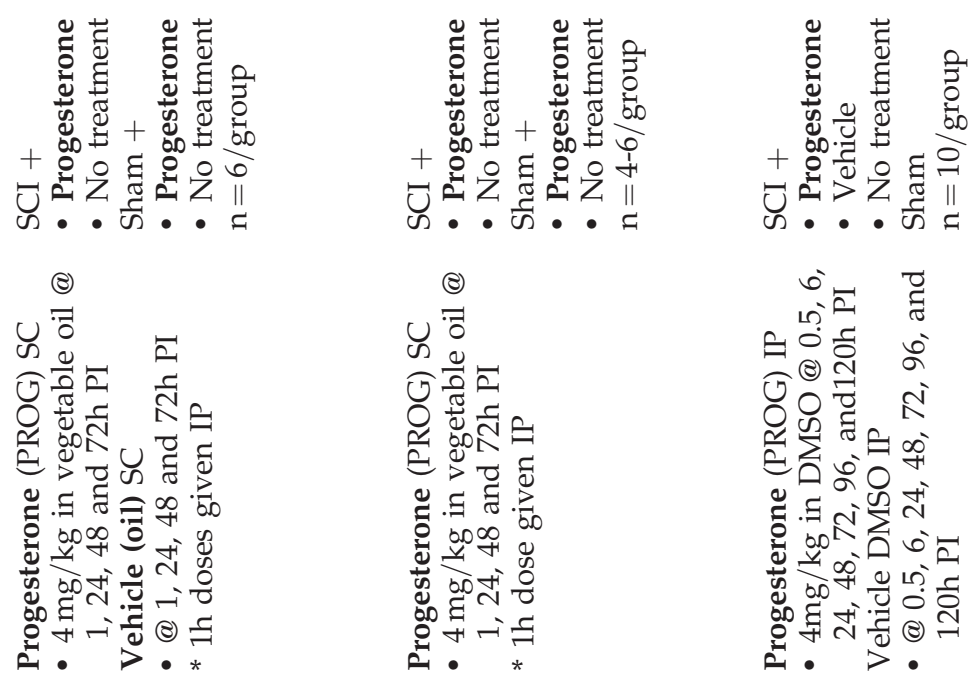

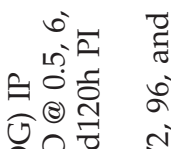

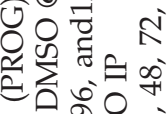

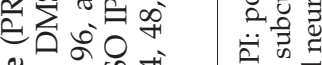

:

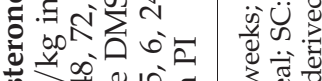

की

路过资 (8)

ํㅏㄴ
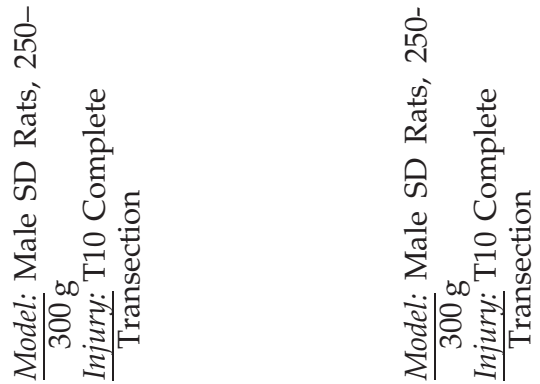

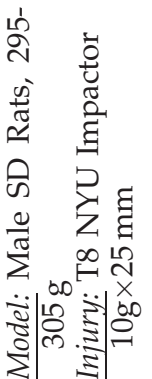
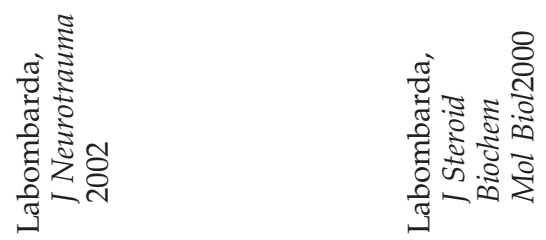

है
के
है हे
हू बे
है

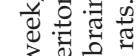

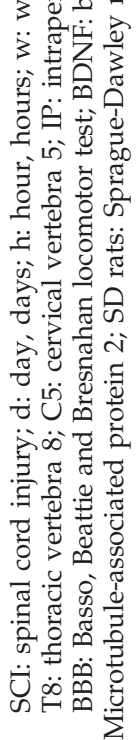




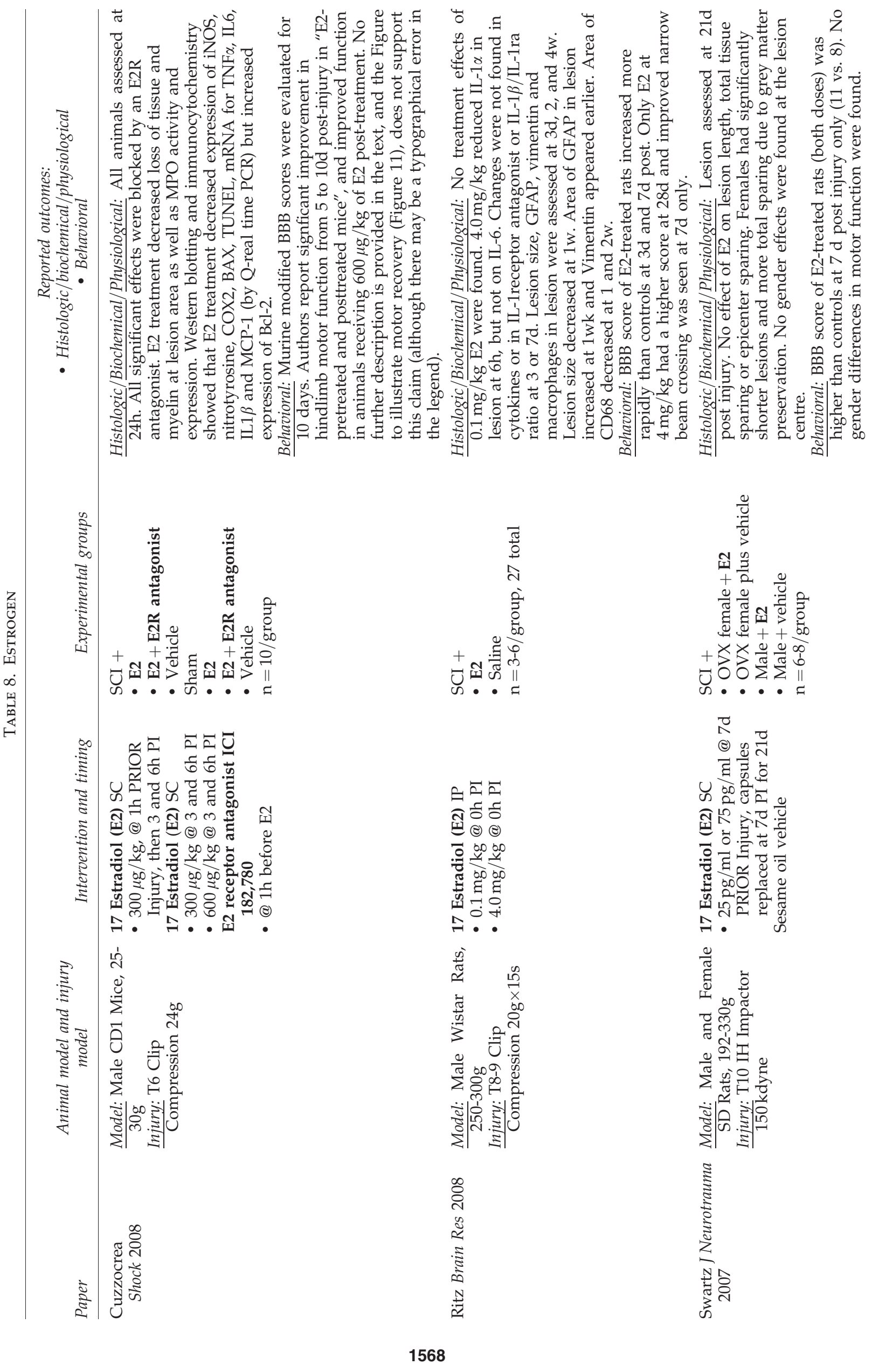




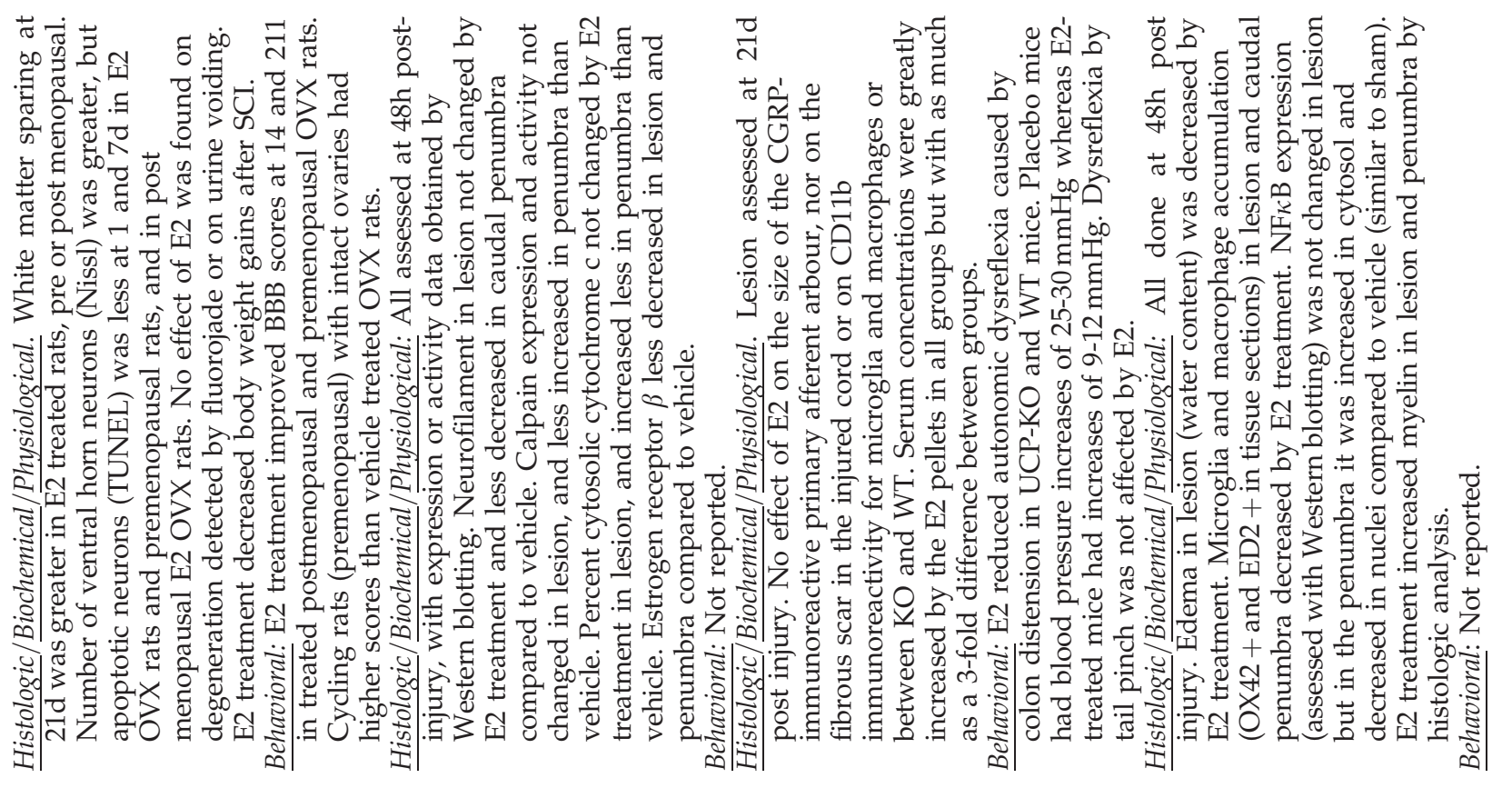

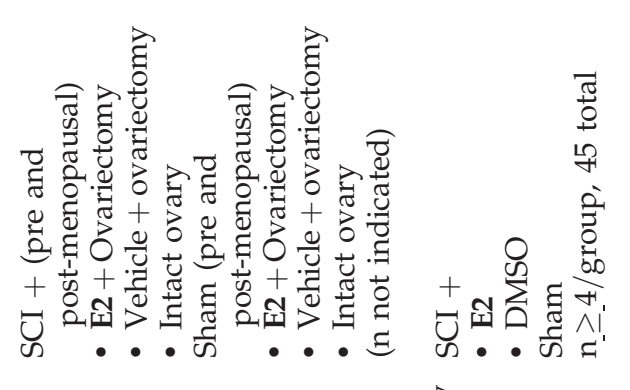
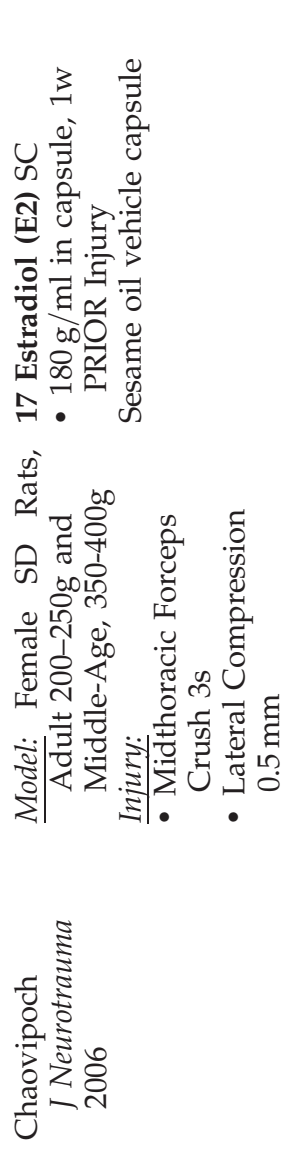
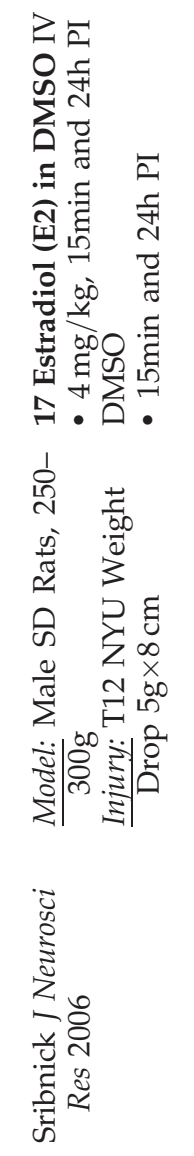
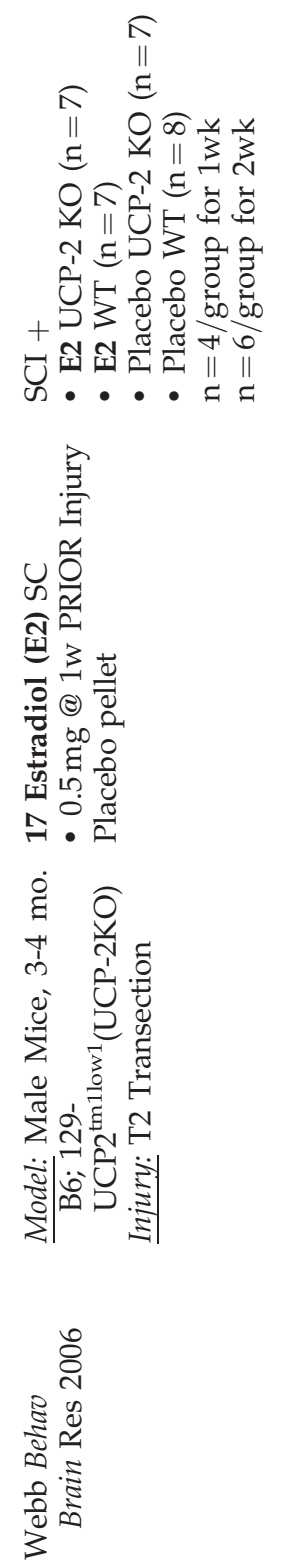

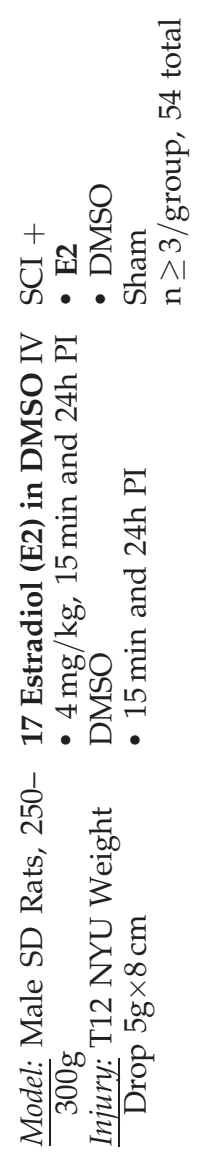

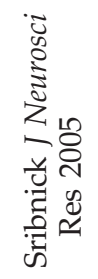




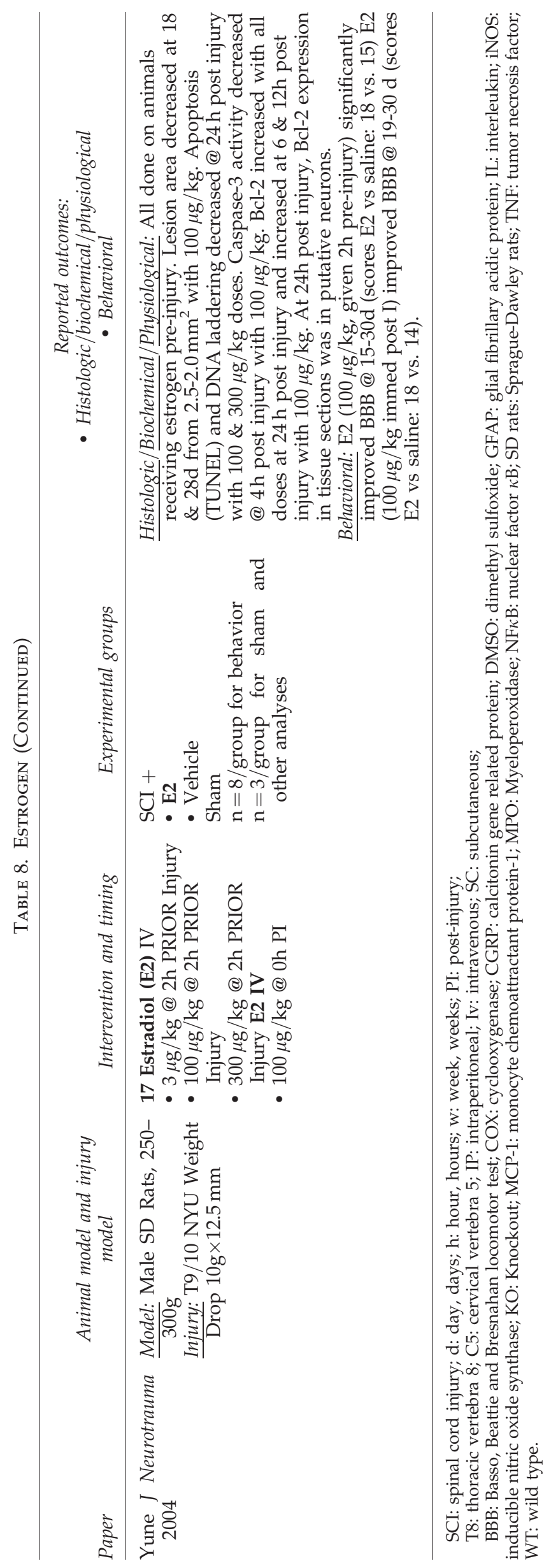


Cuzzocrea and colleagues (2008) was the only one to include a more substantive delay prior to beginning estrogen $(3 \mathrm{~h})$. The "n per group" was variable as well, and ranged from 3 to 10. Non-behavioral outcomes reported included decreased overall secondary tissue damage, reduced MPO activity, microglial/macrophage accumulation, and reduced apoptosis. Behavioral outcomes reported improved BBB scores (although these were measured out to a few weeks post injury in a number of cases). Webb and colleagues (2006) reported reduced autonomic dysreflexia as well. Important to note that almost all of these beneficial behavioral and non-behavioral outcomes were observed in paradigms of estrogen pretreatment (or treatment at the time of injury). Only the Cuzzocrea paper utilized a time window of $3 \mathrm{~h}$ post injury. These authors report improved BBB scores at 5-10 days post injury in animals treated after injury, but this claim is difficult to verify in the figure provided in the article.

\section{Magnesium (Table 9)}

For its long-understood role as a physiologic antagonist of NMDA receptors, magnesium has had a long history of investigation as a potential neuroprotectant in stroke and brain injury. The systematic review resulted in eight studies in which magnesium was used for acute SCI. These have utilized Wistar and SD rats, and in one study a rabbit model was employed (Özdemir et al., 2005). Cord injury has been induced largely by some form of weight-drop contusion, although a clip compression injury model was utilized by Ditor and colleagues (2007). Systemic administration of magnesium has typically been with magnesium sulfate at doses of 100, 300 , or $600 \mathrm{mg} / \mathrm{kg}$ given immediately after injury. In terms of a dose response, the $600 \mathrm{mg} / \mathrm{kg}$ dose was found by Süzer and colleagues (1999) to be more effective than the $300 \mathrm{mg} / \mathrm{kg}$ dose (in non-behavioral outcomes only). Kaptanoglu and colleagues (2003b) also found the $600 \mathrm{mg} / \mathrm{kg}$ dose to be more effective than the $100 \mathrm{mg} / \mathrm{kg}$ dose (in both histologic and behavioral outcomes). A time window of intervention for magnesium sulfate alone had not been extended beyond $30 \mathrm{~min}$ until the recent study by Wiseman and colleagues (2009), in which magnesium administration up to $8 \mathrm{~h}$ post injury (but not 12 or $24 \mathrm{~h}$ post injury) resulted in significantly improved BBB scores over controls. Non-behavioral outcomes include improved tissue sparing, reduced apoptosis and lipid peroxidation, and restoration of BBB integrity. Behavioral outcomes revealed improvements on incline plane testing, but these were evaluated at extremely early time points (e.g., $24 \mathrm{~h}$ post injury) and longer-term outcomes are lacking.

It should be noted that the $600 \mathrm{mg} / \mathrm{kg}$ dose of magnesium sulfate reported to be beneficial in rodent SCI far exceeds the tolerable human dose. The studies by Ditor and colleagues (2007) and Kwon and colleagues (2009) evaluated lower doses of magnesium in combination with polyethylene glycol (PEG). In both studies, magnesium in a PEG formulation was reported to increase tissue sparing at the site of injury and resulted in modest BBB improvements at 6 weeks post injury. The study by Kwon and colleagues (2009) evaluated a dose of magnesium chloride similar to that given to human patients for preeclampsia and cardiac arrest. This study included a dose-response experiment to optimize the dose and infusion regimen, and additionally reported a 4-h window of efficacy for a magnesium chloride in PEG formulation administered as five infusions $8 \mathrm{~h}$ apart.

\section{Riluzole (Table 10)}

The systematic review of riluzole revealed eight studies, which utilized Wistar, Long Evans, or Sprague Dawley rats and a variety of thoracic and cervicothoracic injury models, including weight drop (five), clip compression (one), and balloon compression (one). A complete sacral spinal-cord transection model was employed in the study of Kitzman and colleagues (2009) to examine the effect of riluzole on tail spasticity. Riluzole was most commonly administered intraperitoneally in doses of $5-8 \mathrm{mg} / \mathrm{kg}$, although a dose of $2 \mathrm{mg} / \mathrm{kg}$ administered intravenously was also described (Stutzmann et al., 1996). A dose response has not been reported in the thoracic contusion SCI models. In the study by Kitzman and colleagues (2009), both 8 and $10 \mathrm{mg} / \mathrm{kg}$ doses reduced signs of tail spasticity, but the higher dose was associated with systemic side effects (lethargy, locoomotor ataxia). Therapeutic neuroprotective efficacy has been reported with a delay in intervention of $15 \mathrm{~min}$ (Springer et al., 1997) and $30 \mathrm{~min}$ (Stutzmann et al., 1996). Mu and colleagues (2000b) reported that with a delay of $2 \mathrm{~h}$ in post-thoracic contusion SCI, riluzole alone did not have a beneficial effect either histologically or behaviorally, but did when given in combination with methylprednisolone. Riluzole was administered 4 weeks post injury in the study by Kitzman and colleagues (2009), but this was to examine the effect on established tail spasticity not on local tissue protection or locomotor behavior. Non-behavioral outcomes included improved tissue sparing, reduced MAP-2 loss, decreased lipid peroxidation, and improved electrophysiological recordings. Behavioral outcomes included improved BBB locomotor scores and improved performance on inclined plane testing. Additionally, after 3 days of riluzole treatment, metrics of tail spasticity (e.g., response to stretch, pinch, or light touch) were significantly reduced, but this effect was limited to $3 \mathrm{~h}$ after the final riluzole dose and gone by $6 \mathrm{~h}$.

Of note, a clinical trial for acute human SCI is being initiated through the North American Clinical Trials Network based on this pre-clinical body of evidence and facilitated by the fact that oral riluzole is FDA approved for the treatment of ALS. A similar oral dose of $50 \mathrm{mg}$ twice a day has been proposed, but may be doubled to $100 \mathrm{mg}$ twice a day to provide a typical $70-\mathrm{kg}$ patient with a $2.9 \mathrm{mg} / \mathrm{kg}$ dose - one that more closely approximates the $5-8 \mathrm{mg} / \mathrm{kg}$ dose given intraperitoneally in the animal SCI studies.

\section{Polyethylene glycol (Table 11)}

Polyethylene glycol (PEG) has well-recognized fusogenic properties, and has been evaluated as a neuroprotective agent for its potential ability to repair damaged axons. The systematic review resulted in five studies in which PEG was administered systemically, although this excludes six additional studies by Dr. Richard Borgens in which PEG was directly applied to the damaged spinal cord (Borgens and Shi, 2000; Borgens et al., 2002; Duerstock and Borgens, 2002; Luo and Shi, 2004; Luo and Shi, 2007; Luo et al., 2004). The extensive body of literature from Dr. Borgens' lab on the use of PEG in a guinea-pig model of SCI has arguably served as the basis for interest in PEG as a neurooprotective agent.

Of the five studies identified in this systematic review, three utilized Wistar or Sprague Dawley rats with either clip compression or contusion injuries, one utilized a guinea-pig 


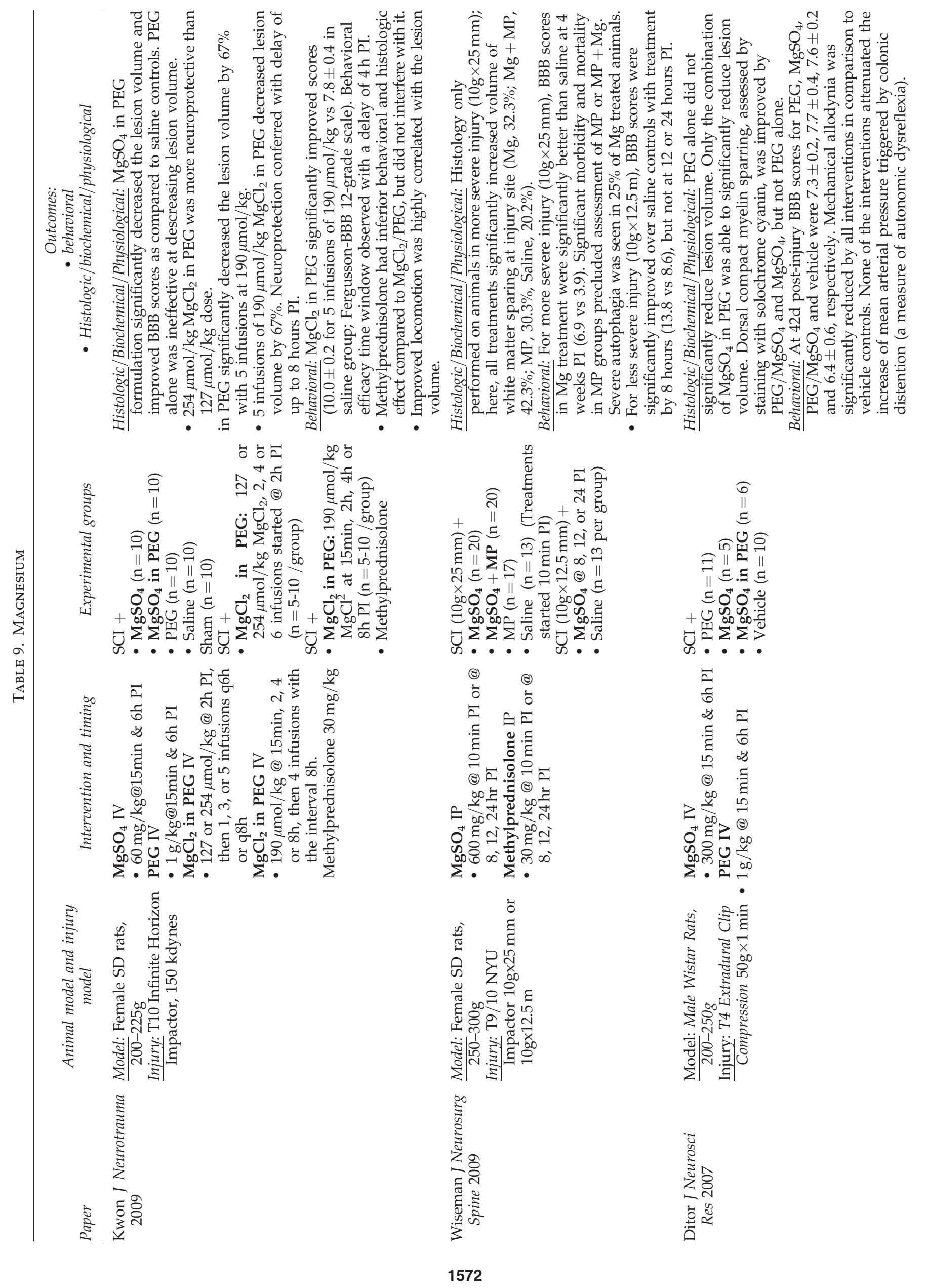




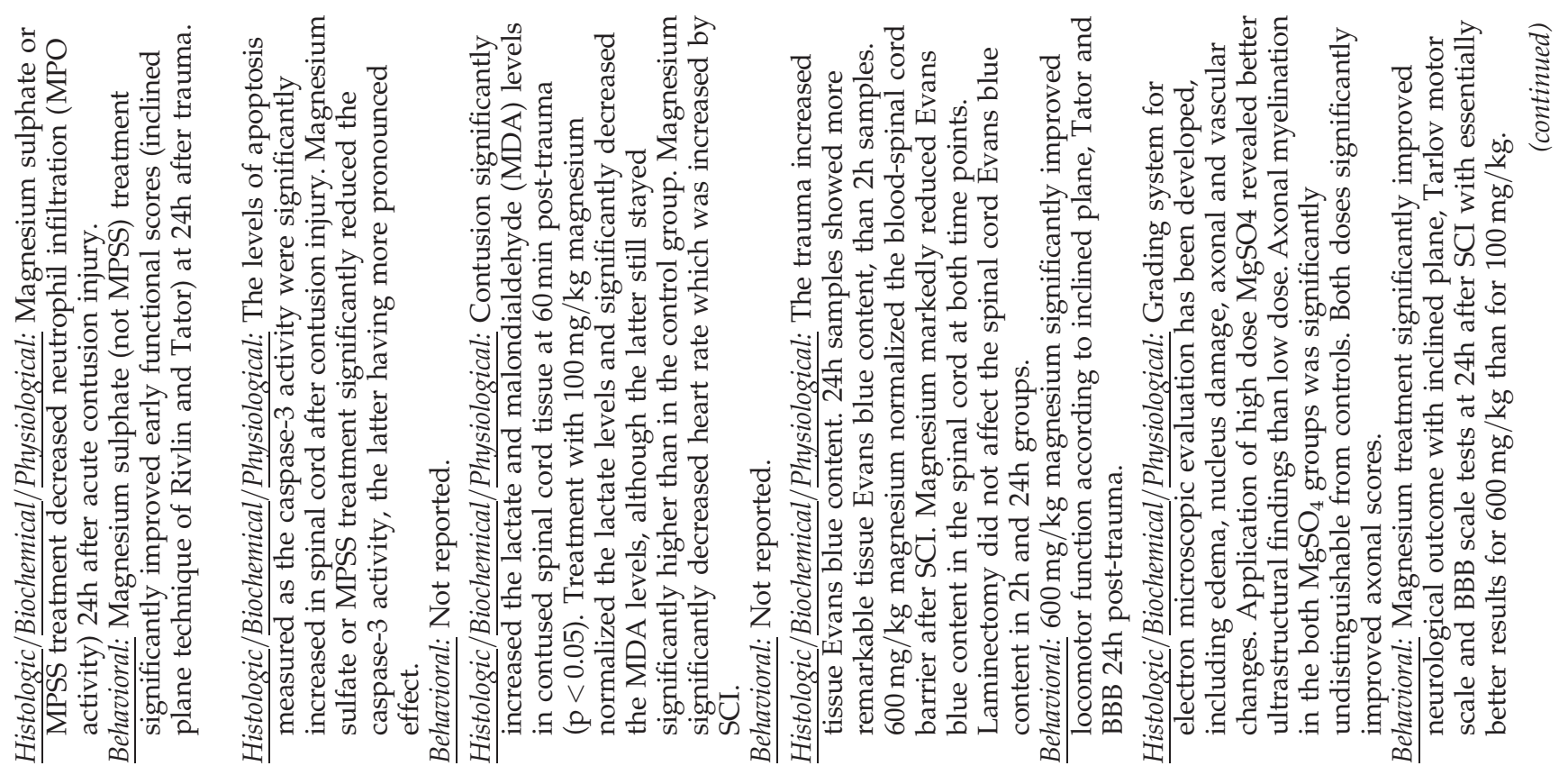

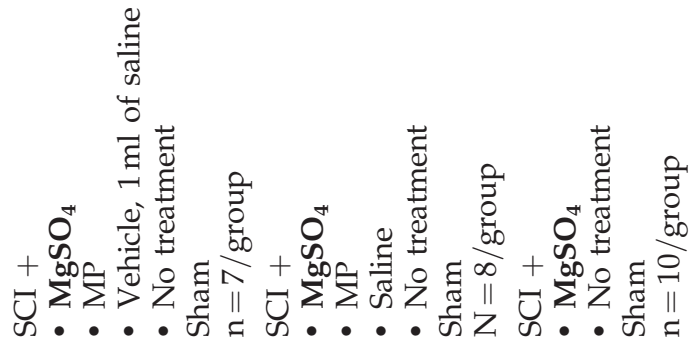
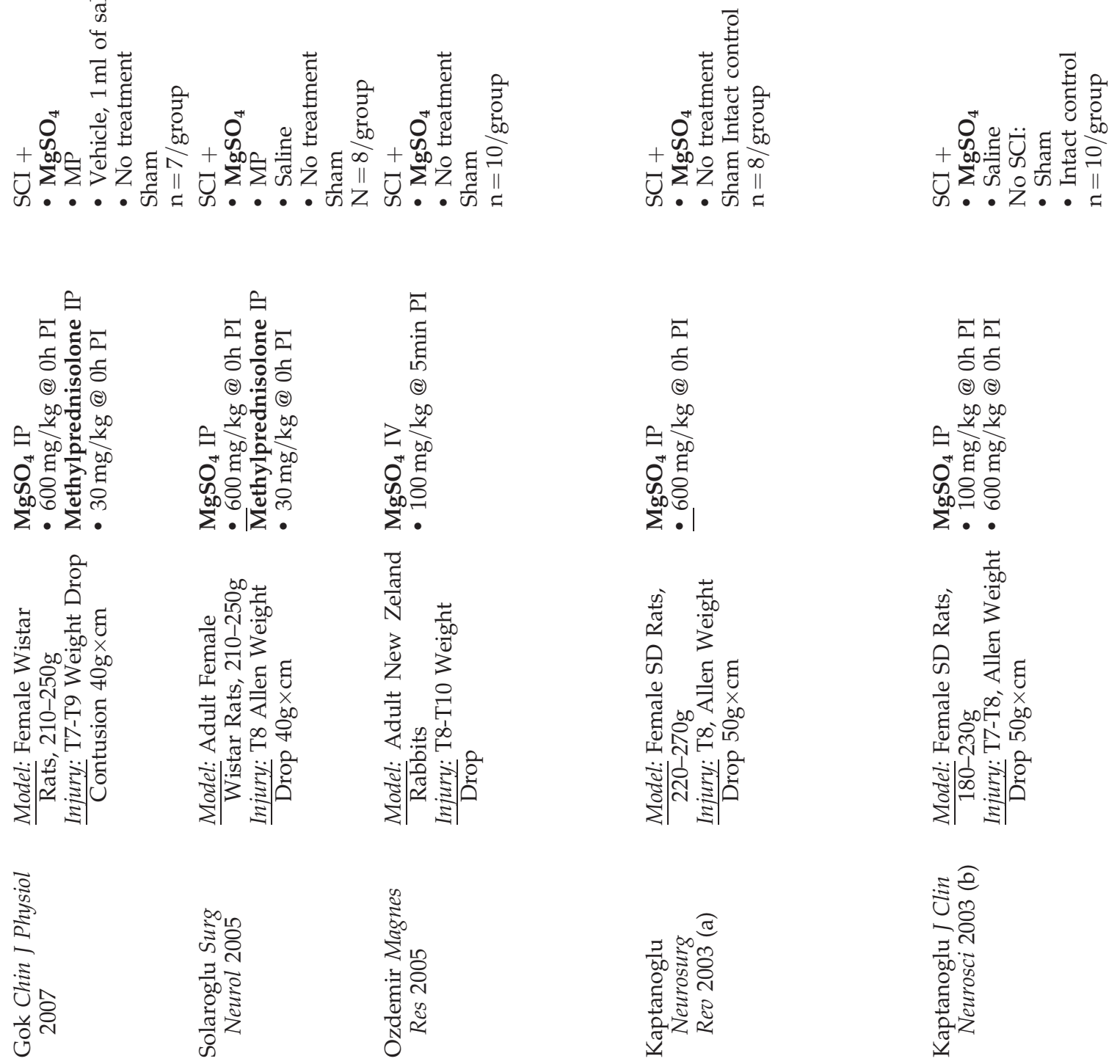


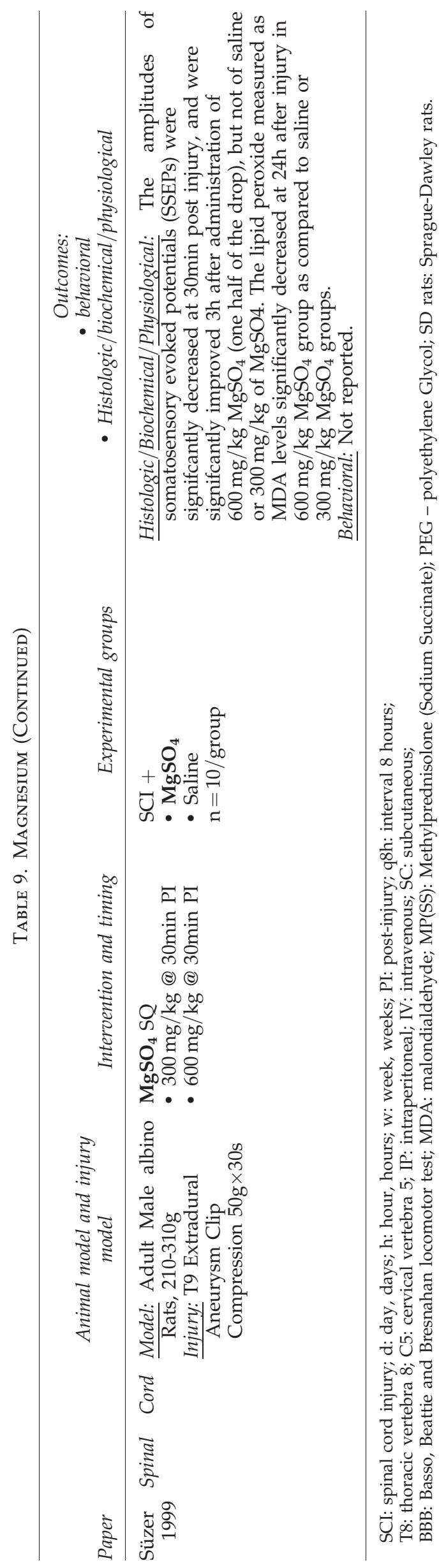




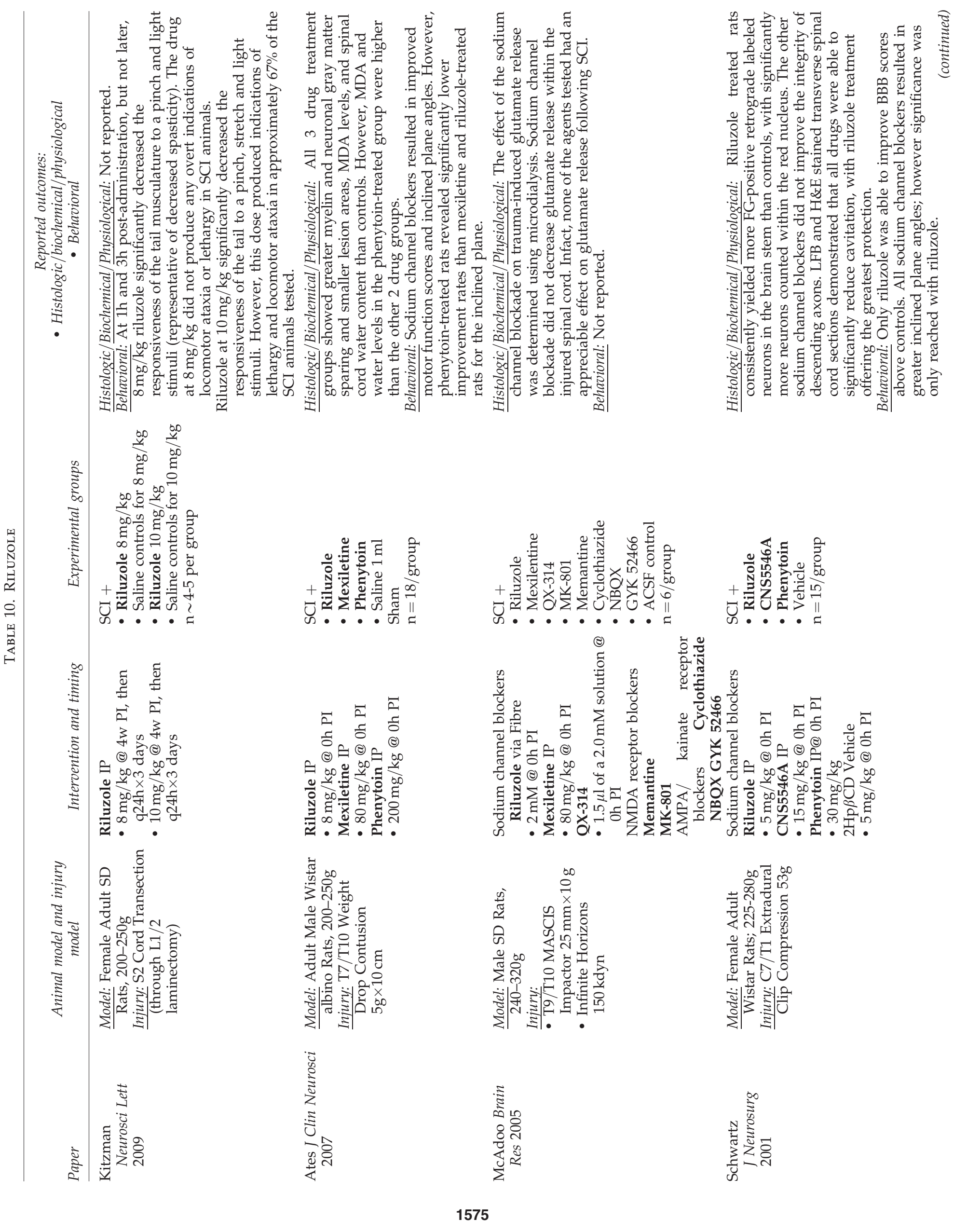




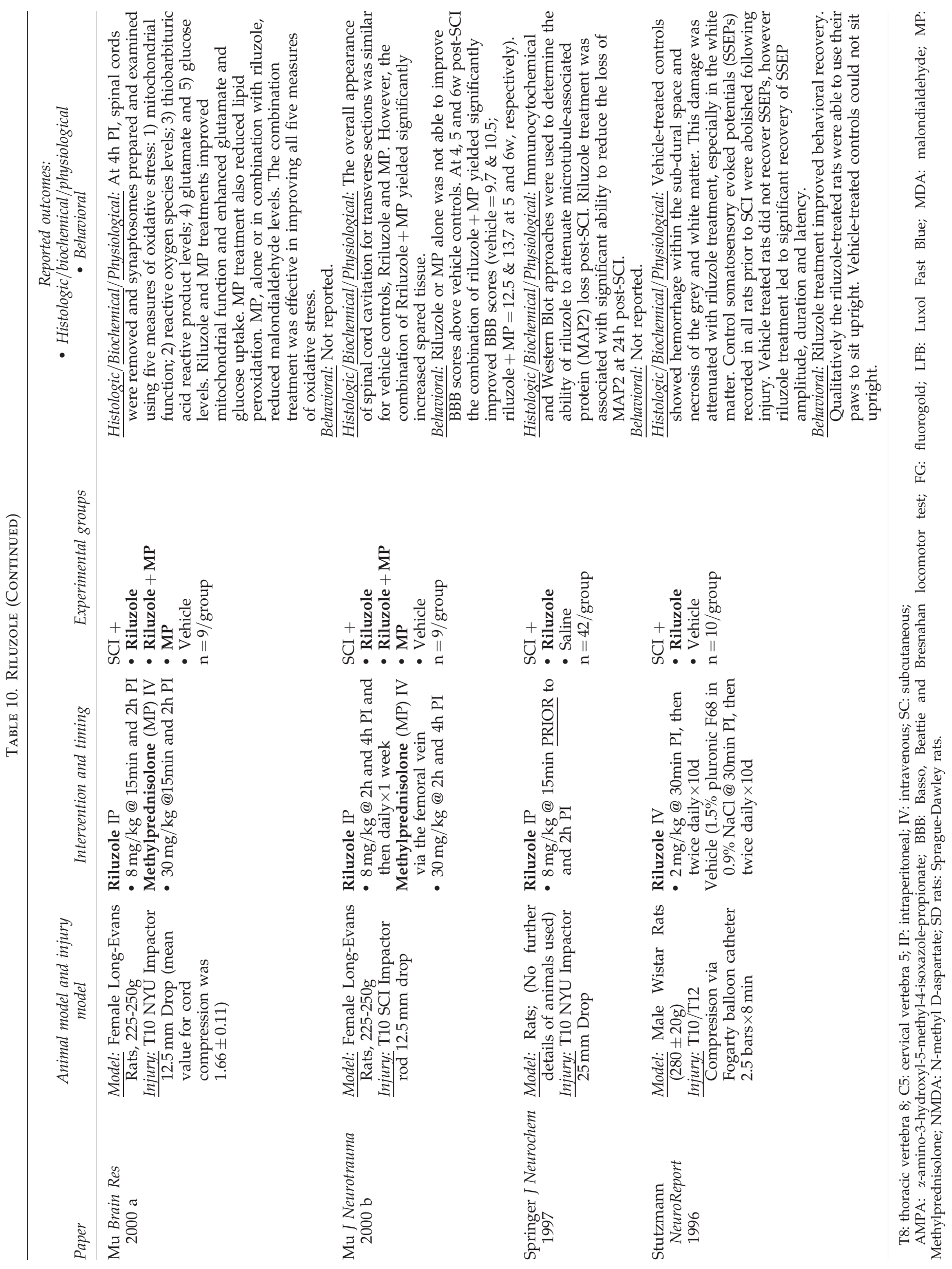




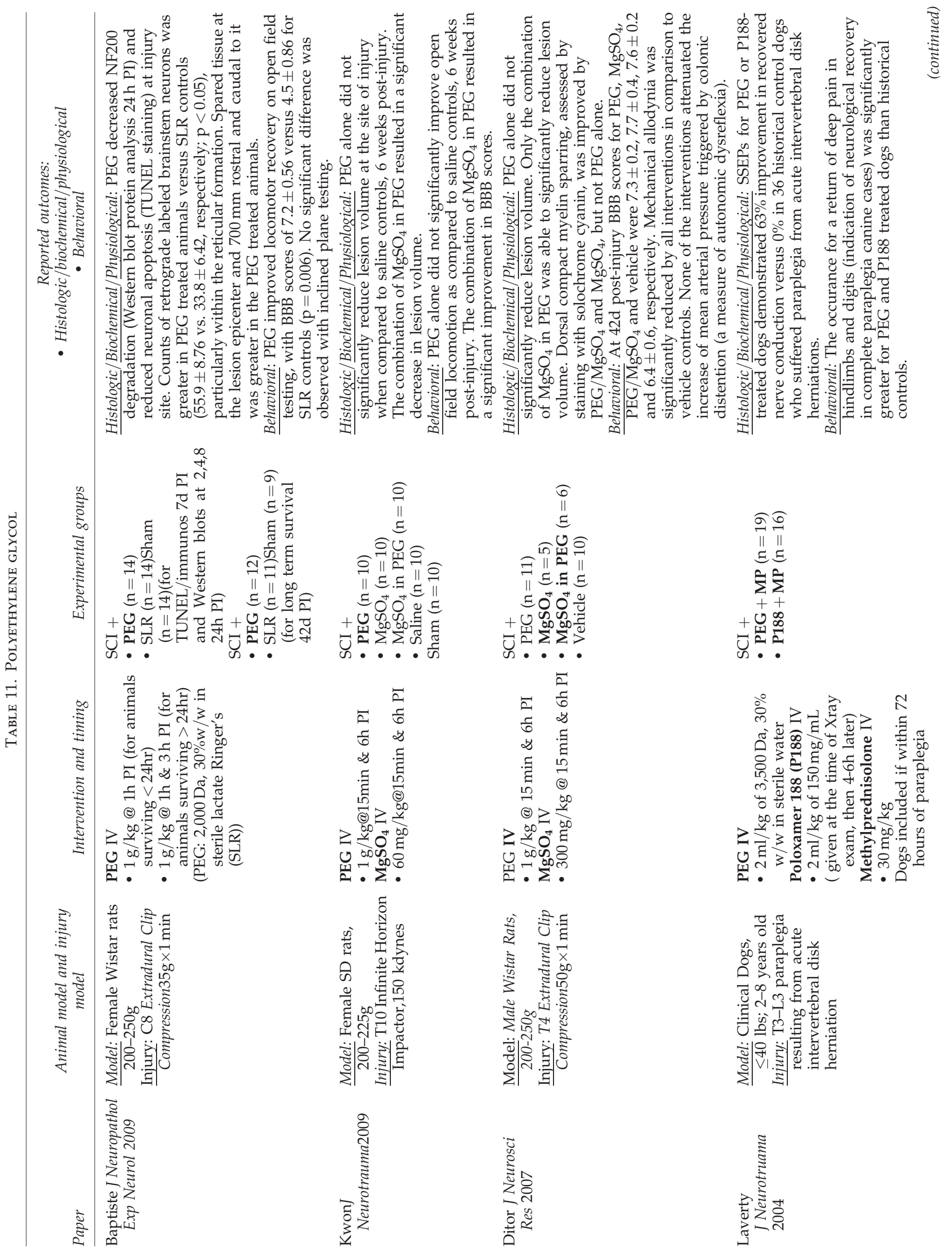




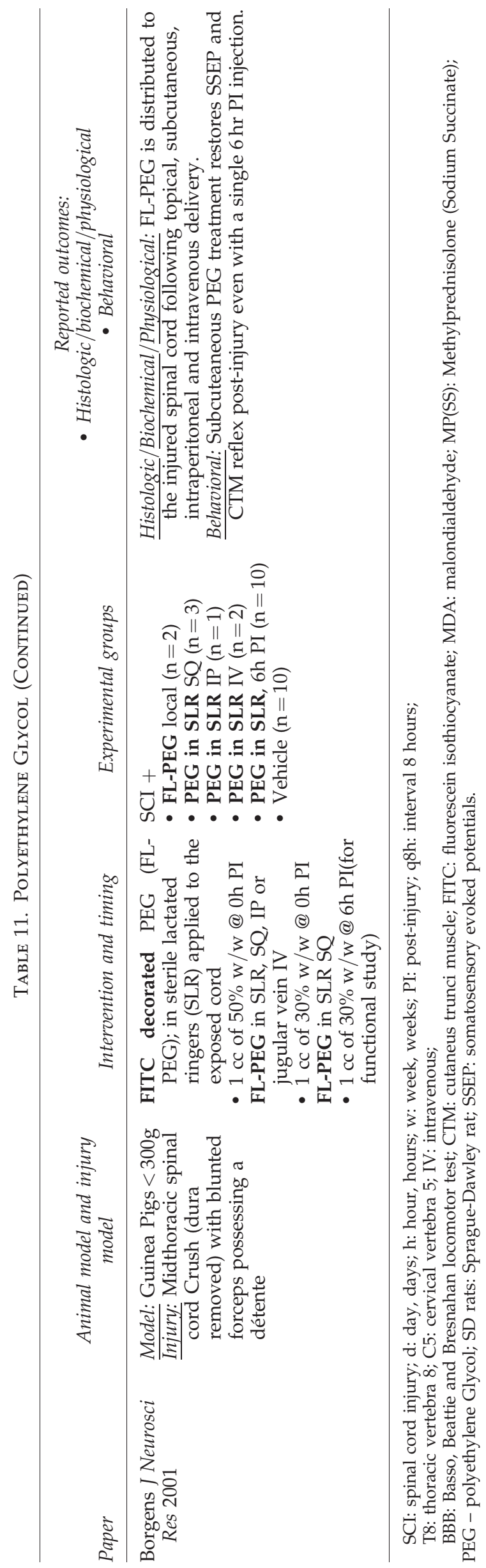


model with a forcep crush injury, and one utilized canines who suffered paraplegia from intervertebral disc herniations. A dose of $1 \mathrm{~g} / \mathrm{kg}$ was most commonly administered. Subcutaneously injected PEG was reported to be effective with a delay in intervention of $6 \mathrm{~h}$ post injury (Borgens and Bohnert, 2001), and dogs treated with PEG within $72 \mathrm{~h}$ of injury were reported to recover better than historical controls. In a rat SCI model, a 1-h time window of efficacy was reported by Baptiste and colleagues (2009).

With respect to non-behavioral outcomes, PEG was reported to decrease NF200 degradation, reduce apopotosis, and improve tissue sparing at the lesion site (Baptiste et al., 2009). In contrast, Kwon and colleagues (2009) and Ditor and colleagues (2007) found no significant tissue neuroprotection with PEG alone. With respect to behavioral outcomes, Borgens and Bohnert (2001) reported improved electrophysiologic recordings and the return of the cutaneous truncal muscle reflex after PEG treatment, and reported improved hindlimb recovery in PEG-treated dogs as compared to historical controls. Baptiste and colleagues (2009) reported modest improvements in BBB scores in PEG-treated animals, but no improvement on inclined plane testing. Ditor and colleagues (2007) also reported very modest improvement in BBB scores and a reduction in allodynia with PEG treatment.

\section{Atorvastatin (Table 12)}

Atorvastatin for acute SCI has been reported in three studies from two laboratories. All studies utilized female SD rats, employed thoracic weight-drop contusion injuries at T12 (Pannu et al., 2005, 2007) and T10 (Dery et al., 2009), and evaluated a $5 \mathrm{mg} / \mathrm{kg}$ dose of atorvastatin. The drug was administered via oral gavage in the two studies by Pannu and colleagues, and by intraperitoneal injection in the study by Dery and colleagues. In terms of a time window for therapeutic efficacy, the first of the two Pannu studies (2005) administered the drug prior to injury, while the subsequent study (2007), included delays of 2, 4, or $6 \mathrm{~h}$ post injury. Daily oral-gavage treatments were continued for 42 days. A 2-h delay in intervention was studied by Dery and colleagues, who continued the atorvastatin injections daily for 2 weeks.

Atorvastatin was found by Pannu and colleagues to reduce the expression of inflammatory cytokines, increase tissue sparing, and reduce Rho activity and GFAP expression and apoptosis. Dery and colleagues also reported a reduction in caspase 3 activation and decreased TUNEL staining, although statistically signficant tissue sparing at the injury site was not achieved in the atorvastatin-treated animals. In all three studies, atorvastatin was found to induce significant behavioral recovery, which was noted to be quite extraordinary in the articles by Pannu and colleagues. While the neuroprotective benefits reported by Dery and colleagues (2009) may not have been as dramatic as those described in the Pannu studies, the fact that this was done independently but with some similarities in experimental design (same species, comparable weight-drop force, same daily dose) reflects, to some degree, a robustness of the treatment.

\section{Inosine (Table 13)}

Inosine is a nucleoside that is commonly taken as a dietary supplement to improve athletic performance. Its potential for SCI was first introduced by Benowitz and colleagues (1999) in a study that revealed that local infusion of inosine to the motor cortex promoted sprouting of corticospinal axons in the medulla. Because of its invasive mode of administration, this study is excluded from this systematic review. However, three subsequent studies have been published that utilize a systemic administration starting at either an acute time point ( $15 \mathrm{~min}$ to $2 \mathrm{~h}$ post injury) or at a chronic time point ( 3 months post injury).

As an acute therapy for SCI, inosine was reported to decrease apoptosis, and, after 6 weeks of administration, reduce the invasion of ED-1 positive cells into the injury site. No reports of improved tissue or axonal sparing are made in either study. No behavioral assessments were made in either study. In a chronic (3 months post injury) setting, inosine reportedly increases sprouting of ascending and descending tracts, and was associated with recovery of the cutaneous truncal muscle reflex. No locomotor behavior has been reported. In summary, there is little pre-clinical evidence available to support the use of inosine as an acute therapy for SCI. While inosine has been studied by independent labs, behavioral outcomes were not assessed in either of the acute studies, and there is a paucity of histologic outcomes. A time window of $2 \mathrm{~h}$ was indicated by Liu and colleagues (2006), but the histologic outcomes were performed at 3 days post injury.

\section{Pioglitazone (Table 14)}

Pioglitazone is a PPAR (peroxisome proliferator-activated receptor) gamma agonist. PPARs are part of the nuclear hormone receptor superfamily that, upon ligand activation, regulate gene expression. The PPAR $\gamma$ agonists such as pioglitazone and rosiglitazone are in common clinical use for type II diabetes (marketed under the names $\operatorname{Actos}^{\circledR}$ and Avandia ${ }^{\circledR}$ respectively). Beyond their metabolic effects, interest in $\operatorname{PPAR} \gamma$ agonists has grown in the last decade due to their anti-inflammatory, neuroprotective, and even antineoplastic properties (Kapadia et al., 2008; Ondrey, 2009).

Pioglitazone has not yet had extensive testing in models of SCI. Two papers from independent laboratories were identified in the literature search. Both utilized thoracic contusion injuries induced by either the OSU or NYU impactors in Sprague Dawley rats. Pioglitazone was administered intraperitoneally in a range of doses, from 0.5 to $10 \mathrm{mg} / \mathrm{kg}$. Doseresponse effects were observed in both studies, with McTigue and colleagues (2007) reporting better neuroprotection with $10 \mathrm{mg} / \mathrm{kg}$ versus $1.0 \mathrm{mg} / \mathrm{kg}$, and Park and colleagues (2007) reporting better neuroprotection with 3.0 and $1.5 \mathrm{mg} / \mathrm{kg}$ versus $0.5 \mathrm{mg} / \mathrm{kg}$. Park and colleagues (2007) additionally demonstrated that for a $1.5 \mathrm{mg} / \mathrm{kg}$ dose, four administrations over $48 \mathrm{~h}$ were better than one administration. While the optimal dose and treatment regimen remains to be established, it is noteworthy and commendable that these studies both looked at dose, with the Park study examining both dose and regimen. Importantly, the Park study established a 2-h time window of efficacy for the $1.5 \mathrm{mg} / \mathrm{kg}$ dose of pioglitazone; neuroprotective efficacy was lost when the drug was started $4 \mathrm{~h}$ post injury. Interestingly, while Park and colleagues (2007) observed significant recovery on the BBB with pioglitazone at $1.5 \mathrm{mg} / \mathrm{kg}$ and $3.0 \mathrm{mg} / \mathrm{kg}$, McTigue and colleagues (2007) did not see recovery on the BBB in either the $10 \mathrm{mg} / \mathrm{kg}$ or $1 \mathrm{mg} / \mathrm{kg}$, although they did report other behavioral outcome measures that showed some benefit of pioglitazone. Group sizes in both 


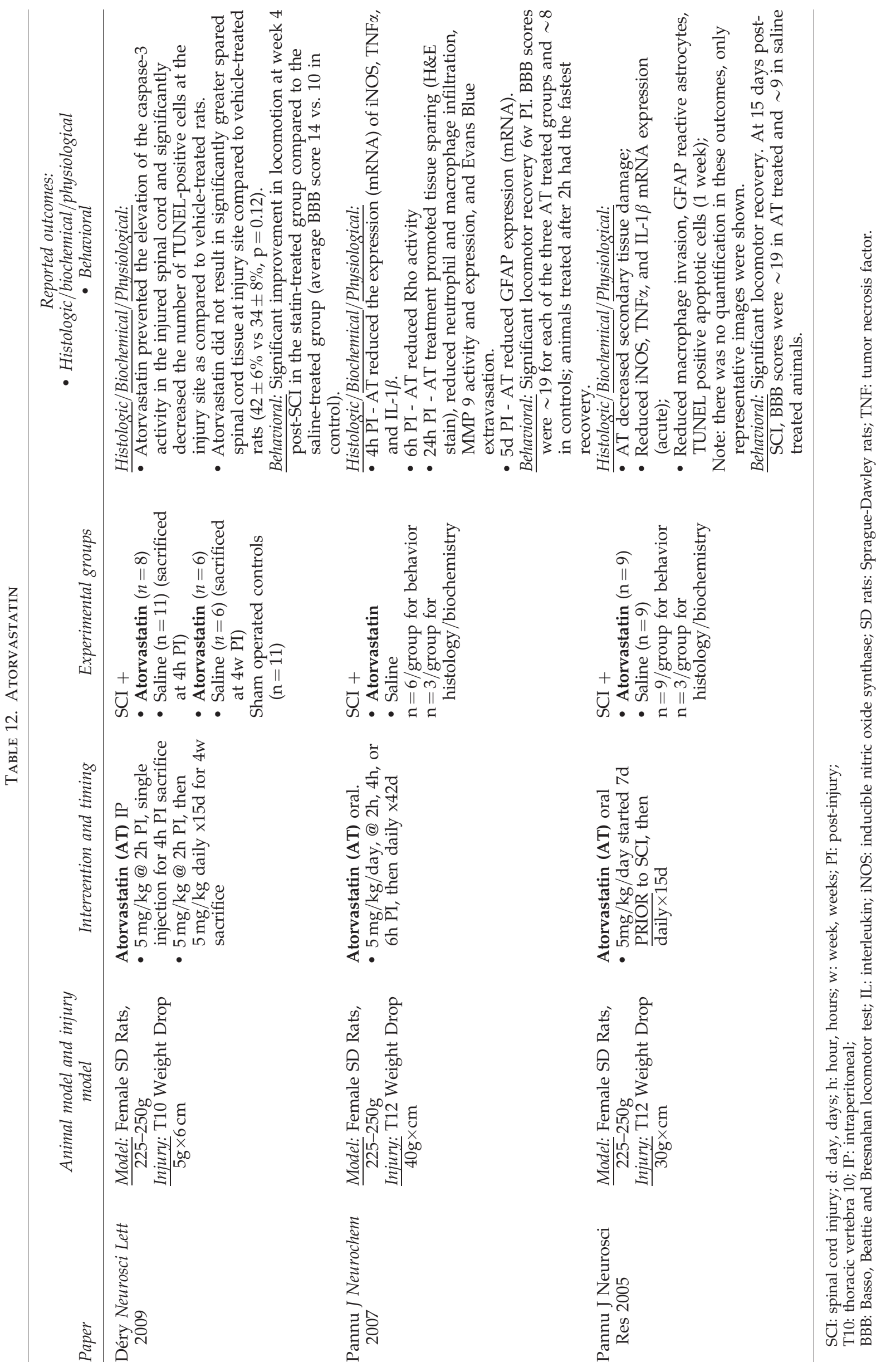




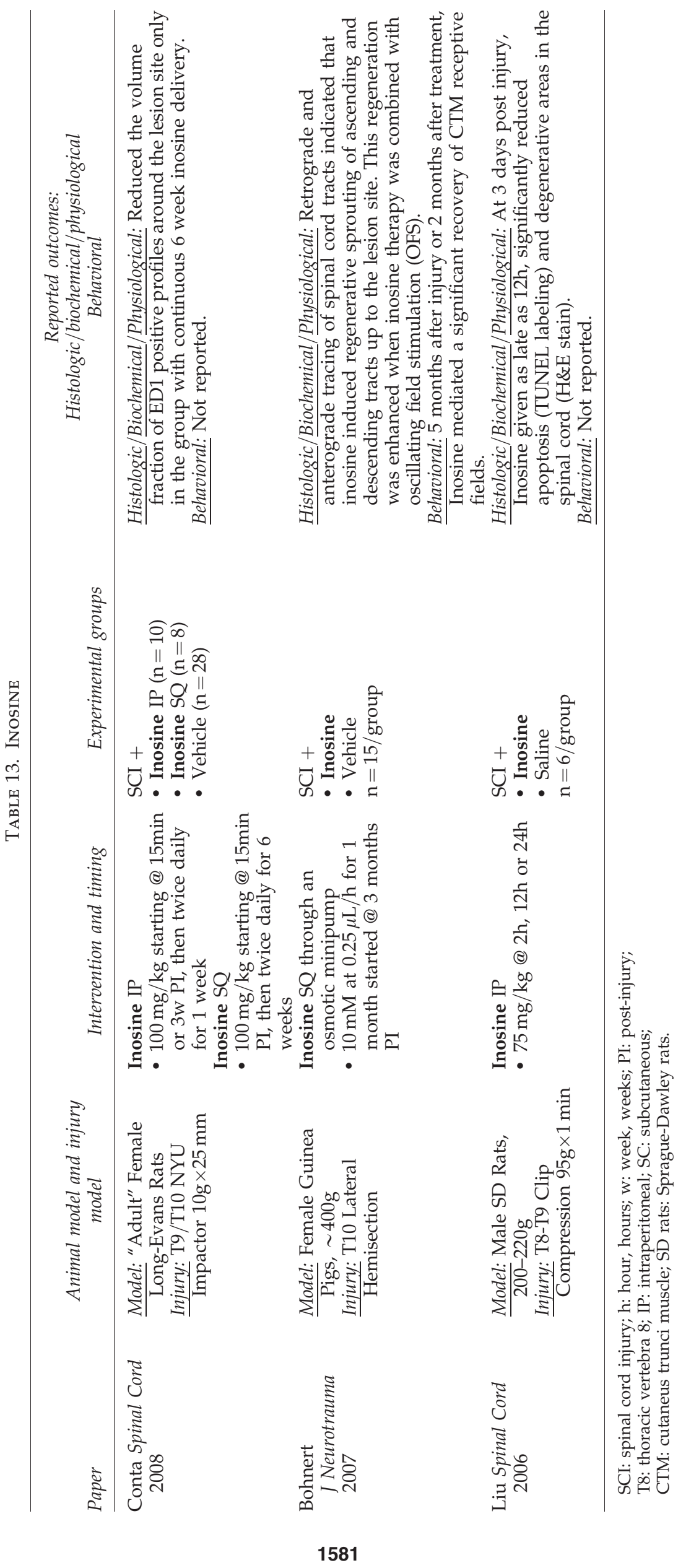




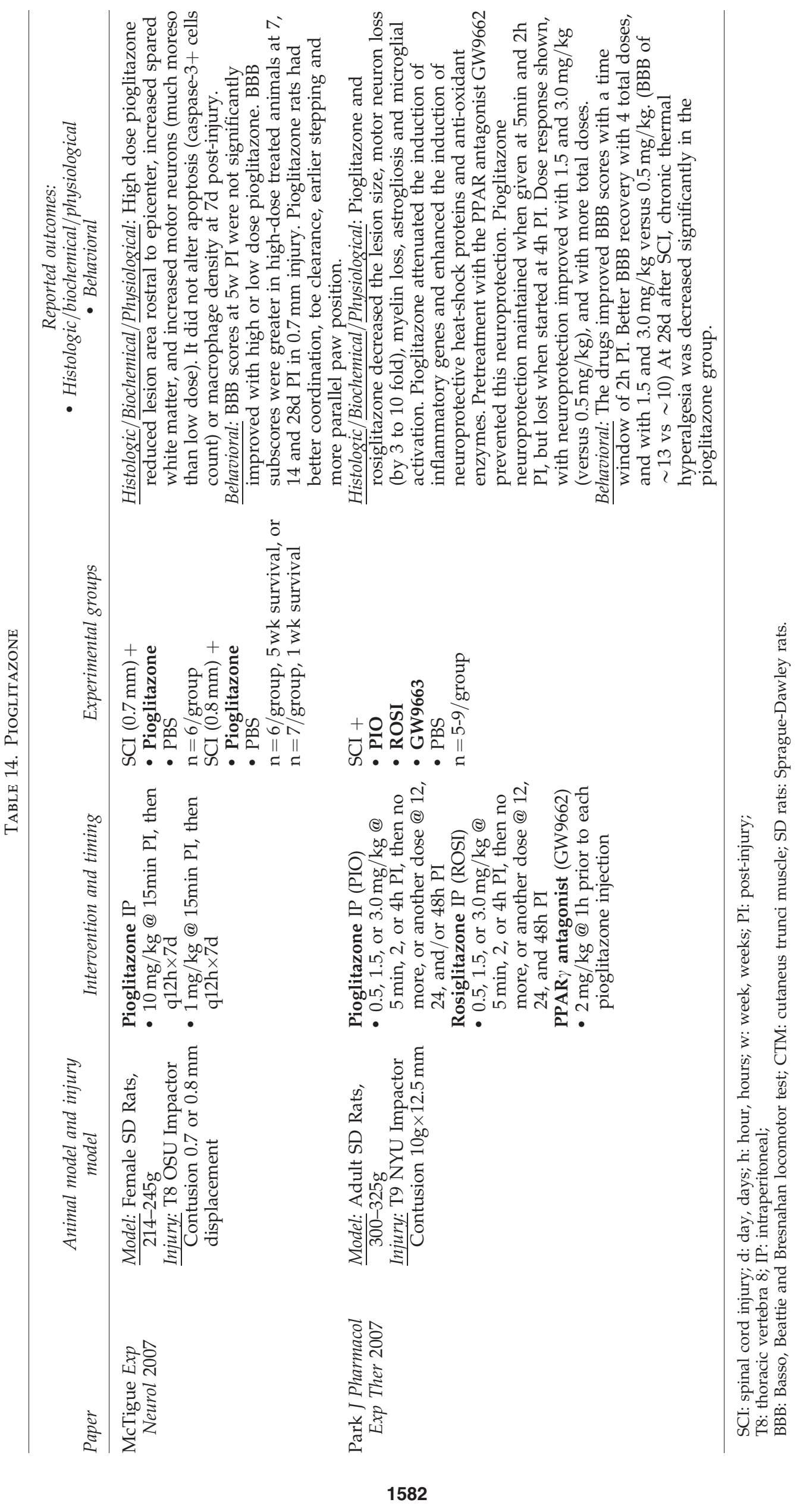


experiments were relatively small in both studies. For example, many of the experiments done by Park and colleagues (for example, the dose and time-window studies) were with an $n$ of only five per group. As a side note, a study of an endogenous PPAR $\gamma$ agonist, 15-deoxy-delta-12,14-prostaglandin J2, found beneficial effects with a $200 \mu \mathrm{g} / \mathrm{kg}$ dose, but deleterious effects with a high doses of $1 \mathrm{mg} / \mathrm{kg}$ (Kerr et al., 2008), illustrating the complexity of this dose issue in such pharmacotherapies for SCI.

\section{Conclusion}

With the urgency to establish novel treatments for acute SCI, it is recognized that the process of bringing forth a new human therapy takes a great deal of time. Novel therapeutics require substantive safety evaluations, which add expense and time to the translation of new treatments. Along this line, the idea of exploring the neuroprotective potential of treatments that are already in human clinical application remains an inviting strategy. This review summarizes the available preclinical literature on the use of such agents in in-vivo models of acute SCI. It is not a comprehensive list of every therapy that has ever been tried in pre-clinical models of SCI, but rather, a systematic review of specific therapies that are currently being considered for human translation. In some cases (such as systemic hypothermia and minocycline), the human barrier has been broken and clinical evaluation has actually begun.

The obvious question to ask when viewing this large body of pre-clinical data is "which are the most promising?" and thus best candidates to take forward into clinical trials. This is a difficult question to answer, for a variety of reasons. The systematic review of these therapies and the description of the individual studies in this tabular form make it evident that significant variability exists across the scientific community in the conduct of these studies. This variability includes animal sex, weight, strain, and species, SCI level, severity, and mechanism, therapeutic dose, dose regime, timing, and survival, and a myriad of different histologic and behavioral outcomes. These differences make it very difficult, if not impossible, to compare across studies to determine which agent had the greatest "effect." While this variability is bemoaned for the difficulty that arises in comparing results from one laboratory to the next, it is at least partly consistent with the variability inherent to human injuries. If something is to "work" in human SCI, it should conceivably "work" in a variety of pre-clinical injury models that utilize different animal strains, weights, and ages, and different injury severities and levels; that is, the beneficial effect of the treatment must be "robust" enough that it can be demonstrated in a variety of experimental settings.

This issue of robustness is central to the discussion of translation, and is reflected in part by the number of independent laboratories that have reported on beneficial effects of a therapy, often with different rodent species, injury models, and doses. In this regard, most of the agents documented in this review achieved this level of "robustness" (e.g., minocycline, erythropoietin, riluzole, systemic hypothermia, progesterone, estrogen, atorvastatin, and magnesium sulfate). However, this has important distinctions from a formal attempt at replicating the positive results of a particular study from another laboratory, in which great efforts are made to simulate as many of the exact experimental conditions as possible. Such replication attempts sponsored by the NIH have been unsuccessful in the case of erythropoietin (Pinzon et al., 2008) and minocycline (Pinzon et al., 2008). In fact, to our knowledge, no formal replication study has yet to reproduce the efficacy reported in the original research article.

The second obvious translational issue for neuroprotective agents administered in the acute SCI setting is that of the time window of efficacy. The length of the time window of efficacy that needs to be established in pre-clinical animal studies in order to suggest that a drug would be effective in a realistic timeframe in human SCI is not currently understood, and it likely differs depending on the precise mechanism of action of the therapeutic agent (which also may not be that well understood). As the therapies reviewed in this paper are largely neuroprotective treatments to be utilized in acute SCI, it is quite revealing to note the paucity of time window of intervention studies that are actually performed. Most studies employ extremely short time windows, in which the intervention is applied either at the time of injury or very soon after. The therapy with the most number of animal studies that met the inclusion criteria of our systematic review was erythropoietin (19 studies), and yet, a time window of behavioral efficacy beyond $1 \mathrm{~h}$ has not yet been established.

Finally, the issue of what actually constitutes "clinically meaningful efficacy" in pre-clinical research is something that is not so well defined. Given that human SCI is ultimately a functional problem, it would seem obvious that in pre-clinical studies, a therapy should, above all else, demonstrate some improvement in behavioral outcomes. As indicated in the tables, most studies (but certainly not all) actually measured behavioral outcomes, the most common being the open field locomotor scores (BBB scale). The tables make it evident that the scientific community places much emphasis on the recovery of locomotor function, which of course is well understood not to be the top priority of patients with spinal cord injuries (Anderson, 2004). From a translational standpoint, at least the use of the BBB allows for a common metric amongst experiments of inevitably varied design, and provides some context to the extent of behavioral recovery that has actually occurred. Exactly what extent of BBB recovery is "clinically meaningful," however, remains controversial, given the recognized differences in locomotor control between rodents and humans.

In summary, this manuscript portrays the state of the preclinical literature on a number of potential acute therapies for SCI that have been studied to various degrees in animal models. Some have already gone into clinical trials (e.g., minocycline in Calgary, Alberta, and systemic hypothermia in Miami, Florida), and others are poised to be soon translated into human SCI (e.g., riluzole, and a magnesium/PEG formulation). While the body of literature on many therapies is not insignificant, a casual review of this systematically collected literature reveals that there are some obvious gaps to fill with respect to demonstrating robustness and confirming relevant time windows of efficacy. Developing guidelines analogous to those that exist within the stroke field to provide direction to the pre-clinical development of these therapies prior to human translation would be valuable.

\section{Acknowledgment}

This work was supported by the Rick Hansen Institute (formerly, The Canadian SCI Solutions Network). BKK holds 
a CIHR New Investigator Award, and WT is the Rick Hansen Man in Motion Chair in Spinal Cord Injury Research.

\section{Author Disclosure Statement}

No competing financial interests exist.

\section{References (Arranged by Therapy)}

\section{Erythropoietin}

Arishima, Y., Setoguchi, T., Yamaura, I., Yone, K., and Komiya, S. (2006). Preventive effect of erythropoietin on spinal cord cell apoptosis following acute traumatic injury in rats. Spine 31, 2432-2438.

Boran, B.O., Colak, A., and Kutlay, M. (2005). Erythropoietin enhances neurological recovery after experimental spinal cord injury. Restor. Neurol. Neurosci. 23, 341-345.

Brines, M., Grasso, G., Fiordaliso, F., Sfacteria, A., Ghezzi, P., Fratelli, M., Latini, R., Xie, Q.W., Smart, J., Su-Rick, C.J., Pobre, E., Diaz, D., Gomez, D., Hand, C., Coleman, T., and Cerami, A. (2004). Erythropoietin mediates tissue protection through an erythropoietin and common beta-subunit heteroreceptor. Proc. Natl. Acad. Sci. USA 101, 14907-14912.

Cetin, A., Nas, K., Buyukbayram, H., Ceviz, A., and Olmez, G. (2006). The effects of systemically administered methylprednisolone and recombinant human erythropoietin after acute spinal cord compressive injury in rats. Eur. Spine J. 15, 15391544.

Fumagalli, F., Madaschi, L., Brenna, P., Caffino, L., Marfia, G., Di Giulio, A.M., Racagni, G., and Gorio, A. (2008). Single exposure to erythropoietin modulates Nerve Growth Factor expression in the spinal cord following traumatic injury: Comparison with methylprednisolone. Eur. J. Pharmacol. 578, 19-27.

Gorio, A., Gokmen, N., Erbayraktar, S., Yilmaz, O., Madaschi, L., Cichetti, C., Di Giulio, A.M., Vardar, E., Cerami, A., and Brines, M. (2002). Recombinant human erythropoietin counteracts secondary injury and markedly enhances neurological recovery from experimental spinal cord trauma. Proc. Natl. Acad. Sci. USA 99, 9450-9455.

Gorio, A., Madaschi, L., Di, S.B., Carelli, S., Di Giulio, A.M., De, B.S., Coleman, T., Cerami, A., and Brines, M. (2005). Methylprednisolone neutralizes the beneficial effects of erythropoietin in experimental spinal cord injury. Proc. Natl. Acad. Sci. USA 102, 16379-16384.

Grasso, G., Sfacteria, A., Erbayraktar, S., Passalacqua, M., Meli, F., Gokmen, N., Yilmaz, O., La, T.D., Buemi, M., Iacopino, D.G., Coleman, T., Cerami, A., Brines, M., and Tomasello, F. (2006). Amelioration of spinal cord compressive injury by pharmacological preconditioning with erythropoietin and a nonerythropoietic erythropoietin derivative. J. Neurosurg. Spine 4, 310-318.

Guìzar-Sahagún, G., Rodriguez-Balderas, C.A., FrancoBourland, R.E., Martinez-Cruz, A., Grijalva, I., Ibarra, A., and Madrazo, I. (2009). Lack of neuroprotection with pharmacological pretreatment in a paradigm for anticipated spinal cord lesions. Spinal Cord 47, 156-160.

Huang, H., Fan, S., Ji, X., Zhang, Y., Bao, F., and Zhang, G. (2009). Recombinant human erythropoietin protects against experimental spinal cord trauma injury by regulating expression of the proteins MKP-1 and p-ERK. J. Int. Med. Res. 37, 511-519.

Kaptanoglu, E., Solaroglu, I., Okutan, O., Surucu, H.S., Akbiyik, F., and Beskonakli, E. (2004). Erythropoietin exerts neuroprotection after acute spinal cord injury in rats: Effect on lipid peroxidation and early ultrastructural findings. Neurosurg. Rev. 27, 113-120.

King, V.R., Averill, S.A., Hewazy, D., Priestley, J.V., Torup, L., and Michael-Titus, A.T. (2007). Erythropoietin and carbamylated erythropoietin are neuroprotective following spinal cord hemisection in the rat. Eur. J. Neurosci. 26, 90100.

Kontogeorgakos, V.A., Voulgaris, S., Korompilias, A.V., Vekris, M., Polyzoidis, K.S., Bourantas, K., and Beris, A.E. (2009). The efficacy of erythropoietin on acute spinal cord injury. An experimental study on a rat model. Arch. Orthop. Trauma Surg. 129, 189-194.

Mann, C., Lee, J.H., Liu, J., Stammers, A.M., Sohn, H.M., Tetzlaff, W., and Kwon, B.K. (2008). Delayed treatment of spinal cord injury with erythropoietin or darbepoetin - A lack of neuroprotective efficacy in a contusion model of cord injury. Exp. Neurol. 211, 34-40.

Okutan, O., Solaroglu, I., Beskonakli, E., and Taskin, Y. (2007). Recombinant human erythropoietin decreases myeloperoxidase and caspase- 3 activity and improves early functional results after spinal cord injury in rats. J. Clin. Neurosci. 14, 364-368.

Pinzon, A., Marcillo, A., Pabon, D., Bramlett, H.M., Bunge, M.B., and Dietrich, W.D. (2008). A re-assessment of erythropoietin as a neuroprotective agent following rat spinal cord compression or contusion injury. Exp. Neurol. 213, 129-136.

Vitellaro-Zuccarello, L., Mazzetti, S., Madaschi, L., Bosisio, P., Fontana, E., Gorio, A., and De, B.S. (2008). Chronic erythropoietin-mediated effects on the expression of astrocyte markers in a rat model of contusive spinal cord injury. Neuroscience 151, 452-466.

Vitellaro-Zuccarello, L., Mazzetti, S., Madaschi, L., Bosisio, P., Gorio, A., and De, B.S. (2007). Erythropoietin-mediated preservation of the white matter in rat spinal cord injury. Neuroscience 144, 865-877.

Yazihan, N., Uzuner, K., Salman, B., Vural, M., Koken, T., and Arslantas, A. (2008). Erythropoietin improves oxidative stress following spinal cord trauma in rats. Injury 39, 14081413.

\section{Systemic hypothermia}

Chatzipanteli, K., Yanagawa, Y., Marcillo, A.E., Kraydieh, S., Yezierski, R.P., and Dietrich, W.D. (2000). Posttraumatic hypothermia reduces polymorphonuclear leukocyte accumulation following spinal cord injury in rats. J. Neurotrauma 17, 321-332.

Duz, B., Kaplan, M., Bilgic, S., Korkmaz, A., and Kahraman, S. (2009). Does hypothermic treatment provide an advantage after spinal cord injury until surgery? An experimental study. Neurochem. Res. 34, 407-410.

Farooque, M., Hillered, L., Holtz, A., and Olsson, Y. (1997). Effects of moderate hypothermia on extracellular lactic acid and amino acids after severe compression injury of rat spinal cord. J. Neurotrauma 14, 63-69.

Jou, I.M. (2000). Effects of core body temperature on changes in spinal somatosensory-evoked potential in acute spinal cord compression injury: An experimental study in the rat. Spine $25,1878-1885$.

Lo, T.P., Jr., Cho, K.S., Garg, M.S., Lynch, M.P., Marcillo, A.E., Koivisto, D.L., Stagg, M., Abril, R.M., Patel, S., Dietrich, W.D., and Pearse, D.D. (2009). Systemic hypothermia improves histological and functional outcome after cervical spinal cord contusion in rats. J. Comp. Neurol. 514, 433-448.

Martinez-Arizala, A., and Green, B.A. (1992). Hypothermia in spinal cord injury. J. Neurotrauma 9, Suppl. 2, S497-S505. 
Morino, T., Ogata, T., Takeba, J., and Yamamoto, H. (2008). Microglia inhibition is a target of mild hypothermic treatment after the spinal cord injury. Spinal Cord 46, 425-431.

Shibuya, S., Miyamoto, O., Janjua, N.A., Itano, T., Mori, S., and Norimatsu, H. (2004). Post-traumatic moderate systemic hypothermia reduces TUNEL positive cells following spinal cord injury in rat. Spinal Cord 42, 29-34.

Strain, G.M., and Waldrop, R.D. (2005). Temperature and vascular volume effects on gastric ulcerogenesis after cord transection. Dig. Dis. Sci. 50, 2037-2042.

Westergren, H., Farooque, M., Olsson, Y., and Holtz, A. (2000). Motor function changes in the rat following severe spinal cord injury. Does treatment with moderate systemic hypothermia improve functional outcome? Acta Neurochir. (Wien) 142, 567-573.

Westergren, H., Farooque, M., Olsson, Y., and Holtz, A. (2001). Spinal cord blood flow changes following systemic hypothermia and spinal cord compression injury: An experimental study in the rat using Laser-Doppler flowmetry. Spinal Cord $39,74-84$.

Westergren, H., Yu, W.R., Farooque, M., Holtz, A., and Olsson, Y. (1999). Systemic hypothermia following spinal cord compression injury in the rat: Axonal changes studied by betaAPP, ubiquitin, and PGP 9.5 immunohistochemistry. Spinal Cord 37, 696-704.

Yamamoto, K., Ishikawa, T., Sakabe, T., Taguchi, T., Kawai, S., and Marsala, M. (1998). The hydroxyl radical scavenger Nicaraven inhibits glutamate release after spinal injury in rats. Neuroreport 9, 1655-1659.

Yu, C.G., Jimenez, O., Marcillo, A.E., Weider, B., Bangerter, K., Dietrich, W.D., Castro, S., and Yezierski, R.P. (2000). Beneficial effects of modest systemic hypothermia on locomotor function and histopathological damage following contusion-induced spinal cord injury in rats. J. Neurosurg. 93, 85-93.

Yu, W.R., Westergren, H., Farooque, M., Holtz, A., and Olsson, Y. (1999a). Systemic hypothermia following compression injury of rat spinal cord: Reduction of plasma protein extravasation demonstrated by immunohistochemistry. Acta Neuropathol. 98, 15-21.

Yu, W.R., Westergren, H., Farooque, M., Holtz, A., and Olsson, Y. (1999b). Systemic hypothermia following compression injury of rat spinal cord: An immunohistochemical study on the expression of vimentin and GFAP. Neuropathol. 19, 172180.

Yu, W.R., Westergren, H., Farooque, M., Holtz, A., and Olsson, Y. (2000). Systemic hypothermia following spinal cord compression injury in the rat: An immunohistochemical study on MAP 2 with special reference to dendrite changes. Acta Neuropathol. 100, 546-552.

NSAIDs

Center for Drug Evaluation and Research, FDA. (2005). Guidance for industry, estimating the maximum safe starting dose in initial clinical trials for therapeutics in adult health volunteers. www.fda.gov/downloads/Drugs/GuidanceCompliance RegulatoryInformation/Guidances/ucm078932.pdf.

Faden, A.I., Lemke, M., and Demediuk, P. (1988). Effects of BW755C, a mixed cyclo-oxygenase-lipoxygenase inhibitor, following traumatic spinal cord injury in rats. Brain Res. 463, 63-68.

Fu, Q., Hue, J., and Li, S. (2007). Nonsteroidal anti-inflammatory drugs promote axon regeneration via RhoA inhibition. J. Neurosci. 27, 4154-4164.

Fujita, Y., Shingu, T., Kurihara, M., Miyake, H., Kono, T., Tsujimura, M., and Mori, K. (1985). Evaluation of a low dose administration of aspirin, dipyridamol and steroid. Therapeutic effects on motor function and protective effects on $\mathrm{Na}+-\mathrm{K}+$-activated ATPase activity against lipid peroxidation in an experimental model of spinal cord injury. Paraplegia 23, 56-57.

Guth, L., Zhang, Z., and Roberts, E. (1994a). Key role for pregnenolone in combination therapy that promotes recovery after spinal cord injury. Proc. Natl. Acad. Sci. USA 91, 12308-12312.

Guth, L., Zhang, Z., DiProspero, N.A., Joubin, K., and Fitch, M.T. (1994b). Spinal cord injury in the rat: Treatment with bacterial lipopolysaccharide and indomethacin enhances cellular repair and locomotor function. Exp. Neurol. 126, 76-87.

Guven, M.B., Cirak, B., Yuceer, N., and Ozveren, F. (1999). Is indomethacin harmful in spinal cord injury treatment? An experimental study. Pediatr. Neurosurg. 31, 189-193.

Hains, B.C., Yucra, J.A., and Hulsebosch, C.E. (2001). Reduction of pathological and behavioral deficits following spinal cord contusion injury with the selective cyclooxygenase-2 inhibitor NS-398. J. Neurotrauma 18, 409-423.

Harada, N., Taoka, Y., and Okajima, K. (2006). Role of prostacyclin in the development of compression trauma-induced spinal cord injury in rats. J. Neurotrauma 23, 1739-1749.

Pantovic, R., Draganic, P., Erakovic, V., Blagovic, B., Milin, C., and Simonic, A. (2005). Effect of indomethacin on motor activity and spinal cord free fatty acid content after experimental spinal cord injury in rabbits. Spinal Cord 43, 519-526.

Resnick, D.K., Graham, S.H., Dixon, C.E., and Marion, D.W. (1998). Role of cyclooxygenase 2 in acute spinal cord injury. J Neurotrauma 15, 1005-1013.

Resnick, D.K., Nguyen, P., and Cechvala, C.F. (2001). Selective cyclooxygenase 2 inhibition lowers spinal cord prostaglandin concentrations after injury. Spine J. 1, 437-441.

Schwab, J.M., Conrad, S., Elbert, T., Trautmann, K., Meyermann, R., and Schluesener, H.J. (2004). Lesional RhoA+ cell numbers are suppressed by anti-inflammatory, cyclooxygenaseinhibiting treatment following subacute spinal cord injury. Glia 47, 377-386.

Sharma, H.S., and Winkler, T. (2002). Assessment of spinal cord pathology following trauma using early changes in the spinal cord evoked potentials: A pharmacological and morphological study in the rat. Muscle Nerve, Suppl. 11, S83-S91.

Sharma, H.S., Olsson, Y., and Cervos-Navarro, J. (1993a). Early perifocal cell changes and edema in traumatic injury of the spinal cord are reduced by indomethacin, an inhibitor of prostaglandin synthesis. Experimental study in the rat. Acta Neuropathol. 85, 145-153.

Sharma, H.S., Olsson, Y., Nyberg, F., and Dey, P.K. (1993b). Prostaglandins modulate alterations of microvascular permeability, blood flow, edema and serotonin levels following spinal cord injury: An experimental study in the rat. Neuroscience 57, 443-449.

Simpson, R.K., Jr., Baskin, D.S., Dudley, A.W., Bogue, L., and Rothenberg, F. (1991). The influence of long-term nifedipine or indomethacin therapy on neurologic recovery from experimental spinal cord injury. J. Spinal. Disord. 4, 420-427.

Wang, X., Budel, S., Baughman, K., Gould, G., Song, K.H., and Strittmatter, S.M. (2009). Ibuprofen enhances recovery from spinal cord injury by limiting tissue loss and stimulating axonal growth. J. Neurotrauma 26, 81-95.

Winkler, T., Sharma, H.S., Stalberg, E., and Olsson, Y. (1993). Indomethacin, an inhibitor of prostaglandin synthesis attenuates alteration in spinal cord evoked potentials and edema formation after trauma to the spinal cord: an experimental study in the rat. Neuroscience 52, 1057-1067. 


\section{Anti-CD11d antibodies}

Bao, F., Chen, Y., Dekaban, G.A., and Weaver, L.C. (2004a). Early anti-inflammatory treatment reduces lipid peroxidation and protein nitration after spinal cord injury in rats. J. Neurochem. 88, 1335-1344.

Bao, F., Chen, Y., Dekaban, G.A., and Weaver, L.C. (2004b). An anti-CD11d integrin antibody reduces cyclooxygenase-2 expression and protein and DNA oxidation after spinal cord injury in rats. J. Neurochem 90, 1194-1204.

Bao, F., Dekaban, G.A., and Weaver, L.C. (2005). Anti-CD11d antibody treatment reduces free radical formation and cell death in the injured spinal cord of rats. J. Neurochem. 94, 1361-1373.

Ditor, D.S., Bao, F., Chen, Y., Dekaban, G.A., and Weaver, L.C. (2006). A therapeutic time window for anti-CD 11d monoclonal antibody treatment yielding reduced secondary tissue damage and enhanced behavioral recovery following severe spinal cord injury. J. Neurosurg. Spine 5, 343-352.

Gris, D., Marsh, D.R., Dekaban, G.A., and Weaver, L.C. (2005). Comparison of effects of methylprednisolone and anti-CD11d antibody treatments on autonomic dysreflexia after spinal cord injury. Exp. Neurol. 194, 541-549.

Gris, D., Marsh, D.R., Oatway, M.A., Chen, Y., Hamilton, E.F., Dekaban, G.A., and Weaver, L.C. (2004). Transient blockade of the CD11d/CD18 integrin reduces secondary damage after spinal cord injury, improving sensory, autonomic, and motor function. J. Neurosci. 24, 4043-4051.

Gris P., Tighe A., Thawer S., Hemphill A., Oatway M., Weaver L., Dekaban G.A., and Brown A. (2009). Gene expression profiling in anti-CD11d mAb-treated spinal cord-injured rats. J. Neuroimmunol. 209, 104-113.

Mabon, P.J., Weaver, L.C., and Dekaban, G.A. (2000). Inhibition of monocyte/macrophage migration to a spinal cord injury site by an antibody to the integrin alphaD: A potential new anti-inflammatory treatment. Exp. Neurol. 166, 52-64.

Oatway, M.A., Chen, Y., Bruce, J.C., Dekaban, G.A., and Weaver, L.C. (2005). Anti-CD11d integrin antibody treatment restores normal serotonergic projections to the dorsal, intermediate, and ventral horns of the injured spinal cord. J. Neurosci. 25, 637-647.

Saville, L.R., Pospisil, H., Mawhinney, L.A., Bao, F., Simedrea, F.C., Peters, A.A., O'Connell, P.J., Weaver, L.C., and Dekaban, G.A. (2004). A monoclonal antibody to CD11d reduces the inflammatory infiltrate into the injured spinal cord: A potential neuroprotective treatment. J. Neuroimmunol. 156, 42-57.

Weaver, L.C., Gris, D., Saville, L.R., Oatway, M.A., Chen, Y., Marsh, D.R., Hamilton, E.F., and Dekaban, G.A. (2005). Methylprednisolone causes minimal improvement after spinal cord injury in rats, contrasting with benefits of an anti-integrin treatment. J. Neurotrauma 22, 1375-1387.

Minocycline

Festoff, B.W., Ameenuddin, S., Arnold, P.M., Wong, A., Santacruz, K.S., and Citron, B.A. (2006). Minocycline neuroprotects, reduces microgliosis, and inhibits caspase protease expression early after spinal cord injury. J. Neurochem. 97, 1314-1326.

Ha, K.Y., Kim, Y.H., Rhyu, K.W., and Kwon, S.E. (2008). Pregabalin as a neuroprotector after spinal cord injury in rats. Eur. Spine J. 17, 864-872.

Hains, B.C., and Waxman, S.G. (2006). Activated microglia contribute to the maintenance of chronic pain after spinal cord injury. J. Neurosci. 26, 4308-4317.

Lee, S.M., Yune, T.Y., Kim, S.J., Park, D.W., Lee, Y.K., Kim, Y.C., Oh, Y.J., Markelonis, G.J., and Oh, T.H. (2003). Minocycline reduces cell death and improves functional recovery after traumatic spinal cord injury in the rat. J. Neurotrauma 20, 1017-1027.

Marchand, F., Tsantoulas, C., Singh, D., Grist, J., Clark, A.K., Bradbury, E.J., and McMahon, S.B. (2008). Effects of etanercept and minocycline in a rat model of spinal cord injury. Eur. J. Pain. 13, 673-681.

Pinzon, A., Marcillo, A., Quintana, A., Stamler, S., Bunge, M.B., Bramlett, H.M., and Dietrich, W.D. (2008). A re-assessment of minocycline as a neuroprotective agent in a rat spinal cord contusion model. Brain Res. 1243, 146-151.

Saganová, K., Orendácová, J., Cízková, D., and Vanick, I. (2008). Limited minocycline neuroprotection after ballooncompression spinal cord injury in the rat. Neurosci. Lett. 433, 246-249.

Stirling, D.P., Khodarahmi, K., Liu, J., McPhail, L.T., McBride, C.B, Steeves, J.D., Ramer, M.S., and Tetzlaff, W. (2004). Minocycline treatment reduces delayed oligodendrocyte death, attenuates axonal dieback, and improves functional outcome after spinal cord injury. J. Neurosci. 24, 2182-2190.

Teng, Y.D., Choi, H., Onario, R.C., Zhu, S., Desilets, F.C., Lan, S., Woodard, E.J., Snyder, E.Y., Eichler, M.E., and Friedlander, R.M. (2004). Minocycline inhibits contusion-triggered mitochondrial cytochrome $\mathrm{c}$ release and mitigates functional deficits after spinal cord injury. Proc. Natl. Acad. Sci. USA 101, 3071-3076.

Wells, J.E., Hurlbert, R.J., Fehlings, M.G., and Yong, V.W. (2003). Neuroprotection by minocycline facilitates significant recovery from spinal cord injury in mice. Brain 126, 1628-1637.

Yune, T.Y., Lee, J.Y., Jung, G.Y., Kim, S.J., Jiang, M.H., Kim, Y.C., Oh, Y.J., Markelonis, G.J., and Oh, T.H. (2007). Minocycline alleviates death of oligodendrocytes by inhibiting pro-nerve growth factor production in microglia after spinal cord injury. J. Neurosci. 27, 7751-7761.

Zhao, P., Waxman, S.G., and Hains, B.C. (2007a). Extracellular signal-regulated kinase-regulated microglia-neuron signaling by prostaglandin E2 contributes to pain after spinal cord injury. J. Neurosci. 27, 2357-2368.

Zhao, P., Waxman, S.G., and Hains, B.C. (2007b). Modulation of thalamic nociceptive processing after spinal cord injury through remote activation of thalamic microglia by cysteine cysteine chemokine ligand 21. J. Neurosci. 27, 8893-8902.

Progesterone

Fee, D.M., Swartz, D.R., Joy, K.M., Roberts, K.N., Scheff, N.N., and Scheff, S.W. (2007). Effects of progesterone on experimental spinal cord injury. Brain Res. 1137, 146-152.

González, S.L., López-Costa, J.J., Labombarda, F., Gonzalez Deniselle, M.C., Guennoun, R., Schumacher, M., and De Nicola, A.F. (2009). Progesterone effects on neuronal ultrastructure and expression of microtubule-associated protein 2 (MAP2) in rats with acute spinal cord injury. Cell. Mol. Neurobiol. 29, 27-39.

González, S.L., Labombarda, F., Gonzalez Deniselle, M.C., Guennon, R., Schumacher, M., and De Nicola, A.F. (2004). Progesterone up-regulates brain-derived neurotrophic factor expression in the injured spinal cord. Neuroscience 125, 605614.

Labombarda, F., González, S.L., Gonzalez Deniselle, M.C., Garay, L., Guennoun, R., Schumacher, M., and De Nicola, A.F. (2006a). Progesterone increases the expression of myelin basic protein and the number of cells showing NG2 immunostaining in the lesioned spinal cord. J. Neurotrauma 23, 181-192.

Labombarda, F., González, S.L., Gonzalez, D.M., Guennoun, R., Schumacher, M., and De Nicola, A.F. (2002). Cellular basis for 
progesterone neuroprotection in the injured spinal cord. J. Neurotrauma 19, 343-355.

Labombarda, F., González, S.L., Gonzalez, D.M., Vinson, G.P., Schumacher, M., De Nicola, A.F., and Guennoun, R. (2003). Effects of injury and protesterone treatment on progesterone receptor and progesterone binding protein 25-Dx expression in the rat spinal cord. J. Neurochem. 87, 902-913.

Labombarda, F., González, S.L., Lima, A., Roig, P., Guennoun, R., Schumacher, M., and De Nicola, A.F. (2009). Effects of progesterone on oligodendrocyte progenitors, oligodendrocyte transcription factors, and myelin proteins following spinal cord injury. Glia 57, 884-897.

Labombarda, F., González, S.L., Roig, P., Lima, A., Guennoun, R., Schumacher, M., and De Nicola, A.F. (2000). Modulation of NADPH-diaphorase and glial fibrillary acidic protein by progesterone in astrocytes from normal and injured rat spinal cord. J. Steroid. Biochem. Mol. Biol. 73, 159-169.

Labombarda, F., Pianos, A., Liere, P., Eychenne, B., González, S., Cambourg, F., De Nicola, A.F., Schumacher, M., and Guennoun, R. (2006b). Injury elicited increase in spinal cord neurosteroid content analyzed by gas chromatography mass spectrometry. Endocrinol. 147, 1847-1859.

Thomas, A.J., Nockels, R.P., Pan, H.Q., Shaffrey, C.I., and Chopp, M. (1999). Progesterone is neuroprotective after acute experimental spinal cord trauma in rats. Spine 24, 21342138.

\section{Estrogen}

Chaovipoch, P., Jelks, K.A., Gerhold, L.M., West, E.J., Chongthammakun, S., and Floyd, C.L. (2006). 17beta-estradiol is protective in spinal cord injury in post- and pre-menopausal rats. J. Neurotrauma 23, 830-852.

Cuzzocrea, S., Genovese, T., Mazzon, E., Esposito, E., Di Paola, R., Muià, C., Crisafulli, C., Peli, A., Bramanti, P., and Chaudry, I.H. (2008). Effect of 17beta-estradiol on signal transduction pathways and secondary damage in experimental spinal cord trauma. Shock 29, 362-371.

Ritz, M.F., and Hausmann, O.N. (2008). Effect of 17beta-estradiol on functional outcome, release of cytokines, astrocyte reactivity and inflammatory spreading after spinal cord injury in male rats. Brain Res. 1203, 177-188.

Sribnick, E.A., Matzelle, D.D., Ray, S.K., and Banik, N.L. (2006). Estrogen treatment of spinal cord injury attenuates calpain activation and apoptosis. J. Neurosci. Res. 84, 1064-1075.

Sribnick, E.A., Wingrave, J.M., Matzelle, D.D., Wilford, G.G., Ray, S.K., and Banik, N.L. (2005). Estrogen attenuated markers of inflammation and decreased lesion volume in acute spinal cord injury in rats. J. Neurosci. Res. 82, 283-293.

Swartz, K.R., Fee, D.B., Joy, K.M., Roberts, K.N., Sun, S., Scheff, N.N., Wilson, M.E., and Scheff, S.W. (2007). Gender differences in spinal cord injury are not estrogen-dependent. J. Neurotrauma 24, 473-480.

Webb, A.A., Chan, C.B., Brown, A., and Saleh, T.M. (2006). Estrogen reduces the severity of autonomic dysfunction in spinal cord-injured male mice. Behav. Brain Res. 171, 338349.

Yune, T.Y., Kim, S.J., Lee, S.M., Lee, Y.K,. Oh, Y.J., Kim, Y.C., Markelonis, G.J., and Oh, T.H. (2004). Systemic administration of 17beta-estradiol reduces apoptotic cell death and improves functional recovery following traumatic spinal cord injury in rats. J. Neurotruama 3, 293-306.

Magnesium

Ditor, D.S., John, S.M., Roy, J., Marx, J.C., Kittmer, C., and Weaver, L.C. (2007). Effects of polyethylene glycol and magnesium sulfate administration on clinically relevant neuro- logical outcomes after spinal cord injury in the rat. J. Neurosci. Res. 85, 1458-1467.

Gok, B., Okutan, O., Beskonakli, E., and Kilinc, K. (2007). Effects of magnesium sulphate following spinal cord injury in rats. Chin. J. Physiol. 50, 93-97.

Kaptanoglu, E., Beskonakli, E., Okutan, O., Selcuk, S.H., and Taskin, Y. (2003a). Effect of magnesium sulphate in experimental spinal cord injury: Evaluation with ultrastructural findings and early clinical results. J. Clin. Neurosci. 10, 329334.

Kaptanoglu, E., Beskonakli, E., Solaroglu, I., Kilinc, A., and Taskin, Y. (2003b). Magnesium sulfate treatment in experimental spinal cord injury: Emphasis on vascular changes and early clinical results. Neurosurg. Rev. 26, 283-287.

Kwon, B.K., Roy, J., Lee, J.H., Okon, E.B., Zhang, H., Marx, J.C., and Kindy, M.S. (2009). Magnesium chloride in a polyethylene glycol formulation as a neuroprotective therapy for acute spinal cord injury: Preclinical refinement and optimization. J. Neurotrauma DOI:10.1089/neu.20090884 .

Özdemir, M., Cengiz, S.L., Gurbilek, M., Ogun, T.C., and Ustun, M.E. (2005). Effects of magnesium sulfate on spinal cord tissue lactate and malondialdehyde levels after spinal cord trauma. Magnes. Res. 18, 170-174.

Solaroglu, I., Kaptanoglu, E., Okutan, O., Beskonakli, E., Attar, A., and Kilinc, K. (2005). Magnesium sulfate treatment decreases caspase-3 activity after experimental spinal cord injury in rats. Surg. Neurol. 64, Suppl. 2, S17-S21.

Süzer, T., Coskun, E., Islekel, H., and Tahta, K. (1999). Neuroprotective effect of magnesium on lipid peroxidation and axonal function after experimental spinal cord injury. Spinal Cord 37, 480-484.

\section{Riluzole}

Baptiste, D.C., Austin, J.W., Zhao, W., Nahirny, A., Sugita, S., and Fehlings, M.G. (2009). Systemic polyethylene glycol promotes neurological recovery and tissue sparing in rats after cervical spinal cord injury. J Neuropathol Exp Neurol. 68, 661676

Ates, O., Cayli, S.R., Gurses, I., Turkoz, Y., Tarim, O., Cakir, C.O., and Kocak, A. (2007). Comparative neuroprotective effect of sodium channel blockers after experimental spinal cord injury. J. Clin. Neurosci. 14, 658-665.

Kitzman, P.H. (2009). Effectiveness of riluzole in suppressing spasticity in the spinal cord injured rat. Neurosci. Lett. 455, 150-153.

McAdoo, D.J., Hughes, M.G., Nie, L., Shah, B., Clifton, C., Fullwood, S., and Hulsebosch, C.E. (2005). The effect of glutamate receptor blockers on glutamate release following spinal cord injury. Lack of evidence for an ongoing feedback cascade of damage $\rightarrow$ glutamate release $\rightarrow$ damage $\rightarrow$ glutamate release $\rightarrow$ etc. Brain Res. 1038, 92-99.

$\mathrm{Mu}$, X., Azbill, R.D., and Springer, J.E. (2000a). Riluzole improves measures of oxidative stress following traumatic spinal cord injury. Brain Res. 870, 66-72.

$\mathrm{Mu}$, X., Azbill, R.D., and Springer, J.E. (2000b). Riluzole and methylprednisolone combined treatment improves functional recovery in traumatic spinal cord injury. J. Neurotrauma 17, 773-780.

Schwartz, G., and Fehlings, M.G. (2001). Evaluation of the neuroprotective effects of sodium channel blockers after spinal cord injury: Improved behavioral and neuroanatomical recovery with riluzole. J. Neurosurg. 94, 245-256.

Springer, J.E., Azbill, R.D., Kennedy, S.E., George, J., and Geddes, J.W. (1997). Rapid calpain I activation and cyto- 
skeletal protein degradation following traumatic spinal cord injury: Attenuation with riluzole pretreatment. J. Neurochem. 69, 1592-1600.

Stutzmann, J.M., Pratt, J., Boraud, T., and Gross, C. (1996). The effect of riluzole on post-traumatic spinal cord injury in the rat. Neuroreport 7, 387-392.

Polyethylene glycol

Baptiste, D.C., Austin, J.W., Zhao, W., Nahirny, A., Sugita, S., and Fehlings, M.G. (2009). Systemic polyethylene glycol promotes neurological recovery and tissue sparing in rats after cervical spinal cord injury. J Neuropathol Exp Neurol. 68, 661-676.

Borgens, R.B., and Bohnert, D. (2001). Rapid recovery from spinal cord injury after subcutaneously administered polyethylene glycol. J. Neurosci. Res. 66, 1179-1186.

Borgens, R.B., and Shi, R. (2000). Immediate recovery from spinal cord injury through molecular repair of nerve membranes with polyethylene glycol. FASEB J. 14, 27-35.

Borgens, R.B., Shi, R., and Bohnert, D. (2002). Behavioral recovery from spinal cord injury following delayed application of polyethylene glycol. J. Exp. Biol. 205, 1-12.

Ditor, D.S., John, S.M., Roy, J., Marx, J.C., Kittmer, C., and Weaver, L.C. (2007). Effects of polyethylene glycol and magnesium sulfate administration on clinically relevant neurological outcomes after spinal cord injury in the rat. J. Neurosci. Res. 85, 1458-1467.

Duerstock, B.S., and Borgens, R.B. (2002). Three-dimensional morphometry of spinal cord injury following polyethylene glycol treatment. J. Exp. Biol. 205, 13-24.

Kwon, B.K., Roy, J., Lee, J.H., Okon, E.B., Zhang, H., Marx, J.C., and Kindy, M.S. (2009). Magnesium chloride in a polyethylene glycol formulation as a neuroprotective therapy for acute spinal cord injury: Preclinical refinement and optimization. J. Neurotrauma DOI: 10.1089/neu.2009-0884.

Laverty, P.H., Leskovar, A., Breur, G.J., Coates, J.R., Bergman, R.L., Widmer, W.R., Toombs, J.P., Shapiro, S., and Borgens, R.B. (2004). A preliminary study of intravenous surfactants in paraplegic dogs: Polymer therapy in canine clinical SCI. J. Neurotrauma 21, 1767-1777.

Luo, J., and Shi, R. (2004). Diffusive oxidative stress following acute spinal cord injury in guinea pigs and its inhibition by polyethylene glycol. Neurosci. Lett. 359, 167-170.

Luo, J., and Shi, R. (2007). Polyethylene glycol inhibits apoptotic cell death following traumatic spinal cord injury. Brain Res. $1155,10-16$.

Luo, J., Borgens, R., and Shi, R. (2004). Polyethylene glycol improves function and reduces oxidative stress in synaptosomal preparations following spinal cord injury. J. Neurotrauma 21, 994-1007.

\section{Atorvastatin}

Dery, M.A., Rousseau, G., Benderdour, M., and Beaumont, E. (2009). Atorvastatin prevents early apoptosis after thoracic spinal cord contusion injury and promotes locomotion recovery. Neurosci. Lett. 453, 73-76.

Pannu, R., Barbosa, E., Singh, A.K., and Singh, I. (2005). Attenuation of acute inflammatory response by atorvasta- tin after spinal cord injury in rats. J. Neurosci. Res. 79, 340350.

Pannu, R., Christie, D.K., Barbosa, E., Singh, I., and Singh, A.K. (2007). Post-trauma Lipitor treatment prevents endothelial dysfunction, facilitates neuroprotection, and promotes locomotor recovery following spinal cord injury. J. Neurochem. $101,182-200$.

Inosine

Benowitz, L.I., Goldberg, D.E., Madsen, J.R., Soni, D., and Irwin, N. (1999). Inosine stimulates extensive axon collateral growth in the rat corticospinal tract after injury. Proc. Natl. Acad. Sci. USA 96, 13486-13490.

Bohnert, D.M., Purvines, S., Shapiro, S., and Borgens, R.B. (2007). Simultaneous application of two neurotrophic factors after spinal cord injury. J. Neurotrauma 24, 846-863.

Conta, A.C., \& Stelzner, D.J. (2008). Immunomodulatory effect of the purine nucleoside inosine following spinal cord contusion injury in rat. Spinal Cord 46, 39-44.

Liu, F., You, S.W., Yao, L.P., Liu, H.L., Jiao, X.Y., Shi, M., Zhao, Q.B., and Ju, G. (2006). Secondary degeneration reduced by inosine after spinal cord injury in rats. Spinal Cord 44, 421-426.

\section{Pioglitazone}

Kapadia, R., Yi, J.H., and Vemuganti, R. (2008). Mechanisms of anti-inflammatory and neuroprotective actions of PPARgamma agonists. Front. Biosci. 13, 1813-1826.

Kerr, B.J., Girolami, I., Ghasemlou, N., Jeong, S.Y., and David, S. (2008). The protective effects of 15-deoxy-delta-(12,14)prostaglandin J2 in spinal cord injury. Glia 56, 436-448.

McTigue, D.M., Tripathi, R., Wei, P., and Lash, A.T. (2007). The PPAR gamma agonist Pioglitazone improves anatomical and locomotor recovery after rodent spinal cord injury. Exp. Neurol. 205, 396-406.

Ondrey, F. (2009). Peroxisome proliferator-activated receptor gamma pathway targeting in carcinogenesis: Implications for chemoprevention. Clin. Cancer Res. 1, 2-8.

Park, S.W., Yi, J.H., Miranpuri, G., Satriotomo, I., Bowen, K., Resnick, D.K., and Vemuganti, R. (2007). Thiazolidinedione class of peroxisome proliferator-activated receptor gamma agonists prevents neuronal damage, motor dysfunction, myelin loss, neuropathic pain, and inflammation after spinal cord injury in adult rats. J. Pharmacol. Exp. Ther. 320, 10021012.

Address correspondence to: Brian K. Kwon, M.D., Ph.D., FRCSC Department of Orthopaedics, University of British Columbia International Collaboration on Repair Discoveries (ICORD) 6th Floor, Blusson Spinal Cord Center, VGH 818 West 10th Avenue Vancouver, British Columbia V5Z IM9 Canada

E-mail: brian.kwon@vch.ca 